Aus der Abteilung Neurologie

(Prof. Dr. med. M. Bähr)

im Zentrum Neurologische Medizin

der Medizinischen Fakultät der Universität Göttingen

\title{
Funktionelle Charakterisierung einer neuen Proteininteraktion zwischen Parkin und BAG1
}

\author{
INAUGURAL-DISSERTATION \\ zur Erlangung des Doktorgrades \\ der Medizinischen Fakultät der \\ Georg-August-Universität zu Göttingen
}

vorgelegt von

$\underline{\text { Julia Schünemann }}$

aus

Braunschweig

Göttingen

2012 
Dekan: Prof. Dr. med. C. Frömmel

I. Berichterstatter: Prof. Dr. med. P. Kermer

II. Berichterstatter: Prof. Dr. rer. nat. M. Müller

III. Berichterstatter: Prof. Dr. med. M. Oppermann

Tag der mündlichen Prüfung: 19. Juni 2012 


\section{Inhaltsverzeichnis}

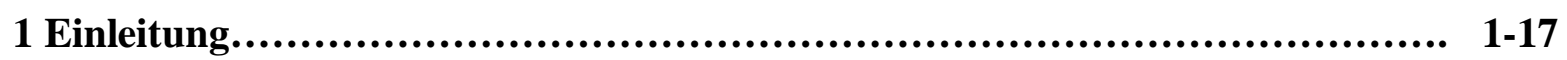

1.1 Die Parkinson-Erkrankung ................................................ 1

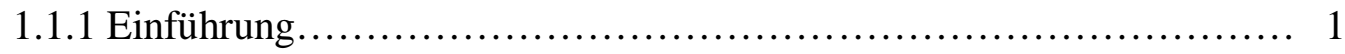

1.1.2 Ätiologie und Pathogenese............................................ 2

1.1.2.1 Mitochondriale Dysfunktion und oxidativer Stress.............. 2

1.1.2.2 Proteinaggregation und proteasomale Dysfunktion.............. 3

1.1.2.3 Risikofaktoren und Umwelteinflüsse........................... 4

1.1.3 Familiäre Formen von Morbus Parkinson und genetische

Risikofaktoren..................................................... 5

1.2 Parkin........................................................................ 6

1.2.1 Klinische Erscheinung der Parkin-assoziierten Parkinson-Erkrankung... 6

1.2.2 Zellbiologische und molekulare Charakteristika......................... 6

1.2.3 Physiologische Funktion................................................ 8

1.2.3.1 Das Ubiquitin-Proteasom-System............................ 8

1.2.3.2 Unterschiedliche Arten der Ubiquitinylierung................. 10

1.2.4 Interagierende Proteine und Substrate............................... 11

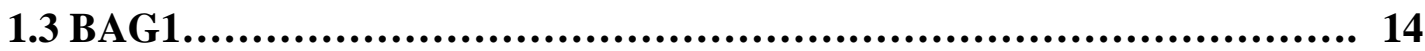

1.3.1 Physiologische Funktion von BAG1 und seine Interaktionspartner...... 14

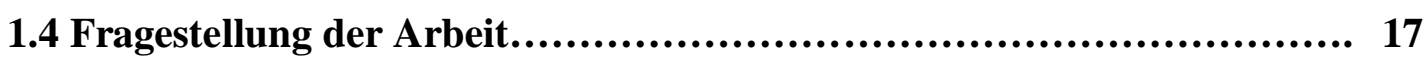

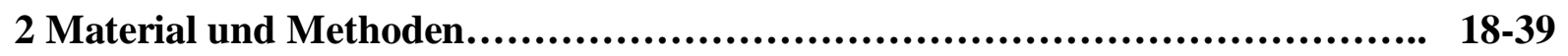

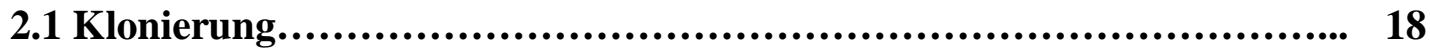

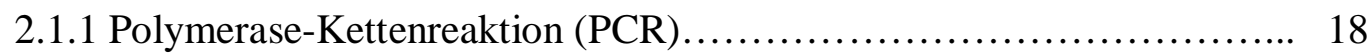

2.1.2 Verwendete Primer............................................... 19

2.1.3 Aufreinigung des PCR-Produktes................................. 20

2.1.4 Restriktionsenzymverdau........................................ 20

2.1.5 Agarosegel-Elektrophorese....................................... 21

2.1.6 DNA-Aufreinigung aus Agarosegelen............................... 22

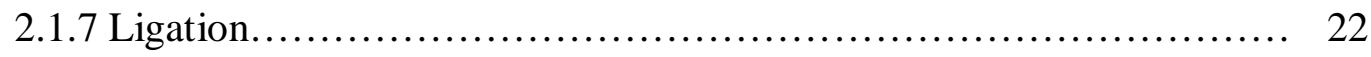

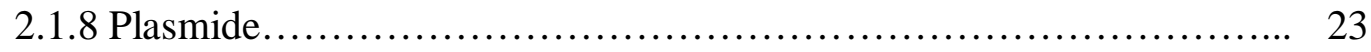

2.1.9 Sequenzierung .................................................... 23

2.1.10 Messung der DNA-Konzentration............................... 24 
2.2 Amplifizierung der Plasmide....................................... 24

2.2.1 Transformation kompetenter Zellen........................... 24

2.2.2 Mini-Präparation............................................ 24

2.2.3 Maxi-Präparation.......................................... 25

2.2.4 Anlegen eines Glycerol-Stocks................................ 26

2.3 Zelllinien..................................................................... 26

2.3.1 HEK293-Zellen.............................................. 26

2.3.2 CSM14.1-Zellen.............................................. 26

2.3.3 SH-SY5Y-Zellen............................................ 27

2.4 Zellkultur................................................................... 27

2.4.1 Kultivierung.............................................. 27

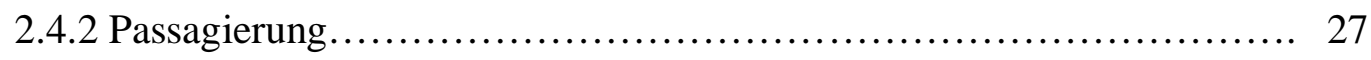

2.4.3 Quantifizierung der Zellen................................... 28

2.4.4 Einfrieren der Zellen.......................................... 28

2.4.5 Auftauen der Zellen............................................. 28

2.4.6 Transfektion................................................. 29

2.5 Proteinanalyse...................................................... 29

2.5.1 Herstellung von zellulären Lysaten mit Triton-X-100.............. 29

2.5.2 Herstellung von zellulären Lysaten mit Harnstoff................... 30

2.5.3 Subzelluläre Fraktionierung.................................. 30

2.5.4 Proteinkonzentrationsbestimmung mittels BCA.................... 31

2.5.5 SDS-Polyacrylamidgel-Elektrophorese (SDS-PAGE)............... 31

2.5.6 Western Blot.................................................. 32

2.5.7 Immunodetektion der Proteine.................................... 33

2.5.8 Coomassie-Färbung.................................................................... 33

2.5.9 Dot Blot.................................................... 33

2.6 Antikörper........................................................... 35

2.6.1 Primär-Antikörper............................................... 35 
2.6.2 Sekundär-Antikörper 35

2.7 Immunozytochemie................................................... 36

2.7.1 Auszählung der Parkin-Aggregate....................................................... 37

2.8 Co-Immunopräzipitation (Co-IP) .................................................................. 37

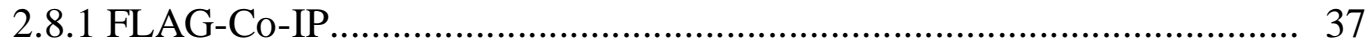

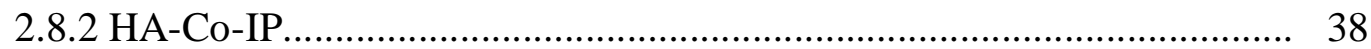

2.9 Quantifizierung des Proteinumsatzes............................................................ 39

2.9.1 Cycloheximid-Experimente................................. 39

2.9.2 Proteasom-Inhibitor MG 132 .................................. 39

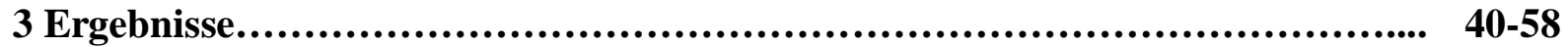

3.1 Nachweis der Interaktion zwischen Parkin und BAG1..................... 40

3.1.1 Co-Immunopräzipitation von Parkin und BAG1 in HEK293-Zellen..... 40

3.1.2 Immunozytochemie von Parkin und BAG1 in CSM14.1-Zellen......... 42

3.2 Kartierung der interagierenden Domäne unter Verwendung verschiedener Parkin-Deletionsmutanten................................. 45

3.2.1 Parkin-Deletionsmutations-Konstrukte......................... 45

3.2.2 Restriktionsenzymverdau der Parkin-Deletionsmutanten............... 46

3.2.3 Sequenzierung der Parkin-Deletionsmutanten ..................... 46

3.2.4 Überexpression der Deletionsmutanten in HEK293- und CSM14.1Zellen........................................................... 46

3.2.5 Kartierungsexperimente unter Verwendung der Parkin-Deletionsmutanten und BAG1......................................... 47

3.3 Funktionelle Untersuchung der E3-Ligase-Funktion von Parkin.

3.3.1 Degradationszeitreihen unter Verwendung von Cycloheximid als Translations-Inhibitor. 
3.3.2 Die Parkin-vermittelte Ubiquitinylierung des Substratproteins CDCrel-1

3.4 Der Einfluss von BAG1 auf die Lokalisation und Löslichkeit von

Parkin 53

3.4.1 Untersuchung zur subzellulären Lokalisation von Parkin. ... 53

3.4.2 Untersuchungen zur Löslichkeit und Ubiquitinylierung von Parkin. 55

4 Diskussion $59-66$

4.1 Identifikation von BAG1 als neuem Parkin-Interaktor. 59

4.2 Beurteilung der Kartierungsexperimente zur Identifikation der interagierenden Parkin-Domäne 61

4.3 BAG1 inhibiert die E3-Ligase-Funktion von Parkin. 62

4.4 BAG1 führt zu einer verstärkten Ubiquitinylierung und Akkumulation von Parkin. 63

4.5 Ausblick....................................................................... 66

5 Zusammenfassung...................................................... $67-68$

5.1 Deutsch.................................................................. 67

5.2 Englisch................................................................ 68

6 Literaturverzeichnis....................................................... 69-78

7 Veröffentlichung zum Thema der Dissertation................................. 79 
A

Abb.

$\mathrm{AD}$

APS

AR

AS

ATP

BAG

BCA

BSA

Bzw.

${ }^{\circ} \mathrm{C}$

CASK

CDCrel

CHIP

Co-IP

Cy3

DA

DAPI

d.h.

DMEM

DMSO

DNA

DTT

ECL

EGFP

FBS

FCS gold

ff

FLAG

g

GFP

HA

$\mathrm{H}_{2} \mathrm{O}_{2}$

HEK293- Zellen
Ampere

Abbildung

Autosomal dominant

Ammuniumperoxodisulfat

Autosomal rezessiv

Aminosäure

Adenosintriphosphat

Bcl-2-associated athanogene

Bicinchonin-Säure

Bovine serum albumine

beziehungsweise

Grad Celsius

$\mathrm{Ca}^{2+}$-calmodulin-dependent serine protein kinase

Cell division control related protein

Carboxyl terminus of the Hsc70-interacting protein

Co-Immunopräzipitation

Indokarcocyanin 3

Dopamin

4`6-diamidine-2`-phenylindole dihydrochloride

das heißt

Dulbecco`s modified eagle`s medium

Dimethylsulfoxid

Desoxyribonukleinsäure

Dithiothreitol

Enhanced Chemoluminesence

Enhanced green fluorescent protein

fötales Rinderserum (fetal bovine serum)

fötales Kälberserum (fetal calf serum)

und folgende

Oktapeptid, als Signalpeptid verwendet

Gramm

Green fluorescent protein

Hämagglutinin

Wasserstoffperoxid

Human embryonic kidney 293-Zellen 
HRP

Hsp

IBR

$\mathrm{kDa}$

L-Dopa

LRRK2

Luminol

LV

$\mathrm{m}$

MAPT

$\mu \mathrm{g}$

MG 132

$\min$

$\mu l$

MP

MPTP

$\mathrm{MPP}^{+}$

Pael-R

PBS

PCR

PD

PDI

PFA

$\mathrm{pH}$

PINK1

Raf-1

RING

RIPA

ROS

Rpm

RT

S

SDS
Meerrettich-Peroxidase (horseradish peroxidase)

Hitzeschockprotein

In-between RING

Kilodalton

Levo-Dopa

Leucine-Rich-Repeat kinase 2

3-Aminophthalhydrazid

Leervektor (Plasmid ohne Insert)

Milli

Microtubule-associated protein tau

Mikrogramm

Carboxybenzoyl-L-Leucyl-L-Leucyl-L-Leucinal

Minute

Mikroliter

Morbus Parkinson

1-Methyl-4-phenyl-tetrahydropyridin

1-Methyl-4-phenyl-pyridin

Parkin-associated endothelin-like receptor

Phosphatgepufferte physiologische Kochsalzlösung

Polymerase-Kettenreaktion

Parkinson's disease

Protein-Disulfid-Isomerase

Paraformaldehyd

negativer dekadischer Logarithmus der Protonenkonzentration

PTEN-induced kinase 1

rapidly growing fibrosarcoma or rat fibrosarcoma-1

Really interesting new gene

Radioimmunoprecipitation assay

Reaktive Sauerstoffspezies (Reactive oxigen species)

Umdrehungen pro Minute (Rounds per minute)

Raumtemperatur

Svedberg (in Verbindung mit Proteinkomplexen verwendete

Einheit)

siehe

Sodiumdodecylsulfat 


$\begin{array}{ll}\text { SDS-PAGE } & \text { SDS-Polyacrylamidgel-Elektrophorese } \\ \text { sec } & \text { Sekunde } \\ \text { SNpc } & \text { Substantia nigra pars compacta } \\ \text { Std } & \text { Stunde } \\ \text { Tab. } & \text { Tabelle } \\ \text { tag } & \text { kurze, einem Protein angefügte Aminosäuresequenz } \\ \text { TBS } & \text { Tris buffered saline solution } \\ \text { TBS-T } & \text { Tris buffered saline solution with Tween } \\ \text { TEMED } & \text { N,N,N`'N`-Tetramethylethylendiamin } \\ \text { Tris } & \text { Trizma Base (Trishydroxymethyl-)aminomethan } \\ \text { U } & \text { Unit } \\ \text { Ubc } & \text { Ubiquitin-conjugating enzyme } \\ \text { UbcH } & \text { Ubiquitin-conjugating human enzyme } \\ \text { UBL } & \text { Ubiquitin-like } \\ \text { UPS } & \text { Ubiquitin-Proteasom-System } \\ \text { V } & \text { Volt } \\ \text { VL } & \text { Volllänge } \\ \text { wt } & \text { Wildtyp }\end{array}$

Chemische Elemente wurden mit den definierten Buchstaben abgekürzt. Aminosäuren wurden im Einbuchstabencode angegeben. Gewichts- und andere Einheiten wurden nach dem internationalen SI-System benannt.

Bei einigen Bezeichnungen wurden die englischen Fachtermini benutzt, weil in der deutschsprachigen Fachliteratur eine Übersetzung dieser Begriffe unüblich und unzureichend ist. 
Abb. 1.1................. 7

Abb. 1.2................. 7

Abb. 1.3................. 9

Abb. 1.4................. 9

Abb. 1.5................. 10

Abb. 1.6................ 12

Abb. $1.7 \ldots \ldots \ldots \ldots \ldots \ldots . . . . . .15$

Abb. $3.1 \ldots \ldots \ldots \ldots \ldots \ldots . . . . . .40$

Abb. $3.2 \ldots \ldots \ldots \ldots \ldots \ldots . . . . . .41$

Abb. $3.3 \ldots \ldots \ldots \ldots \ldots \ldots . . . \ldots 2$

Abb. $3.4 \ldots \ldots \ldots \ldots \ldots \ldots . . . . . .43$

Abb. $3.5 \ldots \ldots \ldots \ldots \ldots \ldots . . . . . .44$

Abb. 3.6................ 45

Abb. $3.7 \ldots \ldots \ldots \ldots \ldots \ldots . . . . . .46$

Abb. $3.8 \ldots \ldots \ldots \ldots \ldots \ldots . . . \ldots 4$

Abb. $3.9 \ldots \ldots \ldots \ldots \ldots \ldots . .48$

Abb. $3.10 \ldots \ldots \ldots \ldots \ldots \ldots . \quad 50$

Abb. $3.11 \ldots \ldots \ldots \ldots \ldots \ldots . . . . . .52$

Abb. $3.12 \ldots \ldots \ldots \ldots \ldots \ldots . . . . . .54$

Abb. $3.13 \ldots \ldots \ldots \ldots \ldots \ldots . . . \ldots 5$

Abb. $3.14 \ldots \ldots \ldots \ldots \ldots \ldots . . . . . .56$

Abb. $3.15 \ldots \ldots \ldots \ldots \ldots . . . . . . \quad 57$

Abb. 3.16................. 58 
Tab. $1.1 \ldots \ldots \ldots \ldots \ldots \ldots . . . . .5$

Tab. 1.2................... 11

Tab. 1.3................... 12

Tab. 1.4................. 13

Tab. 1.5................. 16

Tab. 2.1................. 23

Tab. 2.2.................. 35

Tab. 2.3................. 35 


\section{Einleitung}

\subsection{Die Parkinson-Erkrankung}

\subsubsection{Einführung}

Der Morbus Parkinson (MP) ist eine der häufigsten Bewegungsstörungen und nach dem Morbus Alzheimer die zweithäufigste neurodegenerative Erkrankung (Giasson und Lee 2001).

In seiner Monographie „Essay on the Shaking Palsy“ (Abhandlung über die Schüttellähmung) beschrieb der englische Arzt James Parkinson 1817 erstmalig die Paralysis agitans oder Schüttellähmung als klinisch definiertes Krankheitsbild. Ruhetremor, Brady- oder Akinese und Rigor sind die drei Kardinalsymptome des Morbus Parkinson (Parkinson 2002). Neben der klassischen Symptom-Trias schränken auch nicht-motorische Symptome, wie kognitive Defizite, Schlafstörungen, Veränderungen der Sensorik und des autonomen Nervensystems (Cheon et al. 2009) die Lebensqualität der Patienten ein und verringern deren Lebenserwartung (Chaudhuri et al. 2006). 20-40\% der Parkinson-Patienten erkranken im Verlauf an einer Demenz (Bosboom et al. 2004).

Neuropathologisch zeigt sich unter anderem ein selektiver Verlust von dopaminergen Neuronen in der Substantia nigra, pars compacta ( $\mathrm{SNpc}$ ), der für die klinisch imponierende Bewegungsstörung verantwortlich ist (Dauer und Przedborski 2003, Spillantini et al. 1998). Bei Symptombeginn sind regelhaft bereits $60-70 \%$ der Nervenzellen degeneriert (Lang und Lozano 1998 a). Neben dem Verlust dopaminerger Neurone in der SNpc gehen auch in zahlreichen anderen Hirnregionen, wie in cholinergen (Nucleus basalis Meynert, Nucleus dorsalis vagi), noradrenergen (Locus coeruleus) oder serotonergen Systemen (Raphe-Kerne), der Amygdala, dem Cortex und auch im autonomen Nervensystem Zellen zugrunde (Bosboom et al. 2004, Damier et al. 1999, Dauer und Przedborski 2003). Dieser Zelluntergang ist verantwortlich für die zahlreichen nicht-motorischen Symptome.

Charakteristisch für die Histopatholgie des MP sind des Weiteren sogenannte Lewy-Körper, die sich in betroffenen Hirnarealen finden lassen (Spillantini et al. 1998). Es handelt sich um zytoplasmatische Einschlüsse, die zahlreiche Proteine, wie etwa $\alpha$-Synuclein, Neurofilamente, Ubiquitin, Hitzeschockproteine und Parkin enthalten (Schlossmacher et al. 2002).

Klinisch in Erscheinung tritt die Erkrankung durchschnittlich zwischen dem 55. und 65. Lebensjahr (Weintraub et al. 2008). Sowohl die Prävalenz als auch die Inzidenz steigen mit dem Alter an. So liegt die Prävalenz bei den über 65-Jährigen bei ca. 1\% (Biasini et al. 2004). Im Vergleich dazu bei den über 85-Jährigen schon bei 4-5\% (Giasson und Lee 2001). 
Der Morbus Parkinson ist bis heute eine unheilbare progressiv fortschreitende Erkrankung. Dennoch kann die Behandlung der Symptome eine erhebliche Verbesserung der Lebensqualität für die Patienten bedeuten (Lang und Lozano 1998 b).

Therapeutisch wird versucht, den Mangel an Dopamin (DA) und die dadurch entstandene Dysbalance der Neurotransmitter medikamentös auszugleichen. Grundlegend für die Therapie ist daher die Gabe von L-Dopa, die Vorstufe des Dopamins. Des Weiteren kommen auch Monoaminoxidase-B- und Catechol-O-Methyltransferase-Inhibitoren, Dopaminrezeptoragonisten und Acetylcholinrezeptorantagonisten zum Einsatz (Karow und Lang-Roth 2010). Neben der medikamentösen Therapie steht die tiefe Hirnstimulation, bei der Elektroden in die Basalganglien eingebracht werden, als operative Therapie zur Verfügung (Volkmann 2004). Zunehmend wird auch die Möglichkeiten der Stammzell- und Gentherapie erforscht.

Als Ursachen für den Morbus Parkinson kommen sowohl Umwelteinflüsse, als auch Gene oder eine Kombination von Beiden in Betracht (Hancock et al. 2008, Langston 1998). Die Entdeckung von zahlreichen Genen, die mit seltenen familiären Formen des Morbus Parkinson in Verbindung gebracht werden, hat die Rolle der Genetik in der Entstehung von MP bekräftigt (Lesage und Brice 2009). Die genetische Ursachenforschung ermöglicht einen Weg, die pathologischen Mechanismen, die zur Krankheitsentstehung beitragen, zu verstehen und mögliche Angriffspunkte für künftige neuroprotektive Therapien zu finden.

\subsection{2 Ätiologie und Pathogenese}

Ca. $95 \%$ aller Parkinson-Syndrome treten sporadisch bzw. idiopathisch auf. Nur bei 5\% der Patienten mit MP liegt eine vererbte hereditäre Form mit autosomal dominantem (AD) oder rezessivem (AR) Erbgang vor (Dauer und Przedborski 2003).

Die Ursache für den idiopathischen Morbus Parkinson ist bis heute noch weitgehend unbekannt. Als Faktoren, die zu einer Neurodegeneration bei MP führen können, werden vor allem mitochondriale Dysfunktion und oxidativer Stress, sowie Proteinaggregation und eine Fehlfunktion des Ubiquitin-Proteasom-Sytems (UPS) diskutiert (Lang und Lozano 1998 a).

\subsubsection{Mitochondriale Dysfunktion und oxidativer Stress}

Neben der Regulation von Zellüberleben und programmiertem Zelltod (Apoptose) produzieren Mitochondrien den Energielieferant Adenosintriphosphat (ATP). Bei der Oxidation von beispielsweise Fettsäuren entstehen starke Oxidanzien, sogenannte reaktive Sauerstoffspezies (Reactive oxigen species, ROS), wie etwa Wasserstoffperoxid $\left(\mathrm{H}_{2} \mathrm{O}_{2}\right)$, als 
Nebenprodukt. Sie können Ursache für DNA-Mutationen, oxidative Veränderungen und Inaktivierung von Proteinen oder Lipiden sein und über eine Veränderung der mitochondrialen Membranpermeabilität zum Zelltod führen. Über antioxidative Systeme wie etwa Glutathion können die ROS neutralisiert werden. Dopaminerge Neurone sind besonders anfällig für ROS, da beim Metabolismus von DA zusätzlich $\mathrm{H}_{2} \mathrm{O}_{2}$ entstehen (Hald und Lotharius 2005). Des Weiteren entstehen bei der Autooxidation toxische Dopamin-Chinone, die mit Cystein-Resten von Proteinen reagieren und sie somit schädigen können (Hald und Lotharius 2005). Bei einer Erhöhung des oxidativen Stresses kann die Anzahl von fehlgefalteten Proteinen die Kapazität der zellulären Abbauwege übersteigen.

Zahlreiche Studien liefern Evidenz für erhöhten oxidativen Stress bei MP. Bei Patienten mit der Parkinson-Erkrankung konnte eine erniedrigte Aktivität des Komplexes 1 der Atmungskette (Greenamyre et al. 2001) und Verminderung von Glutathion (Sian et al. 1994) beobachtet werden.

Tiermodelle der Parkinson-Erkrankung bekräftigen die Bedeutung der Mitochondrien bei der Pathogenese. So kann die systemische Verabreichung einiger Neurotoxine, wie MPTP (1Methyl-4-phenyl-tetrahydropyridin), Rotenon, Paraquat und $\mathrm{MPP}^{+}$(1-Methyl-4-phenyl-pyridin), den aktiven Metabolit von MPTP, Symptome des Morbus Parkinson auslösen und zur selektiven Degeneration der Neurone in der SNpc bei Menschen und Tieren führen (Burns et al. 1983, Davis et al. 1979). $\mathrm{MPP}^{+}$und auch Rotenon inhibiert den Komplex 1 in den Mitochondrien (Nicklas et al. 1987). Auch einige Proteine, die für hereditäre Formen des Morbus Parkinson verantwortlich sind, sind entweder mitochondriale Proteine oder mit den Mitochondrien assoziiert und bzw. in deren Metabolismus involviert (Lin TK et al. 2009). So ist etwa PINK1 (PTEN-induced kinase 1) eine mitochondriale Kinase und mit der inneren mitochondrialen Membran assoziiert (Gandhi et al. 2006, Valente et al. 2004). Auch Parkin kann mit der äußeren Membran des Mitochondriums assoziiert sein (Lin TK et al. 2009, Nuytemans et al. 2010).

\subsubsection{Proteinaggregation und proteasomale Dysfunktion}

Proteinaggregate sind typisch für viele neurodegenerative Erkrankungen. Beim MP treten diese in Form von Lewy-Körpern auf. Die Beobachtung, dass Proteinaggregate bei fast allen neurodegenerative Erkrankungen auftreten, lässt vermuten, dass sie toxisch für Neurone sind (Dauer und Przedborski 2003). Es mehren sich jedoch auch Hinweise, dass Lewy-Körper neuroprotektives Potential haben. Lösliche, fehlgefaltete und oligomerisierte Proteine sind toxisch für die Zelle und können direkt das Proteasom hemmen (Bence et al. 2001). Durch die 
Bildung von unlöslichen Lewy-Körpern könnte dieser Effekt minimiert werden (Ciechanover und Brundin 2003).

Proteine, die mit dem erblichen MP in Verbindung gebracht werden und Teil des UPS sind, wie etwa Parkin, verdeutlichen die Bedeutung dieses Systems für die Pathogenese. Das UPS stellt einen der wichtigen Mechanismen zum Abbau mutierter, fehlgefalteter und beschädigter Proteine dar (Lim et al. 2007) (s. Kap. 1.2.3.1). Interessanterweise wurden jedoch bei Patienten mit Mutationen im Parkin-Gen keine Lewy-Körper gefunden (Davie 2008). Daher kann davon ausgegangen werden, dass die Lewy-Körper keine Rolle beim Voranschreiten des pathologischen Prozesses spielen und dass die Ubiquitinylierung von Proteinen wichtig für die Aggregation, Präzipitation und Formierung von diesen sind (Ciechanover und Brundin 2003).

Auch oxidativer Stress könnte eine bedeutende Rolle bei einer Dysfunktion des UPS spielen. Oxidativer Stress führt zu einer Funktionsstörung der Mitochondrien und durch die Reduktion des Energielieferanten ATP zur Störung des ATP-abhängigen Proteasoms. Es entsteht ein Circulus vitiosus: Der verminderte Abbau fehlgefalteter Proteine führt zur Steigerung der ROS und diese wiederum hemmen die Bildung von ATP durch die Dysfunktion der Mitochondrien (Mizuno et al. 2008).

Daneben könnte auch eine Sequestrierung von Bestandteilen des UPS die Dysfunktion des Proteasoms erklären. Die Arbeitsgruppe um McNaught fand eine signifikant verminderte proteasomale Aktivität in der SNpc bei Patienten mit MP (McNaught et al. 2003).

\subsubsection{Risikofaktoren und Umwelteinflüsse}

Das Alter ist bisher der einzige eindeutig identifizierte Risikofaktor (Langston 1998). In einigen Studien wird auch die Bedeutung von Umweltfaktoren für die Entstehung von MP diskutiert. So fand die Arbeitsgruppe um Hernán für Raucher ein um $60 \%$ und für Kaffeetrinker ein um 30\% erniedrigtes Erkrankungsrisiko im Vergleich zu Nicht-Rauchern und Nicht-Kaffeetrinkern (Hernán et al. 2002). Eine befriedigende Erklärung für den vermeintlich schützenden Effekt wurde jedoch noch nicht gefunden. Ein langjähriger Umgang mit Pestiziden dagegen erhöht das Risiko, an MP zu erkranken (Hancock et al. 2008).

Auch ein inflammatorischer Prozess als mögliche Ursache für den nigrostriatalen Zelluntergang wurde bereits postuliert (Herrera et al. 2005). 


\subsubsection{Familiäre Formen von Morbus Parkinson und genetische Risikofaktoren}

In den letzten Jahrzehnten wurden zahlreiche monogenetische Ursachen und SuszeptibilitätsGene für den MP entdeckt. Diese krankheitsassoziierten Gene haben durch Tier- und Zellkulturmodelle einen Einblick in pathophysiologische Bedingungen des MP gegeben. Zu diesen Genen gehören unter anderem $\alpha$-Synuclein, Parkin, PINK1, DJ-1 und Leucin-rich repeat kinase 2 (LRRK2). Tabelle 1.1 zeigt eine wachsende Liste Parkinson-assoziierter Genloci und Vererbungsformen.

Nicht nur Mutationen in den untengenannten Genen, sondern auch bestimmte genetische Variationen können die Penetranz, das Alter zu Beginn, die Schwere und die Progression der Erkrankung beeinflussen (Lesage und Brice 2009). Bestimmte Variationen, sogenannte Single nucleotide polymorphism, im $\alpha$-Synuclein-, Microtubule-associated protein tau(MAPT) und LRRK2-Gen, gehen mit einer erhöhten Wahrscheinlichkeit einher, an Parkinson zu erkranken (Simón-Sánchez et al. 2009).

\begin{tabular}{|c|c|c|c|}
\hline PARK Locus & Gen & $\begin{array}{l}\text { Chrom. } \\
\text { Lokalisation }\end{array}$ & Parkinson Form \\
\hline PARK 1 & $\alpha$-Synuclein & $4 q 21$ & EO-MP AD und sporadisch \\
\hline PARK 2 & Parkin & $6 q 25-q 27$ & juveniler und EO-MP AR und sporadisch \\
\hline PARK $3 *$ & unbekannt & $2 \mathrm{p} 13$ & LO-MP AD \\
\hline PARK 4 & $\alpha$-Synuclein & $4 p 15$ & EO-MP AD und sporadisch \\
\hline PARK 5* & UCH-L1 & $4 \mathrm{p} 14$ & LO-MP AD \\
\hline PARK 6 & PINK 1 & $1 \mathrm{p} 35-\mathrm{p} 36$ & EO-MP AR \\
\hline PARK 7 & DJ-1 & $1 \mathrm{p} 36$ & EO-MP AR \\
\hline PARK 8 & LRRK2 & $12 q 12$ & LO-MP AD und sporadisch \\
\hline PARK 9 & ATPI3A2 & $1 \mathrm{p} 36$ & juveniler AR \\
\hline PARK $10^{*}$ & unbekannt & $1 \mathrm{p} 32$ & unbekannt \\
\hline PARK $11 ?^{*}$ & GIGYF2 & $2 q 36-q 37$ & LO-MP AD \\
\hline PARK $12 *$ & unbekannt & $\mathrm{Xq}$ & unbekannt \\
\hline PARK 13* & Omi/HTRA2 & $2 \mathrm{p} 13$ & unbekannt \\
\hline PARK $14 ?^{*}$ & PLA2G6 & $22 q 13.1$ & juveniler AR \\
\hline PARK $15 ? *$ & FBX07 & $22 q 12-q 13$ & EO AR \\
\hline
\end{tabular}

Tab. 1.1: Parkinson assoziierte Genloci (modifiziert nach Lesage und Brice 2009 S. 53, Xiromerisiou et al. 2010, S. 2). * Relevanz bis heute noch unklar; EO= Early Onset, GIGYF2= GRB10-interacting GYF protein 2 , Omi/HTR2: Omi /High temperature regulation A serine peptidase2, LO= Late Onset, PLA2G6= Group VI phospholipase A2, UCH-L1= Ubiqutin carboxy-terminal hydrolase 


\subsection{Parkin}

Parkin wurde als Ursache für den autosomal rezessiv vererbten juvenilen MP erstmals 1998 von der Arbeitsgruppe um Kitada bei der Untersuchung von einigen japanischen Familien beschrieben (Kitada et al. 1998). Parkin ist als eine E3-Ligase Bestandteil des UPS und nimmt eine besondere Stellung unter den mit Parkinson-assoziierten Genen ein. Bis zu 50\% der autosomal rezessiven (Lücking et al. 2000) und zusätzlich noch 15\% aller sporadischen EarlyOnset-Formen, d.h. mit einem Beginn der Erkrankung vor dem 40. Lebensjahr, können auf Mutationen im Parkin-Gen zurückgeführt werden (Periquet et al. 2003).

\subsubsection{Klinische Erscheinung der Parkin-assoziierten Parkinson-Erkrankung}

Klinisch zeigt der Parkin-assoziierte MP die typischen Symptome (Brady- oder Akinese, Rigor und Tremor). Besonders ist jedoch der frühe Erkrankungsbeginn, meist vor dem 40. Lebensjahr. Die Symptome sprechen gut auf eine L-Dopa-Therapie an. Als zusätzliche Symptome konnten eine Dystonie der Füße zu Beginn der Erkrankung, Hyperreflexie der unteren Extremität und eine langsame Progression bei Patienten beobachtet werden (Ishikawa und Tsuji 1996).

\subsubsection{Zellbiologische und molekulare Charakteristika}

Das Parkin-Gen liegt auf dem langen Arm von Chromosom 6 (6q25.2-q27). Mit mehr als 1.5 Megabasen ist es eines der größten Gene des menschlichen Genoms. Seine 12 Exons kodieren für ein Protein mit 465 Aminosäuren (AS) und einem Molekulargewicht von $52 \mathrm{kDa}$. Parkin ist hoch konserviert und zeigt Orthologien in verschiedenen Spezies (Horowitz et al. 1999, Kitada et al. 2000). Das Protein wird neben dem Gehirn noch in zahlreichen Geweben exprimiert, unter anderem im Herz, Hoden und Skelettmuskel (Kitada et al. 1998). Im Gehirn wird Parkin ubiquitär in allen neuronalen Zelltypen exprimiert.

In der Zelle ist Parkin hauptsächlich im Zytoplasma lokalisiert (Shimura et al. 1999). Daneben zeigen Studien auch Assoziationen von Parkin mit dem Golgi-Apparat (Kubo et al. 2001, Shimura et al. 1999), synaptischen Vesikeln (Fallon et al. 2002, Kubo et al. 2001), der äußeren Membran von Mitochondrien (Lin TK et al. 2009) und Elementen des Zytoskeletts, wie Aktin (Huynh et al. 2000) und Tubulin (Ren et al. 2003). Parallel hierzu wurde eine Anreicherung im Nukleus beschrieben (Stichel et al. 2000).

In der Primärstruktur von Parkin lassen sich fünf funktionelle Domänen beschreiben (s. Abb. 1.1). Am N-Terminus von der AS 1-76 befindet sich eine Ubiquitin-like-Domäne (UBL), die 
zahlreiche Homologien zu Ubiquitin aufweist. Darüber hinaus verfügt Parkin am C-Terminus über zwei sogenannte RING (Really interesting new gene)-Regionen, die durch eine IBR (Inbetween RING)-Domäne getrennt sind (von Coelln et al. 2004). Zwischen der UBL und dem ersten RING-Motiv befindet sich noch eine so genannte Linkerregion.

\begin{tabular}{|c|c|c|c|c|}
\hline UBL & Linker & RING & IBR & RING \\
\hline
\end{tabular}

Abb. 1.1: Schematische Zeichnung der Primärstruktur von Parkin. Parkin besteht aus einer N-terminalen UBL-Domäne, einer zentralen Linkerregion und zwei C-terminalen RING-Domänen mit einer dazwischen liegenden IBR-Domäne (Modifiziert nach von Coelln et al. 2004, S. 176).

Seit der Entdeckung der ersten Deletionsmutation im Exon 5 (Kitada et al. 1998) konnten noch zahlreiche Mutationen im Parkin-Gen identifiziert werden: Deletionen in einzelnen oder mehreren Exons, Duplikationen oder Triplikationen von Exons, Frameshift- und Punktmutationen, die zum Austausch einer AS führen (Missense) oder den Einbau eines Stopcodons zur Folge haben (Nonsense) (Abbas et al. 1999, Lücking et al. 2000, West et al. 2002). Ein Großteil der Punktmutationen betrifft die sogenannte Ring-Box, d.h. RING-IBRRING-Region am C-Terminus von Parkin und hier besonders die erste RING-Domäne (von Coelln et al. 2004) (s. Abb. 1.2). Die RING-Box ist wichtig für die Rekrutierung der E2Ligasen und repräsentiert die katalytische Gruppe (Zhang et al. 2000). Es ist daher nicht verwunderlich, dass eine Vielzahl der familiären Punktmutation in dieser Region gefunden wurde (Lim et al. 2003, von Coelln et al. 2004). Einen eindeutigen Mutationshotspot gibt es jedoch nicht, da die Mutationen über das ganze Parkin-Gen verteilt sind.

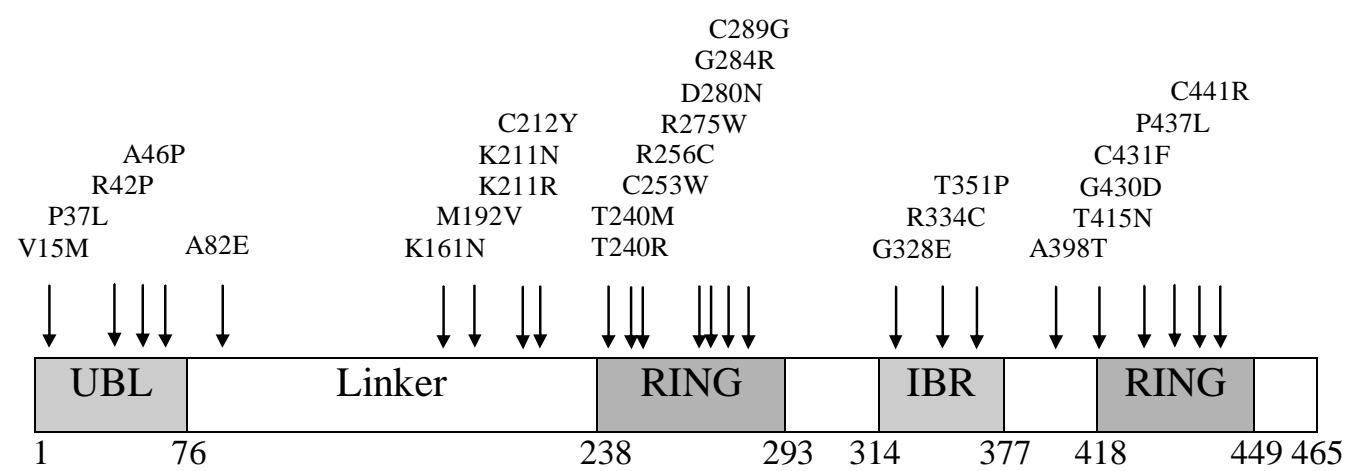

Abb. 1.2: Schematische Zeichnung von Parkin und mit Parkinson assoziierte Mutationen. Die Lokalisationen der Missense- oder Nonsense-Mutationen sind mit Pfeilen gekennzeichnet (Modifiziert nach von Coelln et al. 2004, S.176). 


\subsubsection{Physiologische Funktion}

In den letzten Jahren wurden zahlreiche Proteine mit RING-Motiv, so auch Parkin als Ubiquitin-E3-Ligase identifiziert (Imai et al. 2000, Shimura et al. 2000, Zhang et al. 2000). E3-Ligasen sind Teil des UPS und markieren Proteine mit Ubiquitin, welches als Erkennungssequenz für die Degradation durch das Proteasom dient.

Aufgrund seiner Funktion im Ubiquitin-Proteasom-System wurde vermutet, dass die durch Funktionsverlust von Parkin angehäuften Substrate toxisch sind und so zum Untergang der Zelle führen (Kahle und Haass 2004).

Neben der gut beschriebenen Funktion als E3-Ligase gibt es einige Hinweise, dass Parkin neuroprotektiv wirkt. So gleicht Parkin den negativen Effekt von mutiertem $\alpha$-Synuclein und proteasomalen Inhibitoren auf Be-M17-Zellen aus (Petrucelli et al. 2002). In vivo schützt Parkin vor einer durch Überexpression von Pael-R oder $\alpha$-Synuclein bedingten Toxizität (Yang Y et al. 2003). Des Weiteren konnte gezeigt werden, dass Parkin unter physiologischen Bedingungen in die mitochondriale Homöostase involviert ist. Zudem scheint Parkin die Autophagie bei mitochondrialer Dysfunktion zu induzieren (Nuytemans et al. 2010).

Des Weiteren scheint Parkin auch als Tumorsuppressorgen in der Karzinogenese von zahlreichen soliden Tumoren wie etwa den Ovarial- oder Mamma-Karzinomen, aber auch bei verschiedenen hämatologischen Tumoren eine Rolle zu spielen (Cesari et al. 2003).

\subsubsection{Das Ubiquitin-Proteasom-System}

Das UPS stellt den wichtigsten selektiven Mechanismus für eukaryotische Zellen dar, um mutierte, fehlgefaltete und beschädigte Proteine abzubauen (Lim und Tan 2007).

Daneben hat dieses System über den Abbau von verschiedenen kurz- und langlebigen Proteinen modulierenden Einfluss auf zahlreiche zelluläre Prozesse.

Für die Degradation erfolgt zunächst eine Markierung der Proteine durch reversible kovalente Bindung kleiner spezifischer Proteine. Am bekanntesten ist die Verknüpfung mit Ubiquitin, einem 8 kDa großen Protein. Der Übertragungsprozess von Ubiquitin an die Substratproteine findet mit Hilfe von 3 Enzymklassen statt (Ciechanover und Brundin 2003). Durch ein sogenanntes E1-Enzym wird Ubiquitin unter Verbrauch von ATP aktiviert. In einem zweiten Schritt erfolgt die Übertragung des aktivierten Ubiquitins auf ein Cystein im aktiven Zentrum eines E2-Enzyms. Für die spezifische Ubiquitinylierung wird zuletzt eine E3-Ligase benötigt. Dieses Enzym erkennt das Substratprotein und katalysiert die kovalente Bindung des Ubiquitins an Lysin-Reste des Substrats (s. Abb. 1.3). Da Ubiquitin selbst über Lysin-Reste 
verfügt, entsteht durch mehrfache Wiederholung dieses Vorganges eine Polyubiquitinkette, die dem Proteasom als Erkennungssequenz dient (Hochstrasser 1996).

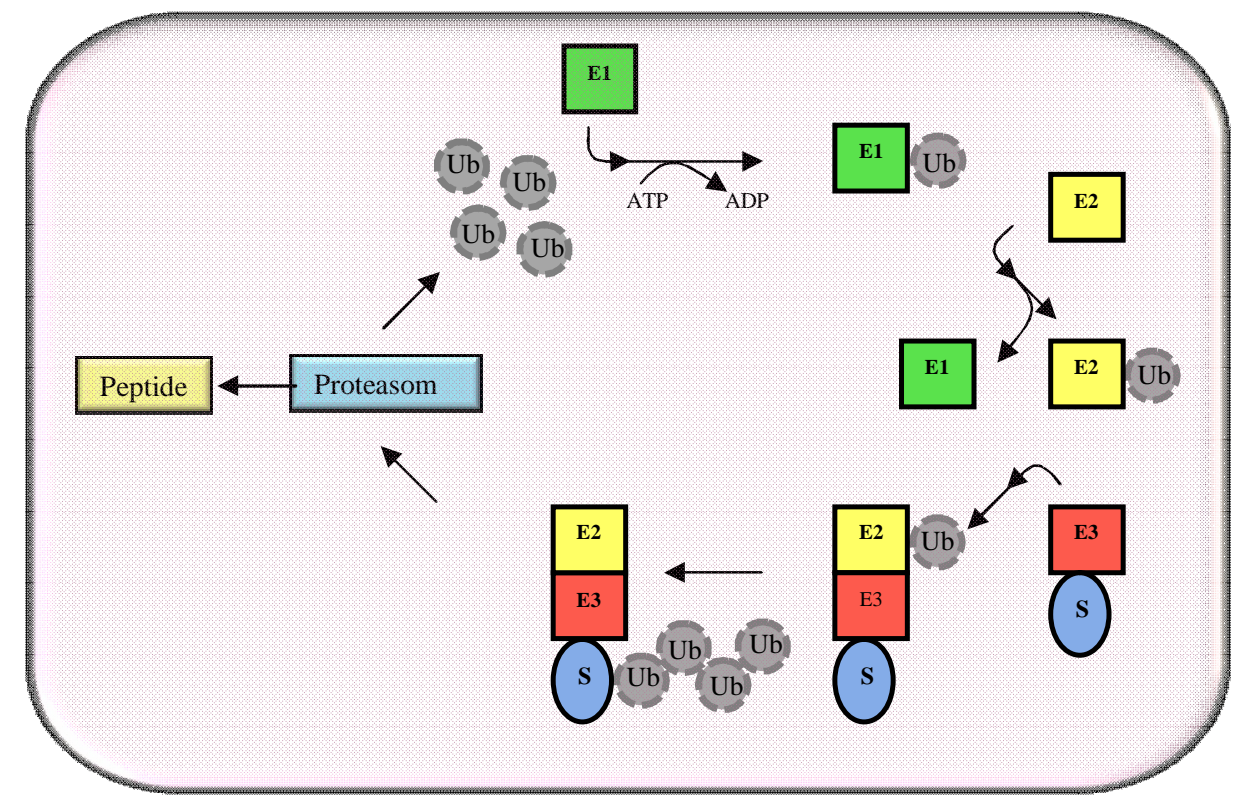

Abb. 1.3: Das Ubiquitin-Proteasom-System. Das E1-Enzym aktiviert Ubiquitin unter Verbrauch von ATP. Darauf erfolgt die Übertragung des Ubiquitins auf ein E2-Enzym. Die E3-Ubiquitin-Ligase katalysiert die Bindung von Ubiquitin an das gebundene Substrat. S: Substrat; Ub: Ubiquitin (modifiziert nach Betarbet et al. 2005, S. 19).

Das Proteasom ist ein großer Protease-Komplex, der nach seinem Sedimentationskoeffizient auch 26S-Proteasom genannt wird und aus zwei Teilkomplexen besteht (s. Abb. 1.4). Das zentrale fassähliche 20S-Proteasom ist aus $\alpha$ - und $\beta$-Untereinheiten aufgebaut, die in Form eines hohlen Zylinders angeordnet sind. Die Innenseite der $\beta$-Untereinheiten besitzt die proteolytische Aktivität (Baumeister et al. 1998).

Die zweite Untereinheit ist die 19S-Kappe und befindet sich jeweils an den beiden äußeren Anteilen des 20S-Komplexes (Baumeister et al. 1998). Dieser vermittelt die Erkennung und Entfaltung der ubiquitinylierten Substrate, ihre Deubiquitinylierung, sowie die Translokation ins Lumen des 20S-Proteasoms (Glickman et al. 1998).

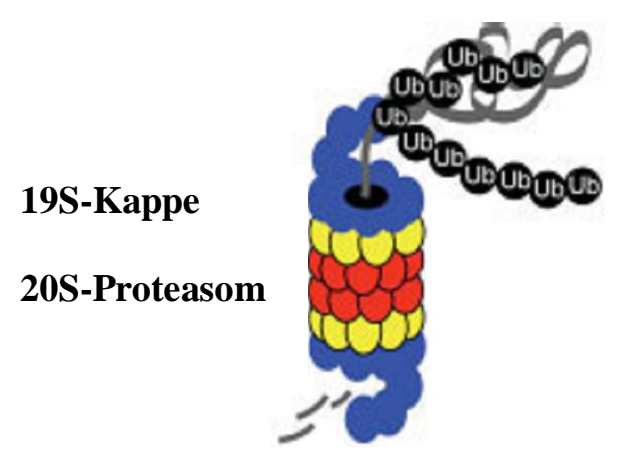

Abb. 1.4: Das 26S-Proteasom. Das 26S-Proteasom besteht aus zwei Teilkomplexen. Dargestellt ist das 20SProteasom mit den ringförmig angeordneten proteolytischen $\alpha$ - und $\beta$-Untereinheiten und die ober- und unterhalb der 20S-Untereinheit befindlichen 19S-Kappen (modifiziert nach Olanow und McNaught 2006 S. 1810). 


\subsubsection{Unterschiedliche Arten der Ubiquitinylierung}

Ubiquitinylierung spielt nicht nur bei der proteasomalen Degradation, sondern auch in der post-translationalen Modifikation von Proteinen eine Rolle.

Für die Bedeutung der Ubiquitinylierung sind die Verknüpfung der Ubiquitin-Moleküle untereinander und die Länge der Ubiquitinkette entscheidend (Hicke 2001) (s. Abb. 1.5). Da Ubiquitin über mehrere Lysinreste verfügt, können die Moleküle unterschiedlich verbunden werden.

Eine Polyubiquitinylierung über Lysin-48 markiert Proteine für den proteasomalen Abbau (Hochstrasser 1996). Parkin besitzt ein Lysin-48 in der UBL-Region. So ist es nicht verwunderlich, dass Parkin durch Selbstubiquitinylierung auch seinen eigenen Abbau fördert (Zhang et al. 2000).

Hingegen spielt eine Verknüpfung der Ubiquitinmoleküle über Lysin-63 bei der posttranslationalen Modifikation eine Rolle. Endozytose, DNA-Reparatur und Aktivierung von Proteinkinasen können so veranlasst werden. Monoubiquitinylierung konnte unter anderem bei der Regulation von Histonen (Robzyk et al. 2000) und der Endozytose von Plasmamembran-Proteinen (Hicke 1999) beobachtet werden. Anders als bei der Polyubiquitinylierung über Lysin-48 sind monoubiquitinylierte Proteine stabil oder werden nach der Endozytose von Lysosom abgebaut (Hicke 2001).

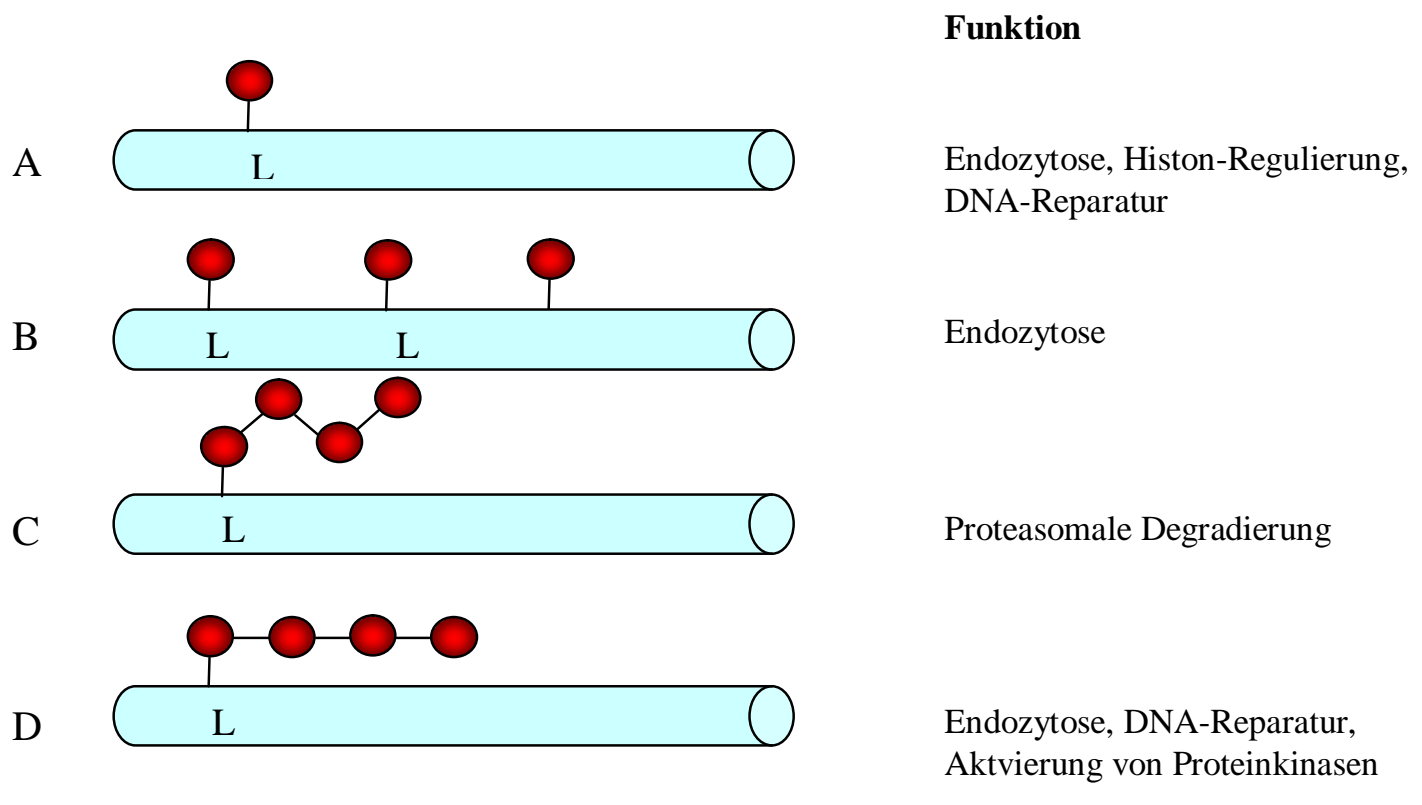

Abb. 1.5: Unterschiedliche Arten der Ubiquitin-Verknüpfung. Proteine können an einem (Monoubiquitinylierung) oder an mehreren (Multimonoubiquitinylierung) Lysin-Resten mit einem UbiquitinRest verkünpft werden (A, B). Bei Polyubiquitinylierung über Lysin-48 erfolgt eine proteasomale Degradierung des markierten Proteins (C). Konjugation einer Polyubiquitinkette über Lysin-63 hat dagegen eine regulatorische Funktion (D). L= Lysinrest (modifiziert nach Hicke 2001, S. 195). 


\subsubsection{Interagierende Proteine und Substrate}

Entsprechend der Funktion als E3-Ligase bindet Parkin an zahlreiche E2-Enzyme (s. Tab. 1.2). Sowohl die Arbeitsgruppe um Shimura als auch um Imai haben die zytoplasmatisch lokalisierten UbcH7 (Ubiquitin-conjugating human enzyme) und UbcH8 als Interaktoren für Parkin beschrieben (Shimura et al. 2000, Imai et al. 2000). Zusätzlich interagieren noch die mit dem Endoplasmatischen Retikulum assoziierten E2-Ligasen Ubc6 und 7 (Ubiquitinconjugating enzym) mit Parkin (Imai et al. 2001).

\begin{tabular}{|l|l|l|}
\hline E2-Ligase & Lokalisation & Referenz \\
\hline UbcH7 & Zytoplasmatisch & $\begin{array}{l}\text { Shimura et al. 2000 } \\
\text { Imai et al. 2000 }\end{array}$ \\
\hline UbcH8 & Zytoplasmatisch & $\begin{array}{l}\text { Zhang et al. 2000 } \\
\text { Imai et al. 2000 }\end{array}$ \\
\hline Ubc6 & $\begin{array}{l}\text { Endoplasmatisches } \\
\text { Retikulum }\end{array}$ & Imai et al. 2001 \\
\hline Ubc7 & $\begin{array}{l}\text { Endoplasmatisches } \\
\text { Retikulum }\end{array}$ & Imai et al. 2001 \\
\hline
\end{tabular}

Tab. 1.2: Beschriebene Parkin interagierende E2-Enzyme und deren intrazelluläre Lokalisation. Ubc: Ubiquitin-conjugating enzyme, UbcH: Ubiquitin-conjugating human enzyme

Neben den E2-Ligasen wurden zahlreiche andere Bindungspartner für Parkin beschrieben (s. Tab. 1.3). So hat Parkin zusätzlich zu der Bindung an das Proteasom Einfluss auf zelluläre Proteinfaltungshelfer (Chaperone) wie etwa CHIP (Carboxyl terminus of the Hsc70interacting protein), Hsp70 (Hitzeschockprotein) und das Cochaperon BAG5 (Bcl-2associated athanogene 5). Des Weiteren scheint Parkin mit anderen Parkinson-assoziierten Genen zu interagieren. So bindet Parkin etwa an PINK1 (Um et al. 2009) und kann die durch Parkinson-typische Mutationen im PINK1-Gen verursachten morphologischen Veränderungen von Mitochondrien wiederherstellen (Exner et al. 2007). Auch eine Interaktion mit DJ-1-Mutanten (Moore et al. 2005) und sogar eine Komplexbildung aus den drei Proteinen wurde beschrieben (Xiong et al. 2009). 


\begin{tabular}{|l|l|l|}
\hline $\begin{array}{l}\text { Parkin-interagierende } \\
\text { Proteine }\end{array}$ & Mögliche Funktion & Referenz \\
\hline BAG5 & Cochaperon & Kalia SK et al. 2004 \\
\hline $\begin{array}{l}\text { Rpn-10 } \\
\text { S5a }\end{array}$ & $\begin{array}{l}\text { Proteasomale } \\
\text { Untereinheit }\end{array}$ & $\begin{array}{l}\text { Sakata et al. 2003 } \\
\text { Dächsel et al. 2005 } \\
\text { Safadi und Shaw 2010 }\end{array}$ \\
\hline PINK1 & Mitochondriale Kinase & $\begin{array}{l}\text { Exner et al. 2007 } \\
\text { Um et al. 2009 }\end{array}$ \\
\hline Hsp70 & Chaperon & Imai et al. 2002 \\
\hline CHIP & Chaperon, E3-Ligase & Imai et al. 2002 \\
\hline DJ-1-Mutanten & Redox-Proteine ? & Moore et al. 2005 \\
\hline p32 & Mitochondriales Protein & Li et al. 2011 \\
\hline Ambra1 & Reguliert Autophagie & Van Humbeeck et al. 2011 \\
\hline Aktin-Filamente & Zytoskelett & Huynh et al. 2000 \\
\hline CASK/Lin2 & Plasmamembran-Protein & Fallon et al. 2002 \\
\hline Cullin-1 & Multiprotein-Ligase & Staropoli et al. 2003 \\
\hline LRRK2 & Kinase & Smith et al. 2005 \\
\hline
\end{tabular}

Tab. 1.3: Potentiell Parkin-interagierende Proteine und deren Funktion. CASK: $\mathrm{Ca}^{2+}$-calmodulin-dependent serine protein kinase, Ambra: activating molecule in Beclin 1-regulated autophagy

Abbildung 1.6 zeigt schematisch die Bindungsstellen einiger Cofaktoren an die Primärstruktur von Parkin. Teile des 19S-Proteasaoms binden an die UBL-Domäne. E2-Ligasen, Hsp70 und das Cochaperon CHIP binden an die RING-Box am C-Terminus (Kahle und Haass 2004). Für BAG5 wurde die Linker-Region als Bindungsstelle beschrieben (Kalia SK et al. 2004).

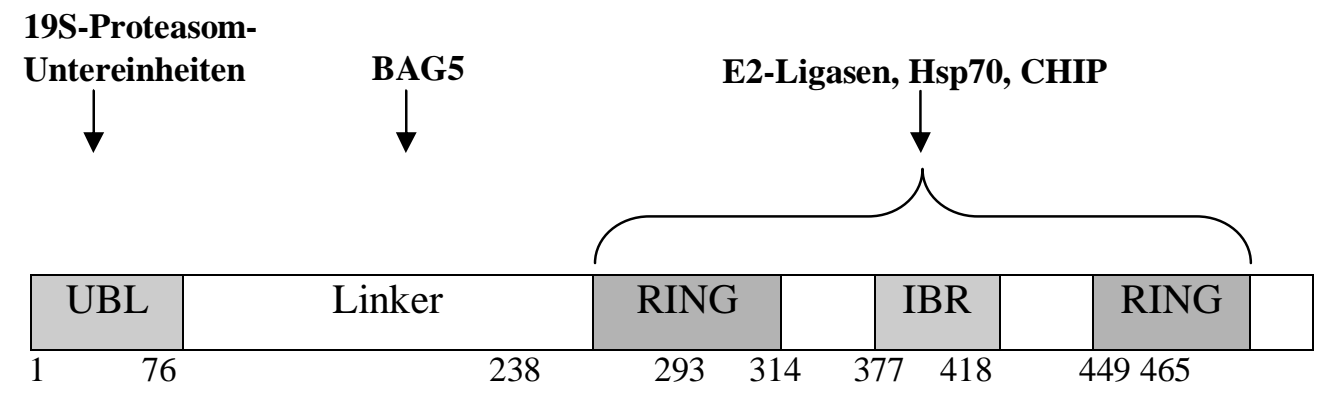

Abb. 1.6: Schematische Zeichnung von Parkin und den Bindestellen einiger Interaktoren. An die UBLRegion binden vor allem Teile des 19S-Proteasoms. Verschiedene Coenzyme wie beispielsweise E2-Ligasen, Hsp70 oder CHIP binden vor allem an den C-Terminus. Für BAG5 wurde die Linker-Region als Bindungsstelle beschrieben (Abbildung modifiziert nach Kahle und Haass 2004, S. 682). 
Bis heute wurden zahlreiche Substrate der E3-Ligase Parkin mit verschiedenster zellulärer Lokalisation und Funktion durch Yeast-two-hybrid- oder Co-Immunopräzipitationsversuche entdeckt (s. Tab. 1.4): Proteine, die einen Einfluss auf die Freisetzung von synaptischen Vesikeln haben, wie etwa das CDCrel-1 (Cell division control related protein) (Zhang et al. 2000), Kontrollproteine des Zellzyklus wie Cyclin E (Staropoli et al. 2003), Teile des Proteinsynthese-Apparates (Corti et al. 2003, Ko et al. 2006), Proteine von Signaltransduktionskaskaden wie etwa der Pael-Rezeptor (Parkin-associated endothelin-like receptor) (Dusonchet et al. 2009, Imai et al. 2001), Teile des Zytoskeletts (Huynh et al. 2007, Ren et al. 2003) oder Kerntransportproteine (Um et al. 2006). Hierdurch zeigt sich die vielfältige Bedeutung des Parkin-Proteins, vor allem für das Nervensystem.

\begin{tabular}{|c|c|}
\hline Substrat & Mögliche Bedeutung \\
\hline & Vesikel und Synapse \\
\hline CDCrel-1 & Zhang et al. 2000 \\
\hline CDCrel-2a & Choi et al. 2003 \\
\hline$\alpha \operatorname{Sp} 22$ & Shimura et al. 2001 \\
\hline Synphilin-1 & Chung et al. 2001 \\
\hline Synaptotagmin XI & Huynh et al. 2003 \\
\hline DAT & Jiang H et al. 2004 \\
\hline Cyclin E & $\begin{array}{l}\text { Zellzyklus } \\
\text { Staropoli et al. } 2003\end{array}$ \\
\hline $\begin{array}{l}\text { p38 } \\
\text { FBP1 }\end{array}$ & $\begin{array}{l}\text { Proteinbiosynthese } \\
\text { Corti et al. } 2003 \\
\text { Ko et al. } 2006\end{array}$ \\
\hline Pael-R & $\begin{array}{l}\text { Zell. Transduktion/Signalkaskaden } \\
\text { Imai et al. 2001, Dusonchet et al. } 2009\end{array}$ \\
\hline $\begin{array}{l}\alpha / \beta \text { Tubulin } \\
\text { Ataxin-2 }\end{array}$ & $\begin{array}{l}\text { Zytoskelett } \\
\text { Ren et al. } 2003 \\
\text { Huynh et al. } 2007\end{array}$ \\
\hline RanBP2 & $\begin{array}{l}\text { Kerntransport } \\
\text { Um et al. } 2006\end{array}$ \\
\hline
\end{tabular}

Tab. 1.4: Mögliche Parkin-Substrate und deren Bedeutung. $\alpha$ Sp22: O-glykosyliertes $\alpha$-Synuclein, DAT: Dopamin-Transporter, FBP1: Far upstream sequence element-binding protein-1, Pael-R: Parkin-associated endothelin-like receptor, RanBP2: Ran-binding protein 2. 


\subsection{BAG1}

BAG1 wurde ursprünglich als Bindungspartner für das anti-apoptotische Protein Bcl-2 beschrieben (Takayama et al. 1995).

Neben BAG1 zählen noch 5 weitere Proteine zur BAG-Familie (BAG2-6) (Takayama et al. 1999). Gemeinsam haben diese Proteine eine evolutionär konservierte BAG-Domäne an ihrem Carboxy-Terminus (Takayama et al. 1999), die zwischen 110 und 124 AS lang ist. Auch in anderen Spezies wie beispielsweise der Maus oder Drosophila kann diese BAGDomäne nachgewiesen werden (Doong et al. 2002). Von BAG1 wurden 4 Isoformen beschrieben (BAG1, BAG1-L, -M und -S), die sich lediglich in ihre Größe unterscheiden und durch alternatives Splicing entstehen (Takayama et al. 1998, Yang X et al. 1998).

\subsubsection{Physiologische Funktion von BAG1 und seine Interaktionspartner}

BAG1 hat durch seine zahlreichen Interaktionspartner Einfluss auf viele zelluläre Prozesse, wie Zellproliferation, Proteindegradierung, Transkription und Apoptose (s. Tab. 1.5).

Die anti-apoptotische Wirkung von Bcl-2 wird durch BAG1 verstärkt (Takayama et al. 1995). Zusätzlich fungiert es als Cochaperon und nukleärer Austauschfaktor für das Chaperon Hsp70 (Alberti et al. 2003). BAG1 vermag die Aktivität von Hsp70 und die anschließende Substratfreigabe zu stimulieren (Gassler et al. 2001, Liman et al. 2005, Takayama et al. 1997). Einige Studien zeigen jedoch auch einen inhibierenden Einfluss von BAG1 auf die Aktivität von Hsp70 (Bimston et al. 1998, Nollen et al. 2001, Novoselov et al. 2005). Diese Diskrepanz verdeutlicht die Komplexität der zellulären Faltungsmaschinerie und deren Abhängigkeit von Cofaktoren.

Vor allem im Nervensystem spielt BAG1 eine wichtige Rolle. Es stimuliert die neuronale Differenzierung (Kermer et al. 2002), schützt vor einem ischämischen Schaden und zahlreichen anderen apoptotischen Stimuli, wie etwa dem Glutamat-induzierten Zelltod (Kermer et al. 2003). Des Weiteren hat BAG1 über die Stimulation von Raf-1 (Rapidly growing fibrosarcoma or rat fibrosarcoma-1), einer Serin/Threonin-Kinase, die den MAPKinase Weg aktiviert, Einfluss auf Zellwachstum und Differenzierung (Song et al. 2001).

Sowohl Hsp70 als auch Raf-1 binden an die BAG-Domäne (s. Abb. 1.9). Diese besteht aus drei anti-parallelen $\alpha$-Helices, wobei die zweite und dritte Helix mit der ATPase Domäne von Hsp70 interagiert und die ersten Beiden mit Raf-1 (Song et al. 2001). Die gleichzeitige Bindung der beiden Proteine schließt sich damit aus, sodass vermutet wird, dass Hsp70 und Raf-1 um die Bindung an BAG1 konkurrieren. In Abhängigkeit von der zellulären Situation 
kann BAG1 so entweder das Zellwachstum stimulieren oder auf zellulären Stress reagieren (Song et al. 2001).

Die enorme Bedeutung der BAG-Domäne für die neuroprotektive Wirkung von BAG1 verdeutlichte eine Arbeit, in der gezeigt werden konnte, dass BAG $\Delta \mathrm{C}$, eine Deletionsmutante des BAG1, die durch den Verlust von 29 AS am C-Terminus einen Teil der BAG-Domäne einbüßt, seine Fähigkeit, mit Hsp70 zu interagieren, und damit seine neuroprotektive Wirkung verliert. Des Weiteren zeigte sich, dass die BAG-Domäne für die zelluläre Lokalisation des Proteins entscheidend ist. BAG $\Delta \mathrm{C}$ ist, anders als BAG1, nur zytoplasmatisch lokalisiert (Liman et al. 2005).

Neben der BAG-Domäne ist die N-terminale UBL-Domäne eine Region, die sich in allen BAG1-Proteinen finden lässt (Doong et al. 2002) (s. Abb. 1.7). Hier binden Teile des UPS, wie das 26S-Proteasom und die E3-Ligase CHIP. BAG1 scheint ein Substrat von CHIP zu sein (Alberti et al. 2002). Durch die Bildung eines ternären Komlpexes aus BAG1, CHIP und Hsp70 erfolgt eine verstärkte Ubiquitinylierung von BAG1. Diese scheint jedoch nicht den Abbau on BAG1 zu induzieren, sondern die Assoziation von BAG1 an das Proteasom zu fördern, wo BAG1 regulatorisch tätig ist (Alberti et al. 2002). Durch die Bindung an CHIP wird etwa der Abbau des Glukokortikoid-Rezeptors verstärkt (Demand et al. 2001).

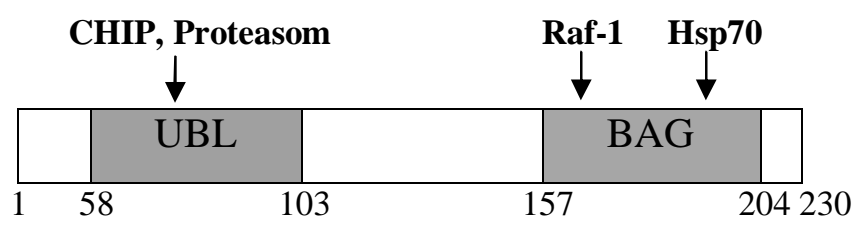

Abb. 1.7: Schematische Zeichnung von BAG1 und Bindestellen einiger Interaktoren. Die Primärstruktur von BAG1 besteht aus einer N-terminalen UBL-Domäne, an die das Proteasom und die E3-Ligase CHIP binden, und aus einer C-terminalen BAG-Domäne, die Bindungsstellen für Raf-1 und Hsp70 aufweist (modifiziert nach Takayama et al. 1999, S. 782).

Auch bei anderen Mitgliedern der BAG-Familie konnte eine Verbindung zwischen den Chaperonen und dem UPS dokumentiert werden. BAG5 interagiert sowohl mit Parkin als auch mit Hsp70 und führt über die Inhibition der beiden zur Aggregation von Parkin, seinen Substraten und zu einem vermehrten Zelluntergang (Kalia SK et al. 2004). BAG2 konnte als ein spezifischer Inhibitor der E3-Ligase CHIP identifiziert werden (Arndt et al. 2005) und BAG3 soll die proteasomale Degradation von Hsp70 abhängigen Proteinen hemmen (Doong et al. 2003). Diese Ergebnisse lassen vermuten, dass BAG-Proteine eine wichtige Verbindung zwischen den Chaperonen und dem UPS darstellen.

Bei einigen Erkrankungen spielt BAG1 eine Rolle in der Pathogenese. Durch die Interaktion zu DJ-1 konnte bereits eine Verbindung zum erblichen MP gezogen werden (Deeg et al. 2010). Des Weiteren konnte nachgewiesen werden, dass BAG1 Tau-Proteine stabilisiert 
(Elliott el al. 2007). Bei Patienten mit Morbus Alzheimer zeigte sich zudem eine erhöhte Expression von BAG1-M im Hippocampus und somit ein verminderter Abbau von TauProteinen (Elliott et al. 2009). Auch bei der Entstehung von Tumoren spielt BAG1 als Protoonkogen ein Rolle und konnte in einigen Tumoren, wie etwa Mamma-, Prostata oder auch Kolon-Karzinomen, überexprimiert nachgewiesen werden (Doong et al. 2002).

Tabelle 1.5 zeigt weitere Bindungspartner, den Effekt von BAG1 auf ihre Funktionalität und die jeweiligen interagierende Isoform von BAG1.

\begin{tabular}{|c|c|c|c|}
\hline BAG1 interagierende Proteine & Effekt & BAG1-Isoform & Referenz \\
\hline Bcl-2 & + & BAG1 & Takayama et al. 1995 \\
\hline Hsp70 & $+/-$ & Alle & $\begin{array}{l}\text { Takayama et al. } 1997 \\
\text { Nollen et al. } 2001 \\
\text { Liman et al. } 2005\end{array}$ \\
\hline Raf-1 & + & BAG1 & Song et al. 2001 \\
\hline CHIP & + & BAG1 & Demand et al. 2001 \\
\hline Proteasom & & BAG1 & $\begin{array}{l}\text { Demand et al. } 2001 \\
\text { Alberti et al. } 2002\end{array}$ \\
\hline Vitamin-D-Rezeptor & - & BAG1 & Liu et al. 1998 \\
\hline Glukokortikoid-Rezeptor & - & $\begin{array}{l}\text { BAG1-L } \\
\text { BAG1-M }\end{array}$ & Kullmann et al. 1998 \\
\hline Androgen-Rezeptor & + & BAG1-L & Froesch et al. 1998 \\
\hline Siah 1 & - & BAG1 & $\begin{array}{l}\text { Matsuzawa et al. } \\
1998\end{array}$ \\
\hline $\begin{array}{l}\text { DNA (Stimulation der } \\
\text { Transkription) }\end{array}$ & + & $\begin{array}{l}\text { BAG1-L } \\
\text { BAG1-M }\end{array}$ & Zeiner et al. 1999 \\
\hline $\begin{array}{l}\text { Hepatocyte growth factor; } \\
\text { Platelet-derived growth factor }\end{array}$ & + & BAG1 & Bardelli et al. 1996 \\
\hline $\begin{array}{l}\text { Heparin-binding EGF-like } \\
\text { growth factor }\end{array}$ & + & BAG1 & Lin J et al. 2001 \\
\hline Tau & + & BAG1 & Elliott et al. 2007 \\
\hline DJ-1 & + & BAG1 & Deeg et al. 2010 \\
\hline
\end{tabular}

Tab. 1.5: Mögliche Interaktionspartner von BAG1. Ein Plus-Symbol bedeutet einen stimulatorischen Effekt auf den Bindungspartner, ein Minus-Symbol indiziert einen inhibitorischen Effekt (modifiziert nach Sroka 2008, S.28). Siah 1: seven in absentia homolog 1 


\subsection{Fragestellung der Arbeit}

Parkin spielt als Teil des UPS eine entscheidende Rolle bei der Entstehung des autosomal rezessiv vererbten MP (Lücking et al. 2000). Eine Verminderung der Parkin-Aktivität, beispielsweise durch S-Nitrosylation, kann zudem den Zelluntergang der dopaminergen Neurone beim sporadischen MP verstärken (Chung et al. 2004). Untersuchungen von Parkin bieten daher auch eine Möglichkeit, die Pathogenese des sporadischen MP besser zu verstehen. BAG1 wirkt als Cochaperon des Hsp70 neuroprotektiv und zahlreiche Studien konnten beweisen, dass es ein wichtiges Bindeglied zwischen den Chaperonen und dem UPS darstellt (Alberti et al. 2002, Demand et al. 2001, Matsuzawa et al. 1998). BAG5, ein weiteres Mitglied der BAG-Familie, konnte bereits als inhibierender Interaktionspartner von Parkin identifiziert werden (Kalia SK et al. 2004).

Das Ziel dieser vorliegenden Arbeit ist, eine Interaktion zwischen BAG1 und Parkin darzustellen, die interagierende Parkin-Domäne näher zu beschreiben, Auswirkungen von BAG1 auf die E3-Ligase-Funktion von Parkin sowie eine mögliche Veränderung in der Ubiquitinylierung und Löslichkeit von Parkin zu untersuchen.

Die Fragestellung der vorliegenden Dissertation wurde mit folgenden Arbeitshypothesen konkretisiert:

1. In Co-Immunopräzipitations-Versuchen sollte eine Proteinbindung zwischen Parkin und BAG1 dargestellt werden.

2. Durch Klonierung von Parkin-Deletionsmutanten und Co-Immunopräzipitations-Versuchen mit diesen und BAG1 sollte die Interaktionsstelle an Parkin identifiziert werden.

3. Für die funktionelle Analyse der Proteinbindung sollte der Einfluss von BAG1 auf die E3Ligasefunktion von Parkin durch Untersuchung der Ubiquitinylierung und Halbwertszeit des Parkin-Substrates CDCrel-1 bestimmt werden.

4. Die Beeinflussung von BAG1 auf die zelluläre Lokalisation und die Löslichkeit von Parkin sollten durch spezielle Zelllyseverfahren (subzelluläre Lysierung, Harnstofflyse), Dot-BlotAnalysen und Immunozytochemie-Versuche untersucht werden. 


\section{Material und Methoden}

\subsection{Klonierung}

Klonierung beschreibt die Einführung eines DNA-Fragments (Insert) in einen Plasmid-Ring (zirkuläre doppelsträngige DNA). Durch den Verdau mit Restriktionsendonukleasen wird das Insert und der Plasmidring an spezifischen Punkten geschnitten (Restriktionsschnittstellen), um im Anschluss durch das Enzym T4-DNA-Ligase miteinander verknüpft zu werden (Ligation). Bei einer Klonierung können bestimmte Signalpeptide, sogenannte tags, an das DNA-Fragment angehängt werden (z. B. HA-, FLAG- oder GFP-tag). Kompetente E.coli Bakterien werden mit dem fertigen Plasmidring transformiert und vervielfältigen die DNA. Die selektive Vermehrung wird durch Antibiotikaresistenzen im Plasmidring gewährleistet. Anschließend kann die vervielfältigte DNA durch Expression in verschiedenen Zellreihen untersucht werden.

Zur Untersuchung der genauen Interaktionsstelle zwischen Parkin und BAG1 wurden verschiedene Parkin-Deletionsmutanten kloniert.

\subsubsection{Polymerase-Kettenreaktion (PCR)}

Die Polymerase-Kettenreaktion (PCR) dient zur selektiven Amplifizierung von DNAFragmenten mittels thermostabiler DNA-Polymerase und spezifischer Oligonukleotide (Primer). Zur Herstellung der Parkin-Deletionsmutanten wurde folgender PCR-Ansatz verwendet:

50 ng Template DNA

$5 \mu 1$ 10x PFU Puffer (Stratagene, La Jolla, USA)

$2 \mu \mathrm{l} 10 \mathrm{mM}$ dNTP (Amersham Biosciences, Freiburg)

$1 \mu \mathrm{l} 10 \mu \mathrm{M}$ Primer 1 (Sigma Aldrich, Steinheim)

$1 \mu \mathrm{l} 10 \mu \mathrm{M}$ Primer 2 (Sigma Aldrich, Steinheim)

2,5 U PFU-Polymerase (Stratagene, La Jolla, USA)

Mit $\mathrm{H}_{2} \mathrm{O}$ auf $50 \mu \mathrm{l}$ auffüllen. 
Die PCR-Reaktion wurde im Mastercycler Gradient der Firma Eppendorf (Hamburg) nach folgendem Schema durchgeführt:

\begin{tabular}{|l|l|l|l|}
\hline Phase & Zeitdauer & Temperatur & Zyklen \\
\hline Denaturierung & $5 \mathrm{~min}$ & $95^{\circ} \mathrm{C}$ & 1 \\
\hline Denaturierung & $20 \mathrm{sec}$ & $95^{\circ} \mathrm{C}$ & \multirow{2}{*}{35} \\
\cline { 1 - 2 } Primeranlagerung & $20 \mathrm{sec}$ & $50-60^{\circ} \mathrm{C}$ & \\
\hline Polymerisation & $90 \mathrm{sec}$ & $72^{\circ} \mathrm{C}$ & 1 \\
\hline Polymerisation & $5 \mathrm{~min}$ & $72^{\circ} \mathrm{C}$ & \multirow{2}{*}{} \\
\hline
\end{tabular}

Bis zur weiteren Verarbeitung wurde das PCR-Produkt bei $4^{\circ} \mathrm{C}$ gelagert. Zur Erfolgskontrolle erfolgte eine Agarosegel-Elektrophorese mit $5 \mu$ des PCR-Ansatzes (s. 2.1.5).

\subsubsection{Verwendete Primer}

Parkin FW $\triangle \mathrm{UBL}$ : EcoRI

5`AATAGAATTCATGGAAAAGTCAAGAAA 3`

Parkin FW $\triangle$ LINKER: EcoRI

5`AATAGAATTCATGCACCCCACCTCTGAC 3`

Parkin FW $\triangle$ RING1: EcoRI

5`AATAGAATTCATGCCATCACTTCAGGAT 3`

Parkin FW $\triangle$ IBR: EcoRI

5`AATAGAATTCATGAGGCCTACAGAGTCG 3`

Für die vier oben genannten Forward-Primer wurde einheitlich folgender Backward-Primer verwendet:

Parkin BW: NotI

5`AATAGCGGCCGCTTACTACACGTCGAA 3`

Vektor: FLAGpcDNA3.1 
Schnittstellen der Restriktionsendonukleasen:

$\begin{array}{lc}\text { A/GAATTC } & \text { EcoRI } \\ \text { GC/GGCCGC } & \text { NotI }\end{array}$

Alle verwendeten Primer wurden von der Firma Sigma-Aldrich (Steinheim) hergestellt.

\subsubsection{Aufreinigung des PCR-Produktes}

Die Aufreinigung des PCR-Produktes erfolgte mit dem Pure Link ${ }^{\mathrm{TM}}$ PCR Purifikation Kit der Firma Invitrogen (Darmstadt) nach Protokoll mit den beigefügten Puffersystemen.

Zunächst wurden $200 \mu \mathrm{l}$ des mit Isopropanol versetzten Bindungspuffers oder Bindungspuffers HC zu den $50 \mu \mathrm{l}$ PCR-Volumen gegeben und vermischt. Das Puffer-ProbenGemisch wurde auf eine mitgelieferte Säule geladen. Darauf erfolgte eine 1-minütige Zentrifugation in der Biofuge fresco der Firma Heraeus (Hanau) bei Raumtemperatur (RT) und 10000 rpm. Die im Sammeltube aufgefangene Flüssigkeit wurde verworfen und zur Säule $650 \mu$ l ethanolhaltiger Waschpuffer hinzugefügt. Es folgte eine weitere Zentrifugation mit den oben genannten Bedingungen. Die Flüssigkeit wurde erneut verworfen und die Säule für weitere 2 min bei 13000 rpm zentrifugiert, um den restlichen Waschpuffer zu entfernen. Nach der Überführung der Säule in ein neues Eppendorf-Tube wurde diese mit $50 \mu$ l Elutionspuffer beladen und für 1 Minute (min) bei RT inkubiert. Durch Zentrifugation für 2 min bei 13000 rpm wurde die DNA in ein Eppendorf-Tube eluiert und bis zur Weiterverarbeitung bei $-20^{\circ} \mathrm{C}$ gelagert.

\subsubsection{Restriktionsenzymverdau}

Zur Vorbereitung des gereingten PCR-Produktes auf die Ligation wurde ein Verdau mit Restriktionsendonukleasen durchgeführt. Hierfür wurde sowohl das Insert als auch der Vektor mit den gleichen Enzymen verdaut.

Für den Restriktionsverdau wurde folgender Ansatz verwendet:

$1 \mu 1 \mathrm{DNA}$

$1 \mu \mathrm{l}$ 10x Enzym-Puffer

ggf. $1 \mu \mathrm{l} 10 \mathrm{x}$ BSA $(1 \mathrm{mg} / \mathrm{ml})$

0,5 $\mu 1$ Restriktionsenzym 1 (EcoRI 20000U/ml)

0,5 $\mu$ l Restriktionsenzym 2 (NotI 10000 U/ml). 
Der Ansatz wurde mit $\mathrm{H}_{2} \mathrm{O}$ auf $10 \mu \mathrm{l}$ eingestellt.

Der Restriktionsverdau-Ansatz wurde für 16 Stunden $(\mathrm{Std})$ bei $37^{\circ} \mathrm{C}$ inkubiert und nach der Inaktivierung der Enzyme bis zur Agarosegel-Elektrophorese bei $4{ }^{\circ} \mathrm{C}$ gelagert.

Alle Enzyme und Puffer wurden unter den vom Hersteller NEB (Frankfurt a. M) empfohlenen Temperatur- und Pufferbedingungen verwendet.

\subsubsection{Agarosegel-Elektrophorese}

Mit Hilfe der Agarosegel-Elektrophorese können DNA-Fragmente ihrer Größe nach in einem elektrischen Feld aufgetrennt werden.

Es wurde ein 1\%iges Agarosegel $(50 \mathrm{ml})$ in TBE-Puffer im Mini-Sub ${ }^{\circledR}$ Cell GT-Systems der Firma Bio-Rad (Hercules, USA) verwendet. Die Proben wurden mit 6x DNA-Puffer versetzt und in die Taschen des Agarosegels geladen. Als DNA-Marker wurde der $1 \mathrm{~kb}$ DNA Ladder Gen ruler der Firma Fermentas (St. Leon-Rot) verwendet. Die Elektrophorese erfolgte bei 100 Volt (V) für ca. 1 Std bei RT.

Im Anschluss wurde die DNA durch Anregung der interkalierenden Substanz Ethidiumbromid mit UV-Licht, unter Verwendung des Fluor-S ${ }^{\mathrm{TM}}$-MultiImagers (Bio-Rad, Hercules, USA) und des Computerprogrammes Quantity One 4.2.2 der Firma Bio-Rad (Hercules, USA), detektiert.

\begin{tabular}{|l|l|l|}
\hline Agarosegel & $\begin{array}{l}\text { 0,5 g Agarose } \\
5 \mu 1 \text { Ethidiumbromid (10mg/ml) } \\
\text { in 1x TBE Puffer }\end{array}$ & $\begin{array}{l}\text { Serva Elektophoresis GmbH (Heidelberg) } \\
\text { Sigma Aldrich (Steinheim) }\end{array}$ \\
\hline 10x TBE & $\begin{array}{l}37,2 \mathrm{~g} \text { EDTA } \\
540 \mathrm{~g} \text { Tris } \\
\text { 275 g Borsäure } \\
51 \text { purifiziertes } \mathrm{H}_{2} \mathrm{O}\end{array}$ & $\begin{array}{l}\text { Carl Roth GmbH (Karlsruhe) } \\
\text { AppliChem GmbH (Darmstadt) } \\
\text { Carl Roth GmbH (Karlsruhe) }\end{array}$ \\
\hline $\begin{array}{l}\text { 6x DNA- } \\
\text { Puffer }\end{array}$ & $\begin{array}{l}0,15 \% \text { Bromphenolblau } \\
0,15 \% \text { Xylene cyanol FF } \\
40 \% \text { Saccharose } \\
\text { in } \mathrm{H}_{2} \mathrm{O}\end{array}$ & $\begin{array}{l}\text { Carl Roth GmbH (Karlsruhe) } \\
\text { Amersham Biosciences (Freiburg) } \\
\text { Carl Roth GmbH (Karlsruhe) }\end{array}$ \\
\hline
\end{tabular}




\subsubsection{DNA-Aufreinigung aus Agarosegelen}

Für die Weiterverarbeitung der aufgetrennten DNA-Fragmente wurden diese unter UV-Licht mit einem Skalpell aus dem Gel getrennt. Im Anschluss erfolgte mit Hilfe des Pure Link ${ }^{\mathrm{TM}}$ Quick Gel Extraktion Kits der Firma Invitrogen (Darmstadt) die Aufreinigung der DNA. Diese wurde mit den beigefügten Puffern nach folgendem Protokoll durchgeführt:

Zunächst wurde das Gel gewogen und L3-Puffer in der dreifachen Menge des Gels in $\mu 1$ hinzugefügt. Unter Erwärmung auf $50^{\circ} \mathrm{C}$ für 10 min wurde das $\mathrm{Gel}$ aufgelöst. $\mathrm{Zu}$ der Lösung wurde die einfache Gelmenge Isopropanol hinzugefügt, vermischt und anschließend auf eine mitgelieferte Säule geladen. Die Säule wurde für $1 \mathrm{~min}$ bei $13000 \mathrm{rpm}$ und RT zentrifugiert. Die im Waschtube aufgefangene Flüssigkeit wurde verworfen. Nach Applikation von $500 \mu 1$ Waschpuffer auf die Säule erfolgte eine weitere Zentrifugation unter den oben genannten Bedingungen. Zur vollständigen Entfernung des Waschpuffers wurde erneut für 2 min zentrifugiert. Die DNA wurde durch Zugabe von $50 \mu 1$ Elutionspuffer, 1-minütiger Inkubation bei RT und anschließender Zentrifugation für $1 \mathrm{~min}$ bei $13000 \mathrm{rpm}$ eluiert.

\section{Isopropanol}

AppliChem GmbH (Darmstadt)

\subsubsection{Ligation}

Bei einer Ligation wird ein DNA-Fragment (Insert) in einen Vektor mit Hilfe einer T4-DNALigase eingefügt, sodass ein fertiger Plasmidring entsteht.

Hierfür wurde ein Ansatz aus $1 \mu 1$ T4-DNA-Ligase, $2 \mu 1$ 10x T4-Puffer, Vektor und Insert mit $\mathrm{H}_{2} \mathrm{O}$ auf $17 \mu \mathrm{l}$ aufgefüllt. Insgesamt betrug die DNA-Konzentration $100 \mathrm{ng}$. Die Berechnung der Gesamtmenge des Vektors und des Inserts wurden mit dem PC-Programm GENtle 1.9.4 unter zu Hilfenahme der jeweiligen DNA-Konzentration und der Anzahl der Basenpaare durchgeführt.

Der Ansatz wurde für 1 Std bei RT inkubiert und anschließend erfolgte die Inaktivierung der Ligase durch eine Erhitzung auf $65^{\circ} \mathrm{C}$ für $10 \mathrm{~min}$.

\begin{tabular}{|l|l|l|}
\hline T4-DNA-Ligase & $400000 \mathrm{U} / \mathrm{ml}$ & NEB (Frankfurt am Main) \\
\hline T4-DNA-Ligase-Puffer & & NEB (Frankfurt am Main) \\
\hline
\end{tabular}




\subsubsection{Plasmide}

\begin{tabular}{|c|c|c|c|c|}
\hline Konstrukt & Vektor & Restritionsenzyme & Resistenz & Herkunft \\
\hline Parkin & pcDNA3 & HindIII, XbaI & Ampicillin & C. Lücking, Paris \\
\hline GFP-Parkin & peGFP-N1 & Xho, KpnI & Kanamycin & W. Gu, Paris \\
\hline BAG1 & pcDNA3 & EcoRI, NotI & Ampicillin & P. Kermer, Göttingen \\
\hline FLAG-BAG1 & pcDNA3 & EcoRI, NotI & Ampicillin & P. Kermer, Göttingen \\
\hline $\mathrm{BAG} \Delta \mathrm{C}$ & pcDNA3 & EcoRI, NotI & Ampicillin & P. Kermer, Göttingen \\
\hline GFP-BAG1 & peGFP & Xho, KpnI & Kanamycin & P. Kermer, Göttingen \\
\hline GFP-BAG $\Delta C$ & peGFP & Xho, KpnI & Kanamycin & P. Kermer, Göttingen \\
\hline GFP-LV & peGFP & MCS & Kanamycin & P. Kermer, Göttingen \\
\hline $\mathrm{LV}$ & pcDNA & MCS & Ampicillin & P. Kermer, Göttingen \\
\hline HA-CDCrel & pRK5-HA & SalI, Not I & Ampicillin & $\begin{array}{l}\text { T. Dawson, } \\
\text { Baltimore, USA }\end{array}$ \\
\hline FLAG-Parkin $_{\triangle \mathrm{UBL}}$ & pcDNA3.1 & EcoRI, NotI & Ampicillin & $\begin{array}{l}\text { J. Schünemann, } \\
\text { Göttingen }\end{array}$ \\
\hline FLAG-Parkin $_{\Delta \text { Linker }}$ & pcDNA3.1 & EcoRI, NotI & Ampicillin & $\begin{array}{l}\text { J. Schünemann, } \\
\text { Göttingen }\end{array}$ \\
\hline FLAG-Parkin $_{\Delta \text { Ring1 }}$ & pcDNA3.1 & EcoRI, NotI & Ampicillin & $\begin{array}{l}\text { J. Schünemann, } \\
\text { Göttingen }\end{array}$ \\
\hline FLAG-Parkin $_{\triangle I B R}$ & pcDNA3.1 & EcoRI, NotI & Ampicillin & $\begin{array}{l}\text { J. Schünemann, } \\
\text { Göttingen }\end{array}$ \\
\hline
\end{tabular}

Tabelle 2.1. Verwendete Plasmide.

Sequenz der Signalpeptide (Tags)

FLAG DYKDDDDK

MYC EQKLISEEDL

HA YPYDVPDYA

\subsubsection{Sequenzierung}

Über den Verdau mit Restriktionsendonukleasen kann nur die Anwesenheit und Lage eines Inserts im Plasmid überprüft werden, jedoch nicht die korrekte Basenfolge. Daher wurde zum Ausschluss von ungewollten Punktmutationen eine zusätzliche Sequenzierung durchgeführt. Die Basenfolge konnte dann manuell mit der bekannten Basensequenz verglichen werden. Die Sequenzierung erfolgte durch das Sequenzierungslabor „Seqlab“ in Göttingen. Für die Sequenzierung wurde folgender Ansatz verwendet:

700 ng DNA, $1 \mu 1$ T7-Primer, $1 \mu$ SB6-Primer, mit $\mathrm{H}_{2} \mathrm{O}$ auf $7 \mu 1$ auffüllen. 


\subsubsection{Messung der DNA-Konzentration}

Zur Bestimmung der DNA-Konzentration wurde $2 \mu \mathrm{l}$ der Plasmid-DNA in $60 \mu 1 \mathrm{H}_{2} \mathrm{O}$ gelöst. Die Messung der Extinktion erfolgte am Bio-Photometer der Firma Eppendorf (Hamburg) bei $260 \mathrm{~nm}$ und $280 \mathrm{~nm}$. Als Referenz dienten $62 \mu \mathrm{l} \mathrm{H}_{2} \mathrm{O}$. Der Reinheitsgrad wurde mit Hilfe des Quotienten aus E260/E280 kontrolliert. Dieser sollte im Mittel bei ca. 1,8 liegen. Sofern eigene Proben eine signifikante Abweichung zeigten, wurden diese erneut aufgereinigt.

\subsection{Amplifizierung der Plasmide}

\subsubsection{Transformation kompetenter Zellen}

Für die Amplifizierung von DNA-Plasmiden können kompetente Zellen verwendet werden. Diese sind Bakterien, die durch eine Behandlung mit Calciumchlorid in der Lage sind, fremde DNA aufzunehmen und zu vervielfältigen. Für die Transformation wurden bei $-80^{\circ} \mathrm{C}$ in Calciumchlorid-Glycerol-Lösung gelagerte DH5 $\alpha$-Zellen (Stratagene, La Jolla, USA) verwendet. $100 \mu \mathrm{l}$ der Lösung wurden auf Eis aufgetaut und im Anschluss mit $20 \mu \mathrm{l}$ des Ligationsansatzes für $30 \mathrm{~min}$ auf Eis inkubiert. Zur Aufnahme des Plasmids in die Zelle wurde der Ansatz für 1 min auf $42^{\circ} \mathrm{C}$ erhitzt und anschließend für 2 min erneut auf Eis inkubiert. Nach Zugabe von $400 \mu 137^{\circ} \mathrm{C}$ warmen LB-Mediums erfolgte eine erneute Inkubation für $1 \mathrm{Std}$ bei $37^{\circ} \mathrm{C}$ auf dem Schüttler. Um ein selektives Wachstum sicher zustellen, wurden die transformierten Bakterien auf Ampicillin-haltigen LB-Agar ausgestrichen und über Nacht bei $37^{\circ} \mathrm{C}$ inkubiert. Aufgrund eines Ampicillin-Resistenzgens im Plasmid kam es nur zum Wachstum von erfolgreich transformierten Bakterien.

\begin{tabular}{|l|l|l|}
\hline Calciumchlorid-Lösung & $\begin{array}{l}50 \mathrm{mM} \mathrm{CaCl} \\
15 \% \text { Glycerin }\end{array}$ & Carl Roth GmbH (Karlsruhe) \\
\hline LB-Agar & $32 \mathrm{~g} / \mathrm{lin}$ purifiziertem $\mathrm{H}_{2} \mathrm{O}$ & Carl Roth GmbH (Karlsruhe) \\
\hline $\begin{array}{l}\text { Antibiotikum-haltiger } \\
\text { LB-Agar }\end{array}$ & $\begin{array}{l}100 \mu \mathrm{g} / \mathrm{ml} \text { Ampicillin bzw. } \\
\text { in LB-Agar }\end{array}$ & $\begin{array}{l}\text { Carl Roth GmbH (Karlsruhe) } \\
\text { Carl Roth GmbH (Karlsruhe) }\end{array}$ \\
\hline
\end{tabular}

\subsubsection{Mini-Präparation}

Die Plasmid-Präparation dient zur Isolierung von amplifizierten Plasmiden aus Bakterien. Eine Mini-Präparation ermöglicht die Isolierung von ca. $20 \mu \mathrm{g}$ Plasmid-DNA.

Nach der Transformation wurden drei Bakterienkolonien vom LB-Agar in je $5 \mathrm{ml}$ Antibiotika-haltiges LB-Medium überführt und für 16 Std bei $37^{\circ} \mathrm{C}$ amplifiziert. 
Die Mini-Präparation wurde anschließend mit Hilfe des Nucleo Spin Plasmid Kit der Firma Macherey-Nagel (Düren) nach Protokoll durchgeführt. Hierfür wurde das Amplifikat für 15 min bei RT und 4000 rpm zentrifugiert und der klare Überstand verworfen. Zur Lyse der Bakterienzellen erfolgte zunächst die Resuspendierung des Pellets in $250 \mu 1$ A1-Puffer. Darauf wurde $250 \mu \mathrm{l}$ A2-Puffer und nach 5-minütiger Inkubation bei RT $300 \mu$ A3-Puffer hinzugefügt. Der Zelldetritus wurde durch Zentrifugation für 5 min bei $11000 \mathrm{rpm}$ vom klaren Überstand getrennt, sodass der Überstand auf eine mitgelieferte Plasmidsäule geladen konnte. Nach einer Zentrifugation bei 11000 rpm für 1 min erfolgte ein Waschschritt mit $600 \mu 1$ A4Puffer. Dieser wurde durch zweimalige Zentrifugation bei $11000 \mathrm{rpm}$, zunächst für 1 und im Anschluss für weitere $2 \mathrm{~min}$, wieder entfernt. Durch Zugabe von $50 \mu \mathrm{l}$ AE-Puffer mit anschließender Zentrifugation bei $11000 \mathrm{rpm}$ für $1 \mathrm{~min}$ erfolgte die Elution der DNA. Die Plasmid-DNA wurde bis zur weiteren Verarbeitung bei $4^{\circ} \mathrm{C}$ gelagert.

\section{LB-Medium} $20 \mathrm{~g} / \mathrm{l}$ in purifiziertem $\mathrm{H}_{2} \mathrm{O}$

Carl Roth GmbH (Karlsruhe)

\subsubsection{Maxi-Präparation}

Über eine Maxi-Präparation kann ca. $500 \mu \mathrm{g}$ Plasmid-DNA aus transformierten E.coli Bakterien isoliert werden. Hierfür wurden die Bakterien zunächst im folgenden Ansatz für 16 Std bei $37^{\circ} \mathrm{C}$ unter leichten Schüttelbewegungen amplifiziert:

$300 \mathrm{ml}$ LB-Medium

$300 \mu \mathrm{l}$ Ampicillin bzw. $600 \mu \mathrm{l}$ Kanamycin

ca. $15 \mu \mathrm{l}$ des Glycerol-Stock.

Die Isolierung der DNA aus den Bakterien erfolgte mit dem QIAfilter Plasmid MaxiPräparations-Kit von der Firma QIAGEN (Hamburg) nach dem beigefügten Protokoll und den mitgelieferten Puffern.

Der Ansatz wurde zunächst für $15 \mathrm{~min}$ bei $4000 \mathrm{rpm}$ in der Megafuge 1.0 R der Firma Thermo Scientific (Waltham, USA) zentrifugiert. Der klare Überstand wurde verworfen und das Pellet zur Lyse in $10 \mathrm{ml}$ P1-Puffer resuspendiert. Des Weiteren wurden $10 \mathrm{ml}$ P2-Puffer und nach einer 5-minütigen Inkubation $10 \mathrm{ml}$ P3-Puffer hinzugefügt. Nach einer weiteren Inkubation für 20 min auf Eis wurde der Zelldetritus durch Zentrifugation bei $15000 \mathrm{rpm}$ für 10 min und $4^{\circ} \mathrm{C}$ abgetrennt. Der Überstand wurde auf eine mitgelieferte QIAGEN-Tip 500 Säule überführt. Die durchgelaufene Flüssigkeit wurde verworfen und die Säule im Anschluss 
zweimal mit QC-Puffer gewaschen. Darauf wurde die DNA mit $15 \mathrm{ml}$ QF-Puffer eluiert. Zur Aufreinigung der DNA wurde diese zunächst mit 10,5 ml Isopropanol ausgefällt. Nach einer Zentrifugation für $30 \mathrm{~min}$ und $4^{\circ} \mathrm{C}$ bei $15000 \mathrm{rpm}$ wurde der Überstand verworfen und $5 \mathrm{ml}$ Ethanol zu dem Pellet hinzugefügt. Nach der Resuspension wurde für weitere $10 \mathrm{~min}$ mit den oben genannten Bedingungen zentrifugiert. Das dabei entstandene Pellet wurde in $800 \mu 110$ $\mathrm{mM}$ Tris pH 8,0 gelöst und dazu $80 \mu \mathrm{l} 3 \mathrm{M} \mathrm{NaAc}$ pH 7,2 sowie $900 \mu 1$ 100\%iger Ethanol hinzugefügt. Es folgte eine weitere Zentrifugation für 5 min bei $13000 \mathrm{rpm}$ bei RT. Der Überstand wurde ein weiteres Mal verworfen und das Pellet in $1000 \mu 1$ 70\%igem Ethanol gelöst. Es schloss sich eine letzte Zentrifugation für $3 \mathrm{~min}$ bei $13000 \mathrm{rpm}$ bei RT an. Das DNA-Pellet wurde in $200 \mu 10 \mathrm{mM}$ Tris pH 8,0 gelöst und bis zur weiteren Verarbeitung bei $4^{\circ} \mathrm{C}$ gelagert.

Um die Anwesenheit des Inserts in der Klonierungsstelle des Plasmidvektors zu überprüfen, erfolgte ein Restriktionsverdau mit den entsprechenden Endonukleasen nach der Maxi- und Mini-Präparation.

\subsubsection{Anlegungen eines Glycerol-Stocks}

Um transformierte Bakterien noch für spätere Maxi-Präparationen verwenden zu können, wurden diese bei $-80^{\circ} \mathrm{C}$ in Glyerol-haltigem LB-Medium kryokonserviert.

\begin{tabular}{|l|l|l|}
\hline Glycerol-Stock & $850 \mu$ l Bakterienkultur & \\
$150 \mu$ l Glycerol & Carl Roth GmbH (Karlsruhe) \\
\hline
\end{tabular}

\subsection{Zelllinien}

\subsubsection{HEK293-Zellen}

HEK293-Zellen stammen von humanen embryonalen Nierenzellen ab, die mit AdenovirusTyp-5-Fragmenten immortalisiert wurden (Graham et al. 1977). Die Zellen wachsen Fibroblasten-artig als Monolayer und exprimieren neben Zytokeratinen und Vimentin auch Neurofilamente.

\subsubsection{CSM14.1-Zellen}

Bei CSM14.1-Zellen handelt es sich um nigro-striatale Rattenzellen, die durch die Einführung eines temperatursensitiven SV40-large-T-Antigens immortalisiert wurden (Durand et al. 1990). 


\subsubsection{SH-SY5Y-Zellen}

SH-SY5Y-Zellen sind humane Neuroblastomzellen. Sie sind als klonale Sublinie aus der Neuroepitheliomzelllinie SK-N-SH hervorgegangen, die 1970 aus der Knochenmarkbiopsie eines vierjährigen Mädchens mit metastasierendem Neuroblastom isoliert wurden (Biedler et al. 1973). SH-SY5Y-Zellen wachsen Epithel-artig als Monolayer und exprimieren sowohl Neurofilamente als auch Vimentin.

\subsection{Zellkultur}

\subsubsection{Kultivierung}

HEK293-und CSM14.1-Zellen wurden unter sterilen Bedingungen in $10 \mathrm{~cm}$ Rundschalen der Firma Greiner Bio-One (Frickenhausen) in DMEM Kulturmedium bei 5\% $\mathrm{CO}_{2}$, Wasserstoffgesättigter Atmosphäre und $37^{\circ} \mathrm{C}$ bzw. $32^{\circ} \mathrm{C}$ kultiviert.

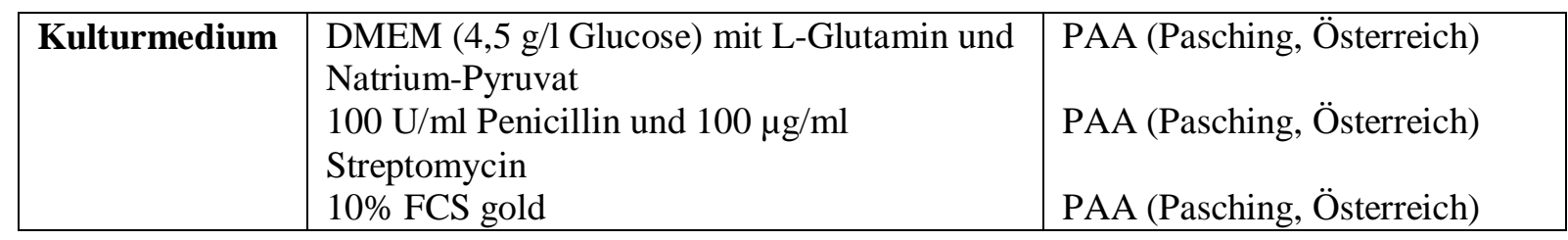

SH-SY5Y wurden bei $37^{\circ} \mathrm{C}, 5 \% \mathrm{CO}_{2}$ und Wasserstoff-gesättigter Atmosphäre kultiviert, jedoch in einem speziellen SH-SY5Y-Kulturmedium.

\begin{tabular}{|l|l|l|}
\hline $\begin{array}{l}\text { SH-SY5Y- } \\
\text { Kulturmedium }\end{array}$ & $\begin{array}{l}\text { DMEM (4,5 g/l Glucose) mit L-Glutamin und } \\
\text { Natrium-Pyruvat } \\
100 \mathrm{U} / \mathrm{ml} \text { Penicillin und } 100 \mu \mathrm{g} / \mathrm{ml} \\
\text { Streptomycin } \\
\text { 15\% FCS gold }\end{array}$ & PAA (Pasching, Österreich) \\
\hline
\end{tabular}

\subsubsection{Passagierung}

Die konfluenten Zellen wurden unter sterilen Bedingungen einmal mit $2 \mathrm{ml}$ PBS gewaschen. Zur Lösung der Zellen von der Rundschale wurden CSM14.1-, HEK293- und SH-SY5YZellen mit $1 \mathrm{ml}$ Trypsin für $15 \mathrm{~min}$ bei $32^{\circ} \mathrm{C}$ (CSM14.1-Zellen) bzw. für 5 min bei $37^{\circ} \mathrm{C}$ (HEK293- und SH-SY5Y-Zellen) inkubiert. Das Trypsin wurde anschließend mit $2 \mathrm{ml}$ Kulturmedium neutralisiert.

Im Anschluss erfolgte eine Zentrifugation der Zellsuspension in der Centrifuge 5810 der Firma Eppendorf (Hamburg) für 5 min bei $1200 \mathrm{rpm}$ und RT. Das Zellpellet wurde in $1 \mathrm{ml}$ 
des jeweiligen Kulturmediums resuspendiert und im Verhältnis 1:5 auf eine neue Rundschale ausplattiert.

\begin{tabular}{|l|l|l|}
\hline 1x Trypsin & $10 x$ Trypsin & PAA (Pasching, Österreich) \\
& $1: 10 \mathrm{in} \mathrm{PBS}$ & \\
\hline PBS (pH 7,4) & $40 \mathrm{~g} \mathrm{NaCl}$ & Carl Roth GmbH (Karlsruhe) \\
& $1 \mathrm{~g} \mathrm{KCl}$ & Carl Roth GmbH (Karlsruhe) \\
& $\begin{array}{l}3,8 \mathrm{~g} \mathrm{Na}_{2} \mathrm{HPO}_{4} * 2 \mathrm{H}_{2} \mathrm{O} \\
1 \mathrm{~g} \mathrm{KH}_{2} \mathrm{PO}_{4}\end{array}$ & Carl Roth GmbH (Karlsruhe) \\
& Merck (Darmstadt) \\
\hline
\end{tabular}

\subsubsection{Quantifizierung der Zellen}

Um für die einzelnen Experimente replizierbare Zellzahlen einzusetzen, erfolgte eine Auszählung vor dem Ausplattieren in einer Neubauer-Zählkammer. Hierfür wurden die Zellen wie beim Passagieren von den Kulturschalen gelöst. Nach der Zentrifugation wurde $25 \mu 1$ der Zellsuspension 1:10 mit Zählmedium verdünnt. Die Zählkammer wurde mit $10 \mu \mathrm{l}$ dieser Dilution gefüllt.

Die ermittelte Zellzahl wurde auf einen Milliliter hochgerechnet und die gewünschte Zellzahl auf die entsprechende Zellkulturplatten ausgesät.

\begin{tabular}{|l|l|l|}
\hline Zählmedium & $\begin{array}{l}50 \% \text { Trypan Blue Solution } \\
(0,4 \%) \text { in PBS }\end{array}$ & Sigma Aldrich (Steinheim) \\
\hline
\end{tabular}

\subsubsection{Einfrieren der Zellen}

Die Zellen wurden, wie in 2.4 .2 beschrieben, von den Rundschalen gelöst und bei 1200 rpm für $5 \mathrm{~min}$ zentrifugiert. Das Zellpellet wurde anschließend in $1 \mathrm{ml}$ Einfriermedium resuspendiert. Die Suspension wurde bei $-80^{\circ} \mathrm{C}$ kryokonserviert.

\begin{tabular}{|l|l|l|}
\hline Einfriermedium & $\begin{array}{l}10 \% \text { DMSO } \\
\text { in FCS gold }\end{array}$ & Sigma-Aldrich (Steinheim) \\
\hline
\end{tabular}

\subsubsection{Auftauen der Zellen}

Die eingefrorenen Zellen wurden im Wasserbad bei $37^{\circ} \mathrm{C}$ erwärmt. Die im Einfriermedium gelösten Zellen wurden in $5 \mathrm{ml}$ Medium aufgenommen und im Anschluss bei $1200 \mathrm{rpm}$ für 5 min bei RT zentrifugiert. Der Überstand wurde verworfen und das Zellpellet anschließend in $1 \mathrm{ml}$ des zellspezifischen Mediums resuspendiert und auf eine $10 \mathrm{~cm}$ Rundschale ausplattiert. 


\subsubsection{Transfektion}

Als Transfektion versteht man das Einschleusen von genetischem Material in eine eukaryotische Zelle. Es wurden ausschließlich transient transfizierte Zellen verwendet. Hierbei wird ein Plasmidring nur temporär in eine Wirtszelle eingebracht und dort vermehrt abgelesen.

Bei CSM14.1- und HEK293-Zellen wurden 5x10 $0^{5}$ Zellen pro well und bei SH-SY5Y-Zellen $10^{6}$ Zellen pro well auf eine 6-well-Platte Cellstar ${ }^{\circledR}$ der Firma Greiner Bio-One (Frickenhausen) ausplattiert. Die Transfektion wurde mit Hilfe des Transfektans Lipofektamine $^{\mathrm{TM}} 2000^{\circledR}$ der Firma Invitrogen (Darmstadt) nach Protokoll durchgeführt. Für die Transfektion einer 6-well-Platte wurde $2 \mu \mathrm{g}$ DNA pro Vektor und $9 \mu$ l Lipofektamine getrennt in je $250 \mu \mathrm{l}$ Optimem (Invitrogen, Darmstadt) für $5 \mathrm{~min}$ bei RT inkubiert. Anschließend wurden die beiden Ansätze zusammengegeben und für weitere 20 min bei RT inkubiert (Die Mengenangaben beziehen sich jeweils auf ein well). Vor Zugabe des Transfektionsgemisches $\mathrm{zu}$ den Zellen erfolgte bei CSM14.1- und HEK293-Zellen ein Mediumtausch des zellspezifischen Mediums durch je $2 \mathrm{ml}$ Serum- und Antibiotika-freiem Kulturmediums. Bei der Transfektion von SH-SY5Y-Zellen wurde das Medium durch $2 \mathrm{ml}$ Optimem ersetzt. Nach 4-stündiger Inkubation bei $37^{\circ} \mathrm{C}$ bzw. $32^{\circ} \mathrm{C}$ und $5 \% \mathrm{CO}_{2}$ erfolgte ein erneuter Mediumtausch hin zum zellspezifischen Kulturmedium. Insgesamt 24 Std nach der Transfektion (HEK293- und CSM14.1-Zellen) bzw. 36 Std bei SH-SY5Y-Zellen wurden diese geerntet.

\subsection{Proteinanalyse}

\subsubsection{Herstellung von zellulären Lysaten mit Triton-X-100}

Die Lyse von Zellen dient der Isolierung von zellulär exprimierten Proteinen. Die isolierten Proteine der Zelllysate können in nachfolgenden Analysen spezifisch untersucht werden. Zur Lyse transfizierter HEK293-, CSM14.1- oder SH-SY5Y-Zellen wurden 80-90\% konfluente 6-well-Platten dreimal mit $1 \mathrm{ml}$ eiskaltem PBS gewaschen. Mit einem Zellschaber wurden die Zellen von der Platte gelöst und im Anschluss für 5 min bei $7500 \mathrm{rpm}$ und $4^{\circ} \mathrm{C}$ zentrifugiert.

Das Zellpellet wurde mit 50-70 $\mu$ l Lysepuffer versetzt. Nach 15-minütiger Inkubation auf Eis erfolgte eine Sonifizierung für $30 \mathrm{sec}$ und eine Zentrifugation bei $13000 \mathrm{rpm}$ für $15 \mathrm{~min}$ bei $4^{\circ} \mathrm{C}$. Der proteinhaltige Überstand wurde bis zur weiteren Analyse bei $-20{ }^{\circ} \mathrm{C}$ gelagert. 


\begin{tabular}{|l|l|l|}
\hline Lysepuffer & $\begin{array}{l}2,5 \mathrm{ml} \text { TBS } \\
25 \mu \mathrm{l} \text { Triton-X-100 } \\
100 \mu \mathrm{l} \text { Proteinase-Inhibitor }\end{array}$ & $\begin{array}{l}\text { Carl Roth GmbH (Karlsruhe) } \\
\text { Roche Diagnostics GmbH (Mannheim) }\end{array}$ \\
\hline TBS & $\begin{array}{l}150 \mathrm{mM} \mathrm{NaCl} \\
50 \mathrm{mM} \text { Tris }\end{array}$ & Carl Roth GmbH (Karlsruhe) \\
&
\end{tabular}

\subsubsection{Herstellung von zellulären Lysaten mit Harnstoff}

Für die Zelllyse mit Harnstoff wurden konfluente HEK293-Zellen wie in 2.5.1 beschrieben von der 6-well-Platte gelöst und zentrifugiert. $\mathrm{Zu}$ dem Zellpellet wurde je $200 \mu$ l HarnstoffLysepuffer hinzugefügt. Der Puffer wurde für 15 min inkubiert und das Lysat für $30 \mathrm{sec}$ sonifiziert. Zur Analyse mittels Western Blot wurden 10\% des Lysats mit 6x SDS-Ladepuffer versetzt, 5 min bei $95^{\circ} \mathrm{C}$ aufgekocht und auf ein SDS-Gel geladen.

\begin{tabular}{|l|l|l|}
\hline Harnstoff-Lysepuffer & $\begin{array}{l}\text { 8M Harnstoff in } \mathrm{H}_{2} \mathrm{O} \mathrm{pH} 8,0 \\
100 \mu \text { l Proteinase-Inhibitor }\end{array}$ & Carl Roth GmbH (Karlsruhe) \\
\hline
\end{tabular}

\subsubsection{Subzelluläre Fraktionierung}

Durch das ProteoExtract Subcellular Proteome Extraction Kit (CalbioChem, Nottingham, UK) ist es möglich Proteine aus dem Zytoplasma, der Membran bzw. den Organellen, dem Nukleus und dem Zytoskelett zu extrahieren und getrennt von einander zu untersuchen. Die Fraktionierung wurde nach dem mitgelieferten Protokoll durchgeführt.

Hierfür wurde für Fraktion I (Zytoplasma) 80 -100 $\mu$ l Extraktion-Puffer I mit 1/6 $\mu 1$ ProteaseInhibitor vermischt (alle Angaben beziehen sich auf eine Probe). Das Zellpellet wurde in dieser Lösung resuspendiert und für $10 \mathrm{~min}$ auf dem Drehrad bei $4^{\circ} \mathrm{C}$ inkubiert. Nach der Zentrifugation ( $8 \mathrm{~min}, 10000 \mathrm{rpm}, 4^{\circ} \mathrm{C}$ ) wurde der Überstand in ein neues Eppendorf-Tube überführt. Das übrig gebliebene Pellet wurde für Fraktion II (Membran und Organellen) mit einem Gemisch aus 80-100 $\mu$ l Extraktion-Puffer II und 1/6 $\mu$ Protease-Inhibitor resuspendiert und im Anschluss für $30 \mathrm{~min}$ bei $4^{\circ} \mathrm{C}$ auf dem Drehrad inkubiert. Die Lösung wurde zentrifugiert $\left(8 \mathrm{~min}, 10000 \mathrm{rpm}, 4^{\circ} \mathrm{C}\right)$ und der Überstand wieder in ein neues EppendorfTube überführt. Um Proteine aus dem Nukleus zu extrahieren (Fraktion III) wurde 40-50 $\mu 1$ Extraktion-Puffer III mit 1/6 $\mu$ l Protease-Inhibitor und 1/12 $\mu$ l Benzonase gemischt und das Zellpellet in dieser Lösung resuspendiert. Nach 10-minütiger Inkubation bei $4^{\circ} \mathrm{C}$ auf dem Drehrad erfolgte eine Zentrifugation wie oben beschrieben und Überführung des Überstandes in ein neues Eppendorf-Tube. Für die vierte Fraktion (Zytoskelett) wurden das Zellpellet mit 40-50 $\mu \mathrm{l}$ Extraktion-Puffer IV und 1/6 $\mu \mathrm{l}$ Protease-Inhibitor erneut resuspendiert. 
Abschießend wurde für 10 min bei $4^{\circ} \mathrm{C}$ auf dem Drehrad inkubiert. Die Proben wurden bis zur weiteren Analyse bei $-20^{\circ} \mathrm{C}$ gelagert.

\subsubsection{Proteinkonzentrationsbestimmung mittels BCA}

Die Proteinkonzentration der zellulären Lysate wurde mit Hilfe des BCA ${ }^{\mathrm{TM}}$ Protein Assay Kit der Firma Pierce (Rockford, USA) bestimmt. Bei dem BCA Assay kommt es zu einem Farbumschlag aufgrund der sogenannten Biuret-Reaktion $\left(\mathrm{Cu}^{2+}\right.$ wird durch Proteine $\mathrm{zu} \mathrm{Cu}^{1+}$ reduziert). Durch die Bildung eines Chelatkomplexes von zwei Molekülen BCA (Bicinchonin-Säure) und einem reduzierten Kupferion entsteht eine lila Färbung. Für den BCA Assay wurde auf einer 96-well-Platte (Greiner Bio-One, Frickenhausen) je $2 \mu \mathrm{l}$ der Lysatproben in je $200 \mu \mathrm{l}$ BCA-Reagenz (Mischungsverhältnis 50:1) für 30 min bei RT auf dem Schüttler inkubiert. Als Konzentrationsstandard dienten verschiedenen BSAProteinmengen (40 $\mu \mathrm{g}, 20 \mu \mathrm{g}, 10 \mu \mathrm{g}, 5 \mu \mathrm{g}, 2,5 \mu \mathrm{g}, 1,25 \mu \mathrm{g}$ und 0,625 $\mu \mathrm{g}$ ). Die Bestimmung der Proteinkonzentration erfolgte in Doppelbestimmung. Die Messung der Absorption erfolgte bei einer Wellenlänge von $562 \mathrm{~nm}$ am Rainbow-ELISA-Photometer der Firma TECAN (Männedorf, Schweiz) unter Verwendung des Computerprogramms Magellan 3. Die Proteinkonzentration wurde anhand der Eichgerade der BSA-Konzentrationsreihe ermittelt.

\begin{tabular}{|l|l|l|}
\hline BCA-Färbelösung & 2\% Reagenz B in Reagenz A \\
\hline Reagenz A & $\begin{array}{l}\text { enthält Natriumcarbonat, Natriumbicarbonat, BCA und Natriumtartrat in } \\
0,1 \text { M Natriumhydroxid }\end{array}$ \\
\hline Reagenz B & enthält 4\% Kupfersulfat \\
\hline BSA & $\begin{array}{l}10 \mu \mathrm{g} / \mu \mathrm{l} \\
\text { in Lysepuffer }\end{array}$ & Sigma-Aldrich (Steinheim) \\
\hline
\end{tabular}

\subsubsection{SDS-Polyacrylamidgel-Elektrophorese (SDS-PAGE)}

Zur Auftrennung und Detektion der jeweiligen Zielproteine wurde eine Kombination aus SDS-PAGE und anschließendem Western Blot durchgeführt.

Die SDS-PAGE dient zur Auftrennung von Proteinen nach ihrem Molekulargewicht durch Anlegung eines elektrischen Feldes. Hierfür wurde das Mini-PROTEAN ${ }^{\circledR}$ 3-cell-System der Firma Bio-Rad (Hercules, USA) verwendet. Zunächst wurde ein SDS-Polyacrylamidgel hergestellt, bestehend aus einem 5\%igen Sammelgel und einem 12\%igen Trenngel. Vor dem Auftragen der Proben in die Geltaschen wurden $15 \mu \mathrm{g}$ Protein im Verhältnis 5:1 mit 6x SDSLadepuffer versetzt und 5 min bei $95^{\circ} \mathrm{C}$ im ThermoStat plus der Firma Eppendorf (Hamburg) gekocht. Als Marker wurden $4 \mu \mathrm{l}$ Page ruler der Firma Fermentas (St. Leon-Rot) verwendet. 
Der Gellauf wurde zunächst bei $80 \mathrm{~V}$ und nach Erreichen des Trenngels bei $120 \mathrm{~V}$ solange durchgeführt, bis die Lauffront den unteren Rand des Gels erreicht hatte (ca. 1,5 Std).

\begin{tabular}{|l|l|l|}
\hline $\begin{array}{l}\text { 5\% iges Sammelgel } \\
\text { (Angaben für ein 0,75 mm Gel) }\end{array}$ & $\begin{array}{l}\text { 12\% iges Trenngel } \\
\text { (Angaben für ein 0,75 mm Gel) }\end{array}$ & \\
\hline $0,68 \mathrm{ml}$ purifiziertes $\mathrm{H}_{2} \mathrm{O}$ & $1,60 \mathrm{ml}$ purifiziertes $\mathrm{H}_{2} \mathrm{O}$ & \\
$0,17 \mathrm{ml} \mathrm{30 \%} \mathrm{Acrylamid}$ & $2,00 \mathrm{ml} 30 \%$ Acrylamid & Carl Roth GmbH (Karlsruhe) \\
$0,13 \mathrm{ml} 1 \mathrm{M}$ Tris $(\mathrm{pH} 6,8)$ & $1,30 \mathrm{ml} 1,5 \mathrm{M}$ Tris $(\mathrm{pH} 8,8)$ & \\
$0,01 \mathrm{ml} 10 \%$ SDS & $0,05 \mathrm{ml} 10 \%$ SDS & Carl Roth GmbH (Karlsruhe) \\
$0,01 \mathrm{ml} 10 \%$ APS & $0,05 \mathrm{ml} 10 \%$ APS & Merck KGaA (Darmstadt) \\
$0,001 \mathrm{ml}$ TEMED & $0,002 \mathrm{ml}$ TEMED & Carl Roth GmbH (Karlsruhe) \\
& & \\
\hline
\end{tabular}

\begin{tabular}{|l|l|l|}
\hline Laufpuffer & $250 \mathrm{mM}$ Tris & AppliChem GmbH (Darmstadt) \\
& $1,9 \mathrm{M}$ Glycin & AppliChem GmbH (Darmstadt) \\
& Carl Roth GmbH (Karlsruhe) \\
\hline 4x Tris Cl/SDS, pH 6,8 & $0,5 \mathrm{M}$ Tris & AppliChem GmbH (Darmstadt) \\
& $0,4 \%$ SDS & Carl Roth GmbH (Karlsruhe) \\
\hline 4x Tris Cl/SDS, pH 8,8 & $1,5 \mathrm{M}$ Tris & AppliChem GmbH (Darmstadt) \\
& $0,4 \%$ SDS & Carl Roth GmbH (Karlsruhe) \\
\hline 6x SDS Ladepuffer & $7 \mathrm{ml}$ 4x Tris Cl/SDS pH 6,8 & \\
& $3 \mathrm{ml}$ Glycerol & Carl Roth GmbH (Karlsruhe) \\
& $0,1 \%$ SDS & Carl Roth GmbH (Karlsruhe) \\
& 0,93 g DTT & Carl Roth GmbH (Karlsruhe) \\
& $1,2 \mathrm{mg}$ Bromphenolblau & Carl Roth GmbH (Karlsruhe) \\
& \multicolumn{2}{|c}{} \\
\hline
\end{tabular}

\subsubsection{Western Blot}

Im Western Blot werden Proteine nach der SDS-PAGE durch Anlegen eines elektrischen Feldes auf eine Membran übertragen und im Anschluss durch Antikörper spezifisch nachgewiesen.

Der Proteintransfer erfolgt bei $350 \mathrm{~mA}, 100 \mathrm{~V}$ und $4^{\circ} \mathrm{C}$ für 1,5- $2 \mathrm{Std}$ in der Nass-Blotkammer Mini-PROTEAN ${ }^{\circledR}$ der Firma Bio-Rad (Hercules, USA). Die Proteine wurden dabei auf eine 6x9 cm große Nitrocellulosemembran (AppliChem $\mathrm{GmbH}$, Darmstadt) transferiert. Im Anschluss an den Blot wurden unspezifische Antikörperbindungsstellen durch Inkubation der Membran für $1 \mathrm{Std}$ in Milchlösung blockiert. Daraufhin erfolgte die Inkubation des Primärantikörpers, der in Milchlösung im Verhältnis 1:1000 gelöst wurde, bei $4^{\circ} \mathrm{C}$ über Nacht. Nach dreimaligem Waschen für 20 min mit TBS-T erfolgte die Inkubation mit dem jeweiligen an HRP (Horseradish-Peroxidase)-konjugierten Sekundärantikörper (Verdünnung 1:2000) für 1 Std bei RT auf dem Drehrad. Zum Schluss erfolgten erneut drei 20-minütige Waschschritte mit TBS-T. 


\begin{tabular}{|l|l|l|}
\hline Transferpuffer & $\begin{array}{l}25 \mathrm{mM} \text { Tris } \\
192 \mathrm{mM} \text { Glycin } \\
20 \% \text { Methanol }\end{array}$ & $\begin{array}{l}\text { AppliChem GmbH (Darmstadt) } \\
\text { AppliChem GmbH (Darmstadt) } \\
\text { Carl Roth GmbH (Karlsruhe) }\end{array}$ \\
\hline Milchlösung & $\begin{array}{l}5 \% \text { Milchpulver } \\
\text { in TBS-T }\end{array}$ & AppliChem GmbH (Darmstadt) \\
\hline 10x TBS-T & $\begin{array}{l}24,2 \mathrm{~g} \text { Tris } \\
80 \mathrm{~g} \mathrm{NaCl} \\
1 \mathrm{ml} \mathrm{Tween} 20(0,1 \%) \\
\text { ad } 11 \mathrm{H}_{2} \mathrm{O}\end{array}$ & $\begin{array}{l}\text { AppliChem GmbH (Darmstadt) } \\
\text { Carl Roth GmbH (Karlsruhe) } \\
\text { AppliChem GmbH (Darmstadt) }\end{array}$ \\
\hline
\end{tabular}

\subsubsection{Immunodetektion der Proteine}

Die gebundenen Sekundärantikörper wurden mit Hilfe eines ECL-Detektionsreagens nachgewiesen. Zur Herstellung des ECL-Reagens wurden ECL-Lösung 1 und ECL-Lösung 2 im Verhältnis 1:1 vermischt und für 2 min auf der Nitrozellulosemembran inkubiert. ECL reagiert als Substrat der HRP, unter Bildung von Chemolumineszenzsignalen, die auf einem Röntgenfilm sichtbar gemacht werden können.

\begin{tabular}{|c|c|c|}
\hline ECL-Lösung 1 & $\begin{array}{l}100 \mu \mathrm{l} \text { Luminol (250 } \mathrm{mM} \text { in DMSO) } \\
44 \mu \mathrm{l} \text { Coumarsäure ( } 90 \mathrm{mM} \text { in DMSO) } \\
1 \mathrm{ml} 1 \mathrm{M} \text { Tris } \mathrm{pH} 8,5 \\
8,85 \mathrm{ml} \mathrm{H}_{2} \mathrm{O}\end{array}$ & $\begin{array}{l}\text { Sigma Aldrich (Steinheim) } \\
\text { Sigma Aldrich (Steinheim) }\end{array}$ \\
\hline ECL-Lösung 2 & $\begin{array}{l}6 \mu \mathrm{H}_{2} \mathrm{O}_{2} \\
1 \mathrm{ml} \mathrm{1} \mathrm{M} \text { Tris pH 8,5 } \\
9 \mathrm{ml} \mathrm{H} \mathrm{H}_{2} \mathrm{O}\end{array}$ & Merck KGaA (Darmstadt) \\
\hline
\end{tabular}

\subsubsection{Coomassie-Färbung}

Zur Qualitätskontrolle des Western Blots wurde das Gel mit einer Coomassie-Lösung gefärbt. Diese Lösung färbt unspezifisch die noch im Gel vorhandenen Proteine an.

Hierfür wurde das Gel für 15 min mit der Coomassie-Lösung auf dem Schüttler inkubiert und im Anschluss für ca. 2 Std mit 10\%iger Essigsäure wieder entfärbt.

\begin{tabular}{|l|l|l|}
\hline Coomassie-Lösung & $25 \%$ Isopropanol & \\
& $10 \%$ Essigsäure & Merck kGaA (Darmstadt) \\
& $0,05 \%$ Coomassie-Brilliantblau & \\
\hline in $\mathrm{H}_{2} \mathrm{O}$ & \\
\hline
\end{tabular}

\subsubsection{Dot Blot}

Vergleichbar mit dem Western Blot dient der Dot Blot zur Detektion und Analyse von Proteinen. Hierbei werden jedoch die Proteinproben direkt punktförmig auf eine Nitrozellulosemembran aufgetragen. Es erfolgt also keine elektrophoretische Auftrennung der 
Größe nach. Bei dieser Methode können Proteinkonzentrationen semiquantitativ bestimmt und insbesondere höhermolekulare Proteinaggregate detekiert werden.

Für den Dot Blot wurden Zellen wie in 2.4.6 beschrieben ausplattiert und transfiziert. Die Lyse erfolgte mit 50-70 $\mu 1$ Triton-X-100-Lysepuffer für 15 min auf Eis. Anschließend wurde für 10 min bei $9000 \mathrm{rpm}$ und $4^{\circ} \mathrm{C}$ zentrifugiert. Der Überstand wurde zur Analyse mittels Western Blot verwendet. Das Pellet wurde erneut mit $50 \mu$ Lysepuffer versetzt und für $10 \mathrm{sec}$ sonifiziert. $20 \mu$ g Protein wurde mit $\mathrm{H}_{2} \mathrm{O}$ auf ein Gesamtvolumen von $250 \mu$ l eingestellt, mit 6x Ladepuffer versetzt und für 5 min bei $95^{\circ} \mathrm{C}$ aufgekocht. Anschließend wurden die Proben in die Vertiefungen der Dot-Blot-Kammer Minifold 1 der Firma Schleicher und Schuell (Dassel) geladen und durch Erzeugung eines Unterdrucks auf die Nitrozellulosemembran geblottet. Die Membran wurde anschließend einmal mit $\mathrm{H}_{2} \mathrm{O}$ gewaschen. Die weiteren Schritte entsprechen denen des Western Blots (s. 2.5.5). Die Proteine wurden ebenfalls mittels ECL-Reagenz detektiert, jedoch mit Hilfe des Fluor-S ${ }^{\mathrm{TM}}$ MultiImagers (Bio-Rad, Hercules, USA) digitalisiert.

\begin{tabular}{|l|l|l|}
\hline 6x Ladepuffer & $7,0 \mathrm{ml}$ Tris/SDS pH 6,8 & \\
& $3 \mathrm{ml}$ Glycerol & Carl Roth GmbH (Karlsruhe) \\
& $1,2 \mathrm{~g}$ SDS & \\
\hline
\end{tabular}




\subsection{Antikörper}

\subsubsection{Primär-Antikörper}

\begin{tabular}{|c|c|c|c|}
\hline Substrat & Verdünnung & Isolierung aus & Firma \\
\hline$\alpha$-Aktin & $\begin{array}{l}\text { WB: } 1: 1000 \\
\text { IF: } 1: 750\end{array}$ & $\begin{array}{l}\text { mouse } \\
\text { monoklonal }\end{array}$ & $\begin{array}{l}\text { BD Bioscience Pharmingen (San } \\
\text { Diego, USA) }\end{array}$ \\
\hline$\alpha$-BAG1 & $\begin{array}{l}\text { WB: } 1: 2000 \\
\text { IF: } 1: 750\end{array}$ & $\begin{array}{l}\text { rabbit } \\
\text { polyklonal }\end{array}$ & C. Reed (La Jolla, USA) \\
\hline$\alpha-\beta$-Tubulin & $\begin{array}{l}\text { WB: } 1: 1000 \\
\text { IF: } 1: 750\end{array}$ & $\begin{array}{l}\text { mouse } \\
\text { monoklonal }\end{array}$ & Sigma-Aldrich (Steinheim) \\
\hline a-Cadherin & WB: $1: 2000$ & $\begin{array}{l}\text { mouse } \\
\text { monoklonal }\end{array}$ & Sigma-Aldrich (Steinheim) \\
\hline$\alpha$-CDCrel-1 & WB: $1: 1000$ & $\begin{array}{l}\text { mouse } \\
\text { monoklonal }\end{array}$ & Santa Cruz (Santa Cruz, USA) \\
\hline$\alpha-\mathbf{H A}$ & WB: $1: 1000$ & $\begin{array}{l}\text { mouse } \\
\text { monoklonal }\end{array}$ & Convance (Princeton, USA) \\
\hline$\alpha$-Histon H2B & WB: $1: 2000$ & $\begin{array}{l}\text { mouse } \\
\text { monoklonal }\end{array}$ & Abcam (Cambridge,USA) \\
\hline$\alpha$-Parkin & $\begin{array}{l}\text { WB: } 1: 1000 \\
\text { IF: } 1: 750\end{array}$ & $\begin{array}{l}\text { rabbit } \\
\text { polyklonal }\end{array}$ & Cell Signaling (Boston, USA) \\
\hline$\alpha$-Ubiquitin & WB: $1: 1000$ & $\begin{array}{l}\text { mouse } \\
\text { monoklonal }\end{array}$ & Santa Cruz (Santa Cruz, USA) \\
\hline$\alpha$-Vimentin & WB: $1: 2000$ & $\begin{array}{l}\text { mouse } \\
\text { monoklonal }\end{array}$ & Sigma-Aldrich (Steinheim) \\
\hline
\end{tabular}

Tab. 2.2.: Verwendete Primärantikörper. WB: Western Blot, IF: Immunfluoreszenz

\subsubsection{Sekundär-Antikörper}

\begin{tabular}{llll}
\hline Substrat & Verdünnung & Isolierung aus & Firma \\
\hline $\begin{array}{l}\text { Cy3-konjugierter } \boldsymbol{\alpha} \text { - } \\
\text { mouse }\end{array}$ & IF: 1:500 & Goat monoklonal & Dianova (Hamburg) \\
\hline $\begin{array}{l}\text { Cy3-konjugierter } \boldsymbol{\alpha} \text { - } \\
\text { rabbit }\end{array}$ & IF: 1:500 & Goat polyklonal & Dianova (Hamburg) \\
\hline $\boldsymbol{\alpha}$-Mouse & WB: 1:2000 & Goat monoklonal & Santa Cruz (Santa Cruz, USA) \\
\hline $\boldsymbol{\alpha}$-Rabbit & WB: 1:2000 & Goat polyklonal & Santa Cruz (Santa Cruz, USA) \\
\hline
\end{tabular}

Tab. 2.3. : Verwendete Sekundärantikörper. WB: Western Blot, IF: Immunfluoreszenz 


\subsection{Immunozytochemie}

Für die Immunozytochemie wurde eine 24-well-Platte mit autoklavierten Cover-Slips bestückt und $10^{4}$ Zellen CSM14.1- bzw. $2 \times 10^{4}$ SHSY-5Y-Zellen pro well ausplattiert. $1 \mu \mathrm{g}$ DNA pro Vektor und $3 \mu$ l Lipofektamine pro well wurden für die Transfektion getrennt in je $50 \mu 1$ Optimem für 5 min bei RT inkubiert. Das Lipofektamine-Gemisch wurde im Anschluss zu der DNA-Lösung hinzugefügt und nach einer 20-minütigen Inkubation auf die Zellen gegeben. 24 Std nach der Transfektion und anschließender Inkubation bei $37^{\circ} \mathrm{C} \mathrm{bzw.} 32^{\circ} \mathrm{C}$ und $5 \% \quad \mathrm{CO}_{2}$ erfolgte die Fixierung der Zellen durch $150 \mu \mathrm{l}$ einer 4\%igen Paraformaldehydlösung in PBS für 15 min bei RT. Dieser und alle weiteren Schritte erfolgten unter Lichtschutz. Nach der Fixierung wurde einmal mit PBS gewaschen. Im Anschluss wurden die Zellen mit $0,1 \%$ Saponine in PBS für 15 min bei RT unter leichten Schüttelbewegungen permeabilisiert. Nach einem weiteren Waschschritt mit PBS erfolgte zur Blockierung unspezifischer Antikörperbildungen die Zugabe von $150 \mu 1$ Blocking solution für 60 min bei RT. Im Anschluss wurden die Zellen mit dem Primärantikörper inkubiert. Dieser wurde in einer Konzentration von 1:750 in Blocking solution gelöst und über Nacht bei $4^{\circ} \mathrm{C}$ auf dem Schüttler inkubiert. Vor der Inkubation der Zellen mit dem Sekundärantikörper erfolgten drei Waschschritte mit PBS für 20 min. Der mit einem Fluoreszenzfarbstoff gekoppelte Antikörper wurde in Verhältnis 1:500 in Blocking solution verdünnt und für eine Std bei RT inkubiert. Nach drei weiteren 20-minütigen Waschschritten mit PBS erfolgte eine Anfärbung der Nuklei mit Hilfe der DAPI-working solution für 2-3 min auf dem Schüttler bei RT und anschließend noch ein Waschung für 2 min mit PBS. Zum Fixieren der Cover-slips auf einem Objektträger wurde Mowiol als Eindeckmedium verwendet. Nach der Trocknung über Nacht erfolgte die Analyse der Zellen am Axioplan 2 imaging-Fluoreszenzmikroskop von der Firma Zeiss (Jena) bei entsprechenden Filtereinstellungen (Cy3, EGFP, DAPI). Als Negativ-Kontrolle wurde für jede Bedingung ein Cover-Slip ohne den Primärantikörper, nach sonst gleichem Protokoll, aufbereitet.

\begin{tabular}{|l|l|l|}
\hline Fixierungsmedium & $\begin{array}{l}\text { 4\% PFA } \\
\text { in PBS }\end{array}$ & Carl Roth GmbH (Karlsruhe) \\
\hline $\begin{array}{l}\text { Permeabilisierungs- } \\
\text { Medium }\end{array}$ & $\begin{array}{l}0,05 \mathrm{~g} \text { Saponine in } \\
50 \mathrm{ml} \text { TBS }\end{array}$ & Sigma-Aldrich (Steinheim) \\
\hline Blocking solution & $\begin{array}{l}1,5 \mathrm{~g} \text { Albumin in } \\
50 \mathrm{ml} \text { TBS }\end{array}$ & AppliChem GmbH (Darmstadt) \\
\hline $\begin{array}{l}\text { DAPI working- } \\
\text { Solution }\end{array}$ & $2 \mu \mathrm{g} / \mathrm{ml}$ in PBS & Sigma-Aldrich (Steinheim) \\
\hline Mowiol & & Carl Roth GmbH (Karlsruhe) \\
\hline
\end{tabular}




\subsubsection{Auszählung der Parkin-Aggregate}

Zur Beurteilung des Aggregationsverhaltens von Parkin bei verschiedenen Konditionen erfolgte eine Auszählung der Zellen mit Hilfe des Axioplan 2 imaging-Fluoreszenzmikroskop von der Firma Zeiss (Jena) bei 40-facher Vergrößerung. Für jede Kondition wurden je drei Cover-Slips mit transfizierten CSM14.1-Zellen mäanderförmig unter dem jeweiligen Filter untersucht und Zellen mit 1 oder mehreren sichtbaren Aggregaten gezählt. Diese wurden in Relation zu allen transfizierten Zellen gesetzt. Nur doppeltransfizierte Zellen wurden berücksichtigt.

\subsection{Co-Immunopräzipitation (Co-IP)}

Mittels einer Co-Immunopräzipitation (Co-IP) lassen sich Protein-Interaktionen nachweisen. Hierfür werden spezielle Beads benötigt. Das sind Agarose-Kugeln, an denen ein Antikörper gebunden ist. Dieser richtet sich gegen eines der interagierenden Proteine. Mittels einer Präzipitation durch Zentrifugation werden diese Beads mit den gebundenen Proteinen isoliert und können im Anschluss im Western Blot analysiert werden. Hierbei richtet sich der verwendete Primärantikörper gegen das andere interagierende Protein.

\subsubsection{FLAG-Co-IP}

Für die Co-IP mit FLAG-Beads wurde auf einer 6-well-Platte ca. 5x105 HEK293-Zellen ausplattiert. Die Zellen wurden mit FLAG-getaggten BAG1- bzw. Parkin-Plasmiden und Parkin-, BAG1-, BAG $\Delta$ C bzw. pcDNA-Leervektor (LV)-Plasmiden cotransfiziert. Zunächst erfolgte die Zelllyse mit je $80 \mu$ l RIPA (Radioimmunoprecipitation assay)-Puffer pro well. Das Lysat wurde für 15 min auf Eis inkubiert und anschließend bei $4^{\circ} \mathrm{C}$ und $7500 \mathrm{rpm}$ für 5 min zentrifugiert. Nach der Bestimmung der Proteinkonzentration mittels BCA wurde 100$200 \mu \mathrm{g}$ Protein auf ein Volumen von $250 \mu \mathrm{l}$ mit RIPA-Puffer eingestellt. Ein Teil des Lysats wurde direkt zur Analyse mittels Western Blot verwendet.

Pro Probe wurden $15 \mu \mathrm{l}$ der FLAG-Bead-Suspension in ein Eppendorf-Tube überführt und dreimal mit RIPA-Puffer gewaschen. Die Beads wurden im Anschluss mit dem Zelllysat vermischt und für $3 \mathrm{Std}$ bei $4^{\circ} \mathrm{C}$ auf dem Drehrad inkubiert. Im Anschluss erfolgte eine Zentrifugation bei $4^{\circ} \mathrm{C}$ und $7500 \mathrm{rpm}$ für $5 \mathrm{~min}$. Der Überstand wurde für weitere Analysen verwendet. Die proteingekoppelten Beads wurden erneut dreimal mit RIPA-Puffer gewaschen. Nach dem letzten Waschgang wurde $30 \mu \mathrm{l} 2 \mathrm{x}$ SDS-Puffer zu den Beads hinzugefügt und für $5 \mathrm{~min}$ bei $95^{\circ} \mathrm{C}$ erhitzt, um das präzipitierte Protein zu eluieren. 
Im Anschluss erfolgte eine Analyse mittels Western Blot.

\begin{tabular}{|l|l|l|}
\hline RIPA-Puffer & $20 \mathrm{mM}$ Tris $\mathrm{pH} 7,5$ & \\
& $150 \mathrm{mM}$ NaCl & \\
& $1 \%$ Nonidet P-40 & AppliChem GmbH (Darmstadt) \\
& $0,5 \%$ Natrium-Deoxycholate & Merck kGaA (Darmstadt) \\
& $1 \mathrm{mM}$ EDTA & \\
& $0,1 \%$ SDS & \\
\hline
\end{tabular}

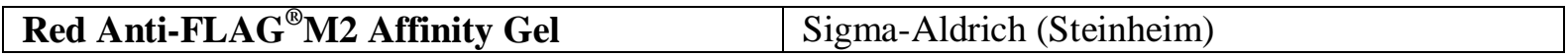

\subsubsection{HA-Co-IP}

Bei diesen Co-IP-Versuchen richtet sich der Antikörper gegen das Signalpeptid Hämagglutinin (HA). Auf einer 6-well-Platte wurden 5×105 HEK293-Zellen ausplattiert und mit HA-CDCrel-1-, Parkin-, BAG1-, BAG $\Delta$ C- bzw. LV-Plasmiden cotransfiziert.

Die Co-Immunopräzipitation erfolgte nach dem mitgelieferten Protokoll und mit den beigefügten Puffern.

Zunächst wurden die Zellen mit $300 \mu$ Lysepuffer versetzt und für 15 min bei $4^{\circ} \mathrm{C}$ inkubiert. Nach einer 15-minütigen Zentrifugation bei $13000 \mathrm{rpm}$ und $4^{\circ} \mathrm{C}$ wurde der Überstand in ein neues Eppendorf-Tube überführt. Das Zelllysat, sowie $300 \mu \mathrm{l}$ 1x IP-Puffer und $10 \mu \mathrm{l}$ HAAgarose-Beads wurden in eine mitgelieferte Spin columm überführt und über Nacht auf dem Drehrad bei $4^{\circ} \mathrm{C}$ inkubiert. Am nächsten Tag erfolgten 6 Waschgänge mit je $700 \mu \mathrm{l} 1 \mathrm{x}$ IPPuffer und einer anschließenden Zentrifugation bei $13000 \mathrm{rpm}$ für $30 \mathrm{sec}$. Ein letzter Waschgang wurde mit 1x PBS durchgeführt. Die Beads wurden in $40 \mu \mathrm{l}$ 1x SDS-Ladepuffer gelöst. Im Anschluss wurden die Proteine durch das Aufkochen für 5 min bei $95^{\circ} \mathrm{C}$ von den Beads gelöst. Die weitere Analyse der Proteine erfolgte mittels Western Blot.

\begin{tabular}{|l|l|}
\hline Anti-HA Immunopräzipitation Kit & Sigma-Aldrich (Steinheim) \\
\hline
\end{tabular}




\subsection{Quantifizierung des Proteinumsatzes}

\subsubsection{Cycloheximid-Experimente}

Cycloheximid ist ein Antibiotikum, welches die eukaryontische Proteinsynthese hemmt. Durch die Inhibition der 60S-Untereinheit der Ribosomen wird die gesamte Proteinneusynthese auf Translationsebene blockiert. Da Proteine weiter über das Proteasom degradiert werden, ist es möglich den zeitlich Verlauf des Abbaus von Zielproteinen zu verfolgen. Es besteht so die Möglichkeit die Halbwertszeit von Proteinen zu bestimmen.

Für die Cycloheximidexperimente wurden HEK293- und CSM14.1-Zellen wie in 2.4.6 ausplattiert und transfiziert. 17 Std nach der Transfektion erfolgte nach einem Mediumwechsel die Zugabe von $20 \mu \mathrm{g} / \mathrm{ml}$ Cycloheximid. Um den Proteinabbau zu verfolgen, wurden die Zellen nach verschiedenen Zeitpunkten geerntet und im Anschluss mittels Western Blot analysiert.

\begin{tabular}{|l|l|l|}
\hline Cycloheximid & $100 \mathrm{mg} / \mathrm{ml}$ in DMSO & Sigma-Aldrich (Steinheim) \\
\hline
\end{tabular}

\subsubsection{Proteasom-Inhibitor MG 132}

Blockiert man den proteasomalen Abbau ubiquitinylierter Proteine in der Zelle durch Zugabe eines Proteasom-Inhibitors, werden diese Proteine in der Zelle aufgestaut und können als hochmolekulare Banden im Western Blot nachgewiesen werden.

Für diese Experimente wurden HEK293-Zellen wie in 2.4.6 beschrieben ausplattiert und transfiziert. 12 Std nach Transfektion erfolgte die Zugabe des Proteasom-Inhibitors MG 132 in einer Konzentration von $20 \mu \mathrm{M}$. Nach erneuter Inkubation für 12 Std wurden die Zellen geerntet, lysiert und im Anschluss mittels Western Blot analysiert. 


\section{Ergebnisse}

\subsection{Nachweis der Interaktion zwischen Parkin und BAG1}

\subsubsection{Co-Immunopräzipitation von Parkin und BAG1 in HEK293-Zellen}

Um eine Interaktion zwischen Parkin und BAG1 darzustellen, wurden zunächst CoImmunopräzipitations-Versuche durchgeführt. Hierfür wurde Parkin mit FLAG-BAG1 transient in HEK293-Zellen überexprimiert. Unter Einsatz eines gegen den FLAG-tag gerichteten Antikörpers erfolgte die Präzipitation von FLAG-BAG1.

Bei der anschließenden Western-Blot-Analyse mit einem Antikörper gegen Parkin zeigte sich ein spezifisches, positives Signal passender Größe. Bei einer Überexpression von FLAGBAG1 mit pcDNA-Leervektor (pcDNA-LV) sowie Parkin mit pcDNA-LV konnte in derselben Zellreihe dagegen kein Signal detektiert werden (s. Abb. 3.1 oben).

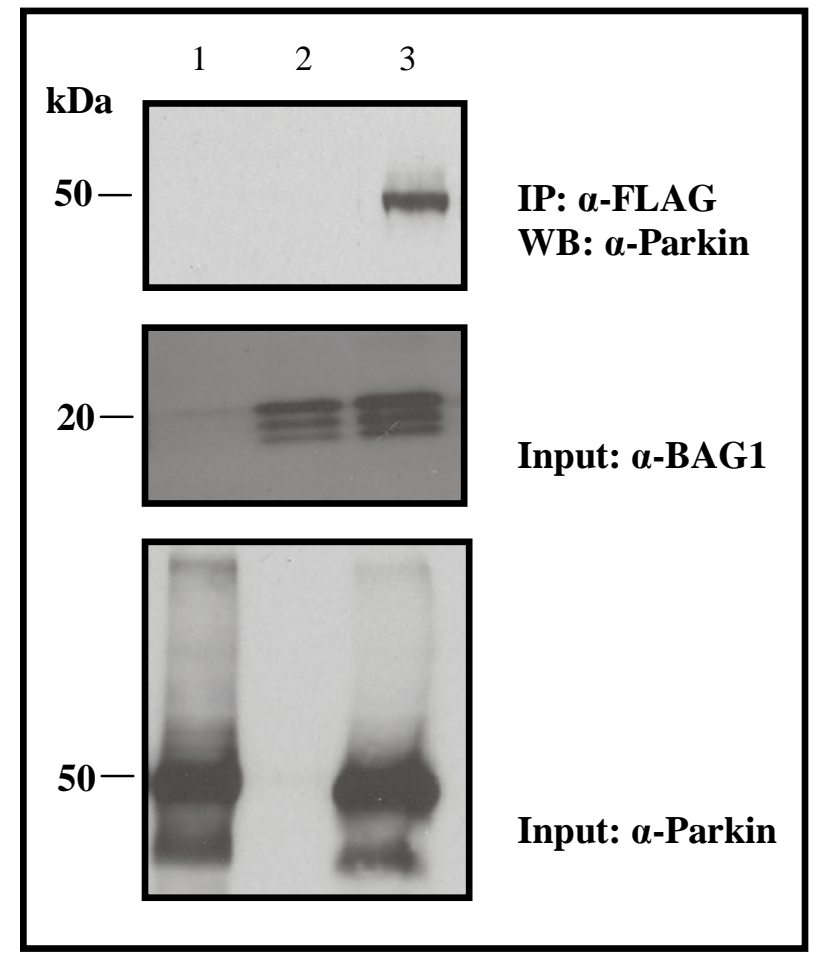

Abb. 3.1: Immunoblot nach Überexpression von Parkin und FLAG-BAG1 in HEK293-Zellen. Überexprimiertes FLAG-BAG1 wurde über FLAG-Beads präzipiert. Anschließend wurde im Western Blot Parkin detektiert (oben). Zur Kontrolle der Expression wurden das Voll-Lysat (Input) mit Parkin- und BAG1Antikörpern analysiert (unten). 1: Parkin+pcDNA-LV; 2: pcDNA-LV+FLAG-BAG1; 3: Parkin+FLAG-BAG1.

In einem zweiten experimentellen Ansatz erfolgte eine Überexpression von FLAG-Parkin und BAG1 mit anschließender Präzipitation über den FLAG-tag. Auch bei dieser Konstellation konnte eine Proteininteraktion über die Darstellung einer spezifischen BAG1-Bande im Western Blot nachgewiesen werden (s. Abb. 3.2 oben). Unspezifische Bindungen über den FLAG-tag konnten somit ausgeschlossen und eine Interaktion zwischen Parkin und BAG1 bei 
Überexpression in HEK293-Zellen dargestellt werden. Diese Interaktion konnte auch in der neuronalen CSM14.1-Zellreihe bestätigend dargestellt werden (Daten nicht gezeigt).

In einem weiteren Experiment wurde untersucht, ob auch BAG $\Delta \mathrm{C}$ noch mit Parkin interagiert. BAG $\Delta \mathrm{C}$ ist eine Deletionsmutante von BAG1, die durch den Verlust von 29 AS am C-Terminus die Fähigkeit verliert, an Hsp70 zu binden.

Für diesen Versuch wurde FLAG-Parkin mit BAG $\Delta$ C transient in HEK293-Zellen überexprimiert und eine Präzipitation über den FLAG-tag, wie oben beschrieben, durchgeführt. Der im Anschluss an die Präzipitation durchgeführte Western Blot zeigte ein spezifisches Signal für BAG $\Delta \mathrm{C}$ und damit die Bestätigung, dass auch BAG $\Delta \mathrm{C}$ an Parkin bindet. Bei der Überexpression von FLAG-Parkin bzw. BAG $\Delta \mathrm{C}$ mit pcDNA-LV konnte dagegen kein spezifisches Signal detektiert werden (s. Abb. 3.2 oben).

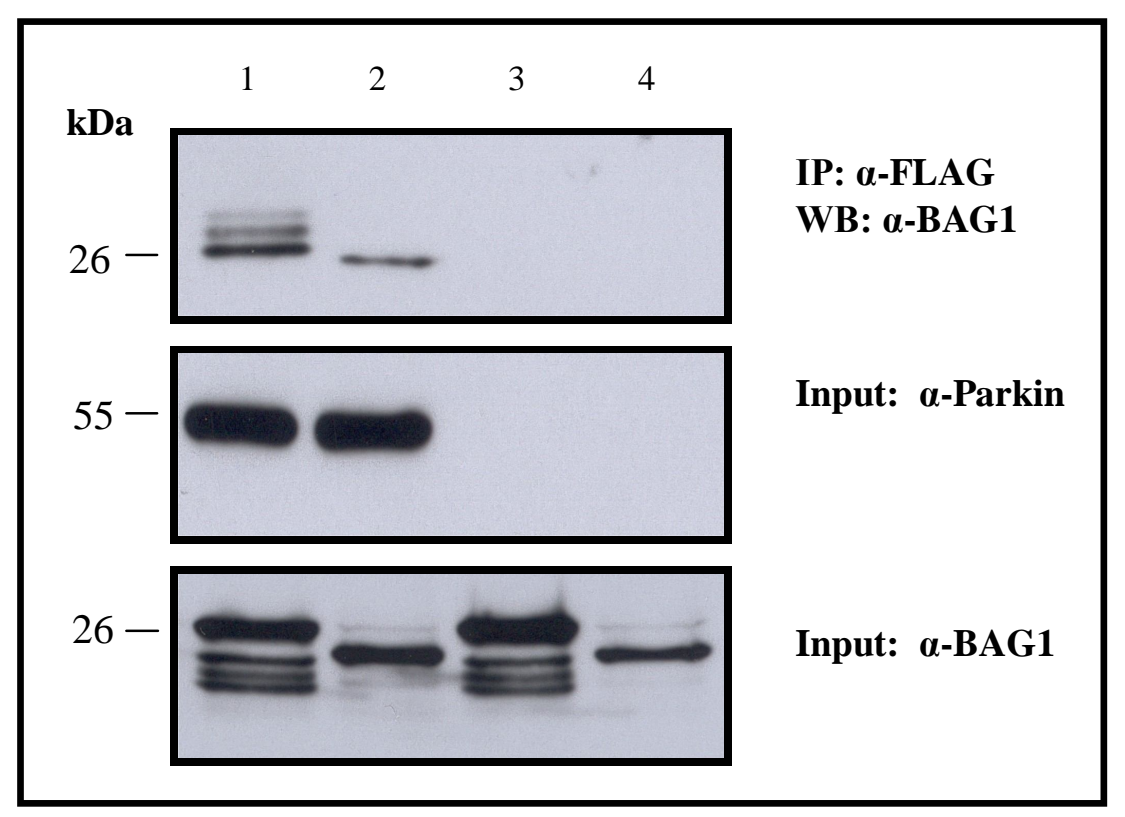

Abb. 3.2: Immunoblot nach Überexpression von FLAG-Parkin und BAG1 bzw. BAG $\Delta$ C in HEK293Zellen. Überexprimiertes FLAG-Parkin wurde über FLAG-Beads präzipiert. Anschließend wurde im Western Blot BAG1 detektiert (oben). Zur Kontrolle der Expression wurden das Voll-Lysat (Input) mit Parkin- und BAG1-Antikörpern analysiert (unten). 1: FLAG-Parkin+BAG1; 2: FLAG-Parkin+BAG $\Delta$ C; 3: pcDNALV+BAG1; 4: pcDNA-LV+BAG BAG $\Delta$ C.

Zusammenfassend konnte durch die oben beschriebenen Co-Immunopräzipitations-Versuche dargestellt werden, dass sowohl BAG1 als auch BAG $\Delta \mathrm{C}$ mit Parkin interagieren. Für die Bindung der beiden Proteine scheint daher die C-terminale BAG-Domäne des BAG1 nicht entscheidend zu sein. 


\subsubsection{Immunozytochemie von Parkin und BAG1 in CSM14.1-Zellen}

In einem zweiten Ansatz sollte eine Co-Lokalisation von Parkin und BAG1 mit Hilfe von Immunozytochemie-Versuchen in der Zelle dargestellt werden. Durch fluoreszierende Signalpeptide, wie beispielsweise dem GFP-tag, oder durch fluoreszierende Antikörper können Proteine in der Zelle und durch die Überlagerung der Farbsignale auch Interaktionen sichtbar gemacht werden. Für die Versuche wurden CSM14.1-Zellen verwendet.

\section{Überexpression von Parkin}

Zunächst erfolgte eine alleinige Überexpression von Parkin. Hierbei zeigte sich eine homogene Verteilung des Parkin-Farbsignals im gesamten Zytoplasma (s. Abb. 3.3 A-C).

In einigen Zellen wurden mehrere kleine zytoplasmatische Aggregate detektiert, andere zeigten perinukleäre Akkumulationen von Parkin (s. Abb. 3.3 D-F). Diese Aggregation konnte sowohl bei einer Überexpression von GFP-Parkin, als auch von Wildtyp-Parkin (wtParkin) mit Anfärbung über fluoreszierende Antikörper dargestellt werden (Daten nicht gezeigt). Daher kann davon ausgegangen werden, dass die Akkumulation nicht auf das GFPSignalpetid zurückzuführen ist.

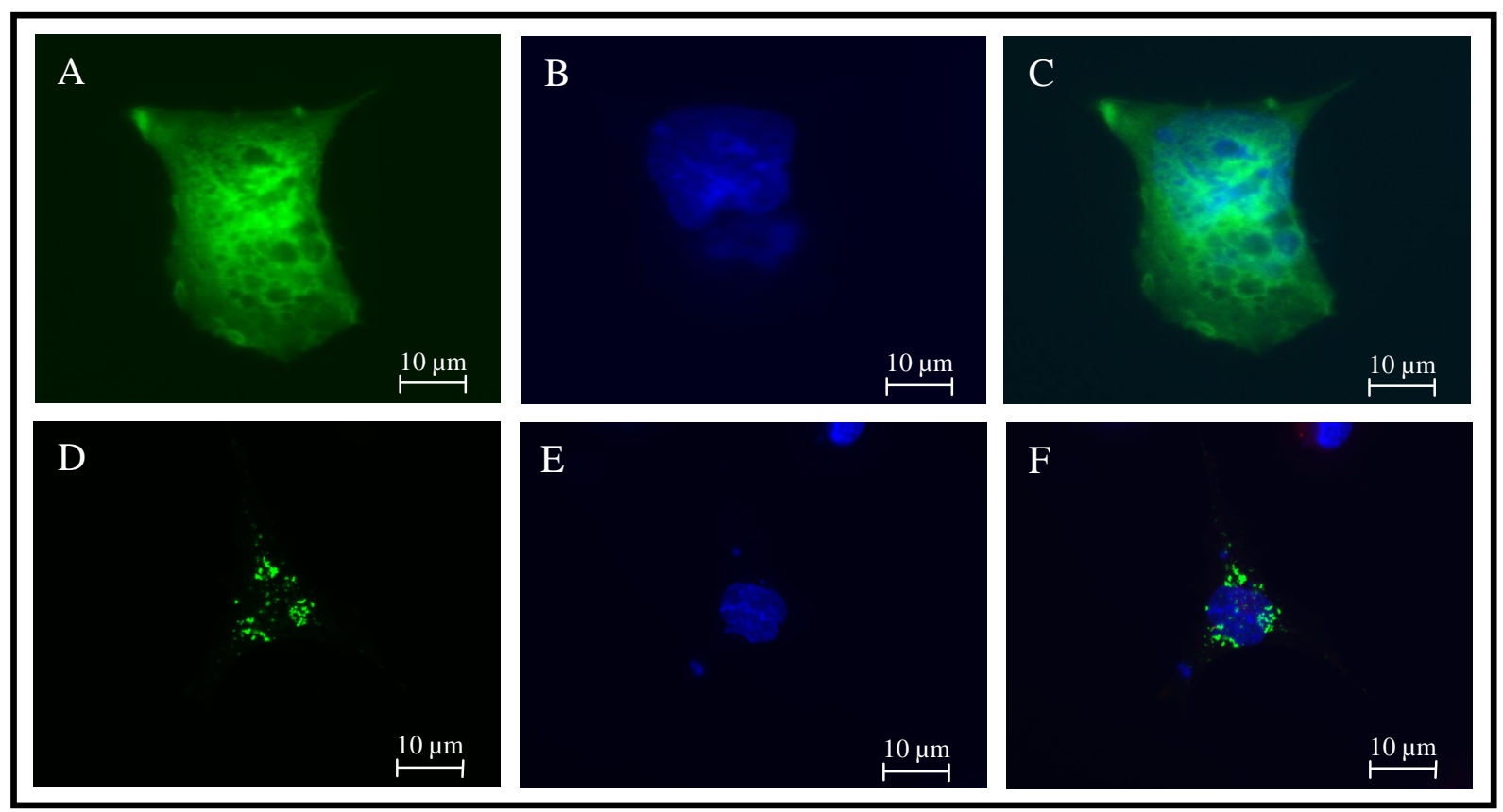

Abb. 3.3: Fluoreszenzmikroskopische Aufnahmen (63x Objektiv) nach Überexpression von GFP-Parkin und pcDNA-LV in CSM14.1-Zellen. Obere Reihe (A-C): Homogene Verteilung von GFP-Parkin im Zytoplasma. Untere Reihe (D-F): Akkumulation von GFP-Parkin in zytoplasmatische Aggregate bei Überexpression. A: GFP-Parkin; B: DAPI; C: Überlagerung; D: GFP-Parkin; E: DAPI; F: Überlagerung. 


\section{Überexpression von BAG1}

Bei der Überexpression von GFP-BAG1 in CSM14.1-Zellen zeigte sich, wie in der Literatur beschrieben (Kermer et al. 2002), eine homogene Verteilung im Zytoplasma sowie eine kräftige Anreicherung von BAG1 im Nukleus (Daten nicht gezeigt).

\section{Überexpression von Parkin und GFP-BAG1}

Zur Darstellung einer Co-Lokalisation beider Proteine wurden Parkin und GFP-BAG1 in CSM14.1-Zellen überexprimiert. GFP-BAG1 zeigt, wie auch schon bei der alleinigen Überexpression, eine zytoplasmatische und nukleäre Lokalisation (s. Abb. 3.4 A). Parkin konnte vor allem im Zytoplasma angefärbt werden (s. Abb. 3.4 B).

Eine Überlagerung der Farbsignale von GFP-BAG1 (grün) mit Parkin (rot) und damit eine mutmaßliche Co-Lokalisation der beiden Proteine konnte in allen doppelt transfizierten Zellen nachgewiesen werden. Diese Co-Lokalisation lies sich vorallem im Zytoplasma darstellen (s. Abb. 3.4 D). Auch bei der Co-Expression von Parkin mit GFP-BAG1 wurden die schon bei alleiniger Parkin-Überexpression beschriebenen Aggregate in einigen Zellen beobachtet (Daten nicht gezeigt).

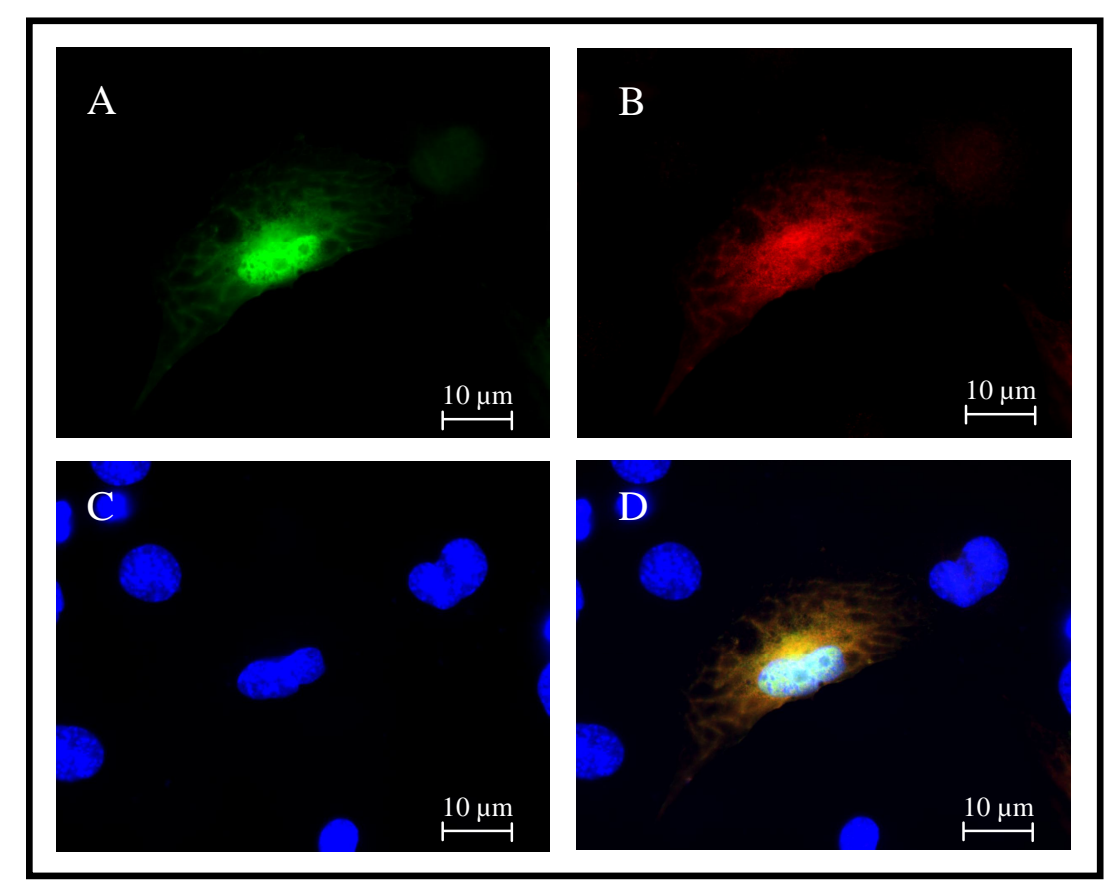

Abb. 3.4: Fluoreszenzmikroskopische Aufnahmen (63x Objektiv) nach Überexpression von Parkin und GFP-BAG1 in CSM14.1-Zellen. Parkin wurde mit einem Cy3-gekoppelten Antikörper gefärbt. A: GFP-BAG1; B: Parkin; C: DAPI; D: Überlagerung. 


\section{Überexpression von Parkin und GFP-BAGAC}

Da bereits in Co-Immunopräzipitations-Versuchen eine Interaktion von Parkin und BAG $\Delta \mathrm{C}$ nachgewiesen werden konnten, sollte diese Bindung bestätigend in ImmunozytochemieVersuchen dargestellt werden. Bei der Überexpression von Parkin und GFP-BAG $\Delta \mathrm{C}$ in CSM14.1-Zellen zeigte sich, wie schon zuvor bei BAG1, eine Übereinstimmung der Lokalisation von Parkin und BAG $\Delta \mathrm{C}$ im Zytoplasma der Zelle (s. Abb. 3.5 D).

Durch die Deletionsmutation am C-Terminus des Proteins verliert BAG $\Delta \mathrm{C}$, wie bereits berichtet (Liman et al. 2005), die nukleäre Lokalisation und ist nur zytoplasmatisch nachweisbar (s. Abb. 3.5 A).

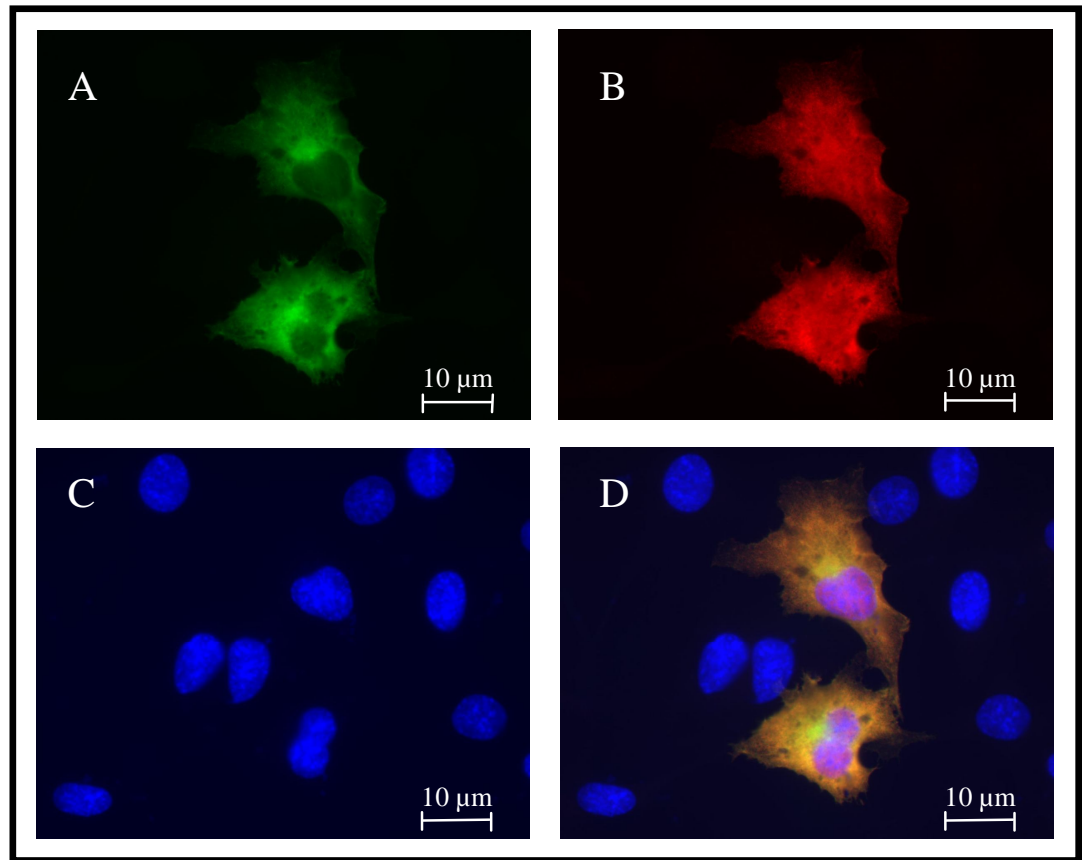

Abb. 3.5: Fluoreszenzmikroskopische Aufnahmen (63x Objektiv) nach Überexpression von Parkin und GFP-BAG $\Delta$ C in CSM14.1-Zellen. Parkin wurde mit einem Cy3-gekoppelten Antikörper gefärbt. A: GFPBAG $\Delta$ C, B: Parkin, C: DAPI, D: Überlagerung.

Mit den Immunozytochemie-Versuchen wurde gezeigt, dass Parkin, BAG1 sowie BAG $\Delta \mathrm{C}$ zytoplasmatische Proteine sind. BAG1 konnte zudem nukleär lokalisiert werden. Parkin, BAG1 sowie BAG $\Delta \mathrm{C}$ verteilen sich homogen im Zytoplasma, wobei Parkin bei Überexpression in einigen Zellen zu zytoplasmatischen Aggregaten akkumuliert. Eine CoLokalisation zwischen Parkin und BAG1 ebenso mit BAG $\Delta \mathrm{C}$ konnte im Zytoplasma immunzytochemisch bestätigt werden. 


\subsection{Kartierung der interagierenden Domäne unter Verwendung verschiedener Parkin- Deletionsmutanten}

Um die für die Interaktion mit BAG1 relevante Parkin-Domäne zu identifizieren, wurden verschiedene FLAG-Parkin-Deletionsmutanten kloniert und im Anschluss für CoImmunopräzipitations-Versuche mit BAG1 überexprimiert.

\subsubsection{Parkin-Deletionsmutations-Konstrukte}

Für ein direktes „mapping“ der interagierenden Domäne wurden zunächst die mit einem FLAG-tag versehenen Parkin-Deletionsmutanten FLAG- $\Delta$ UBL (AS 77- 465), FLAG- $\Delta$ Linker

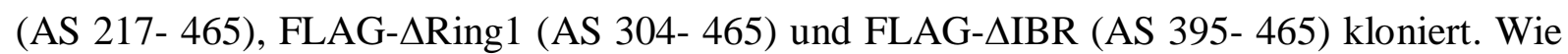
in Abbildung $3.6 \mathrm{zu}$ sehen ist, fehlt der $\Delta$ UBL-Mutante die Ubiquitin-like-Domäne, der $\Delta$ Linker-Mutante zusätzlich Teile der Linker-Region und der $\Delta$ Ring1-Mutante des Weiteren die erste Ring-Domäne. Die $\Delta$ IBR-Mutante besteht funktionell nur noch aus dem zweiten Ring der Ring-IBR-Ring-Domäne. Alle Parkin-Fragmente wurden in den Vektor pcDNA3.1 kloniert. Als Matrize diente pcDNA-FLAG-Parkin, das für humanes wt-Parkin kodiert. Die $\mathrm{N}$-terminalen Deletionsmutanten wurden ausgehend von pcDNA-FLAG-Parkin-Plasmid mit dem jeweiligen EcoRI-Forward- und dem NotI-Backward-Primer amplifiziert. Über die Schnittstellen der Restrikionsendonukleasen EcoRI und NotI wurde das Produkt in das Plasmid pcDNA3.1 ligiert.

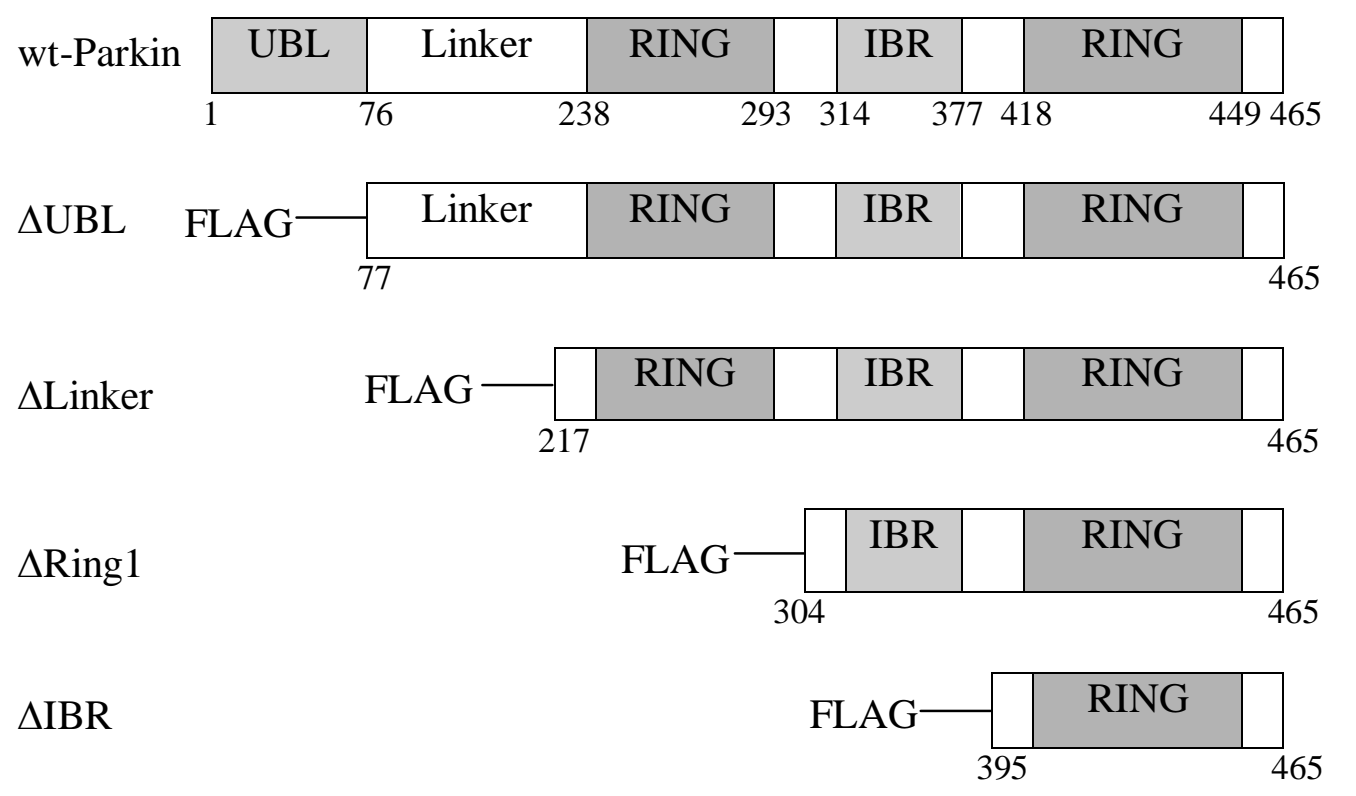

Abb. 3.6: Schematische Darstellung der klonierten Parkin-Deletionsmutantions-Konstrukte. Zusätzlich ist noch wt-Parkin ohne Signalpeptid abgebildet. 


\subsubsection{Restriktionsenzymverdau der Parkin-Deletionsmutanten}

Zur Kontrolle der korrekten Ligatur der Parkin-Deletionsmutanten wurden die Inserts nach einer Mini-Präparation durch die Restriktionsendonukleasen EcoRI und NotI aus dem Vektor herausgeschnitten. Die folgende Abbildung zeigt den Verdau der vier ParkinDeletionsmutanten und des wt-Parkin. Aufgrund der geringen Größe und der damit verbundenen schnelleren Laufgeschwindigkeit im Gel, konnte die $\Delta$ IBR-Mutante bei normaler Belichtungszeit nicht detektiert werden. Eine längere Belichtungszeit bestätigte aber die Anwesenheit des DNA-Fragments (s. Abb. 3.7 rechts). Die dargestellten DNA-Banden weisen alle die jeweils berechnete korrekte Größe in Basenpaaren (bp) auf.

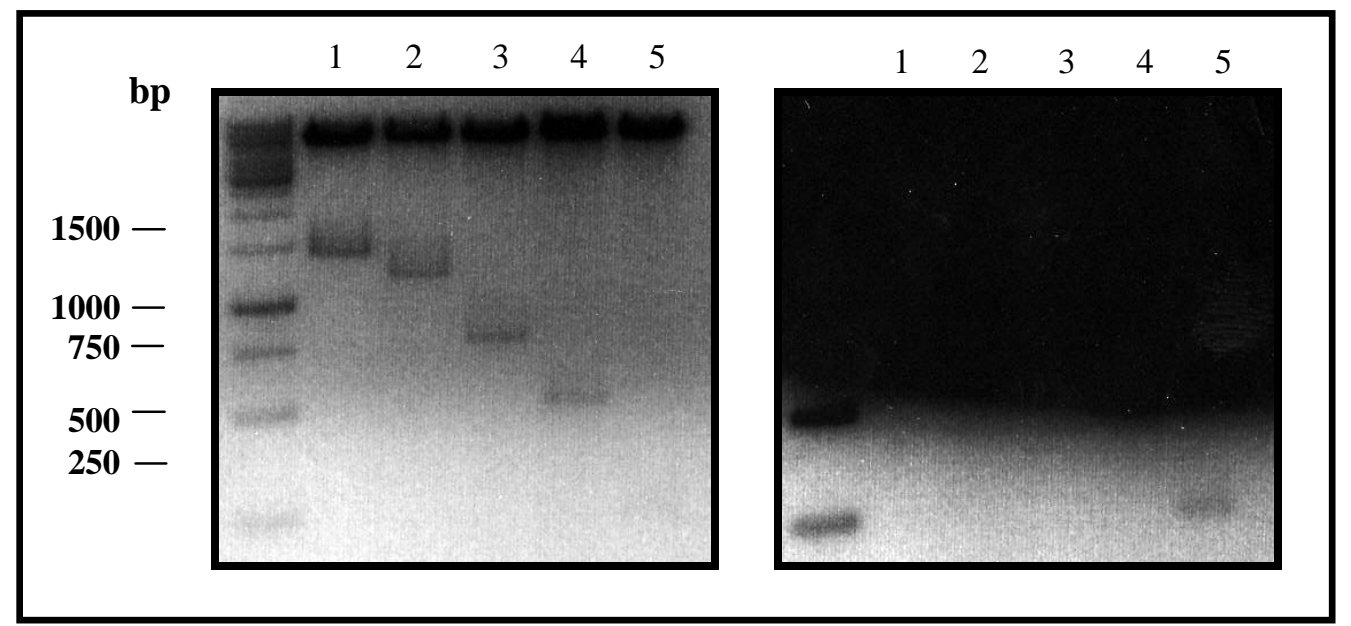

Abb. 3.7: Restriktionsenzymverdau der Parkin-Deletionsmutanten. Links: Normale Belichtungszeit; Rechts: verlängerte Belichtungszeit zur Darstellung der $\Delta$ IBR-Mutante. 1: wt-Parkin; 2: FLAG- $\Delta U B L-M u t a n t e ; ~ 3:$ FLAG- $\Delta$ Linker-Mutante; 4: FLAG- $\Delta$ Ring1-Mutante; 5: FLAG- $\Delta$ IBR-Mutante.

\subsubsection{Sequenzierung der Parkin-Deletionsmutanten}

Die durch die Sequenzierung erhaltende Basenfolge wurde manuell mit der bekannten zugehörigen Parkin-Sequenz verglichen. Bei allen Parkin-Deletionsmutanten konnten ungewollte Punkt- und Rastermutationen ausgeschlossen werden, da die Basenfolgen vollständig mit der zugehörigen Parkin-Sequenz übereinstimmten.

\subsection{4 Überexpression der Deletionsmutanten in HEK293- und CSM14.1-Zellen}

Nach erfolgreicher Klonierung wurden die Parkin-Deletionsmutanten zunächst in HEK293und CSM14.1-Zellen überexprimiert. Die folgende Abbildung zeigt die Transfektion der Parkin-Deletionsmutanten in HEK293-Zellen. Bis auf das FLAG- $\triangle$ IBR-Deletionskonstrukt konnten alle Mutanten erfolgreich in beiden Zelllinien exprimiert und dargestellt werden. Eine Transfektion mit pcDNA-LV diente als Negativkontrolle. 
Als Grund für die erfolglose Expression des FLAG- $\Delta$ IBR-Konstruktes wurde eine erhöhte Abbaurate, zusammenhängend mit der geringen Größe der Mutante, vermutet.

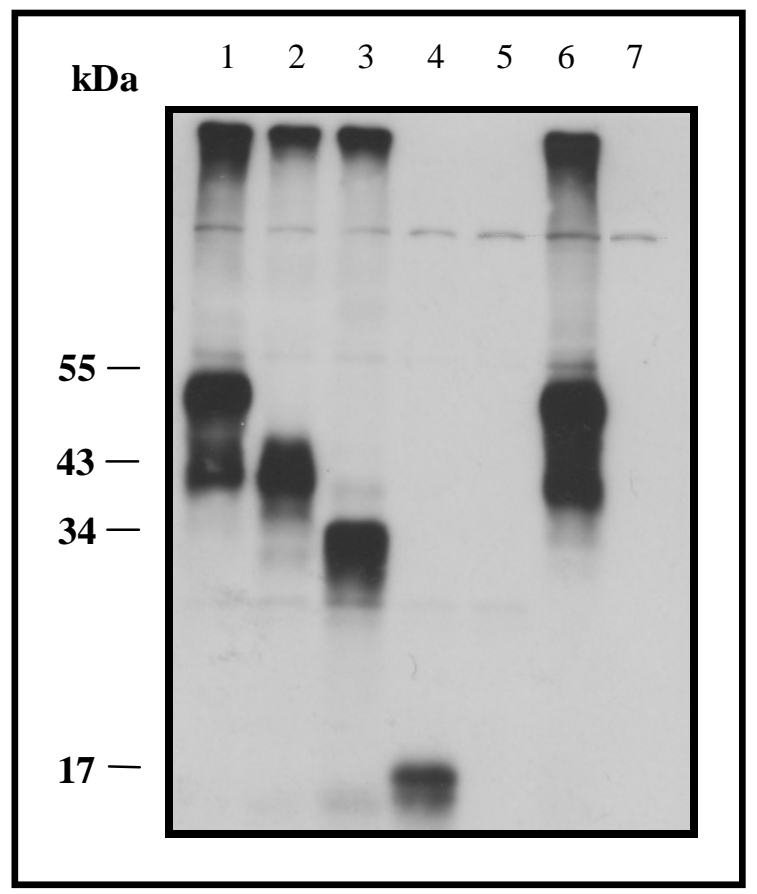

Abb. 3.8: Immunoblot nach Überexpression der Parkin-Deletionsmutanten in HEK293-Zellen. Beim Western Blot wurde Parkin detektiert. 1: FLAG-Parkin; 2: FLAG- $\Delta$ UBL-Mutante; 3: FLAG- $\Delta$ Linker-Mutante; 4: FLAG- $\Delta$ Ring1-Mutante; 5: FLAG- $\Delta$ IBR-Mutante; 6: wt-Parkin; 7: pcDNA-LV.

\subsubsection{Kartierungsexperimente unter Verwendung der Parkin-Deletionsmutanten und}

\section{BAG1}

Zur Kartierung der interagierenden Domäne wurden die vier FLAG-ParkinDeletionsmutanten in HEK293-Zellen zusammen mit BAG1 überexprimiert. Als Negativkontrolle diente die Co-Transfektion von BAG1 mit pcDNA-LV. Zur Positivkontrolle wurde FLAG-wt-Parkin zusammen mit BAG1 überexprimiert. Die Präzipitation erfolgte mittels FLAG-Beads wie bereits in Kap. 3.1.1 beschrieben. Im Anschluss wurde im Western Blot gegen BAG1 detektiert.

Wie in Abbildung 3.9 zu sehen ist, lässt sich eine Interaktion zwischen der FLAG- $\Delta$ UBL-, der FLAG- $\Delta$ Linker- sowie der FLAG- $\Delta$ Ring1-Mutante mit BAG1 darstellen. Bei diesen Konditionen konnte ein spezifisches positives BAG1-Signal im Western Blot, vergleichbar mit der Positivkontrolle, detektiert werden. Bei der Co-Expression der FLAG-AIBR-Mutante mit BAG1 konnte dagegen kein BAG1-Signal dargestellt werden.

Da schon in der oben beschriebenen Expressionskontrolle diese Mutante nicht darstellbar war, kann davon ausgegangen werden, dass das fehlende BAG1-Signal hierauf zurückzuführen ist. 
Auf eine fehlende Interaktion der beiden Proteine kann jedoch nicht geschlossen werden. Die in Abbildung 3.9 dargestellten Ergebnisse konnten auch in der neuronalen Zelllinie CSM14.1 erzielt werden (Daten nicht gezeigt).

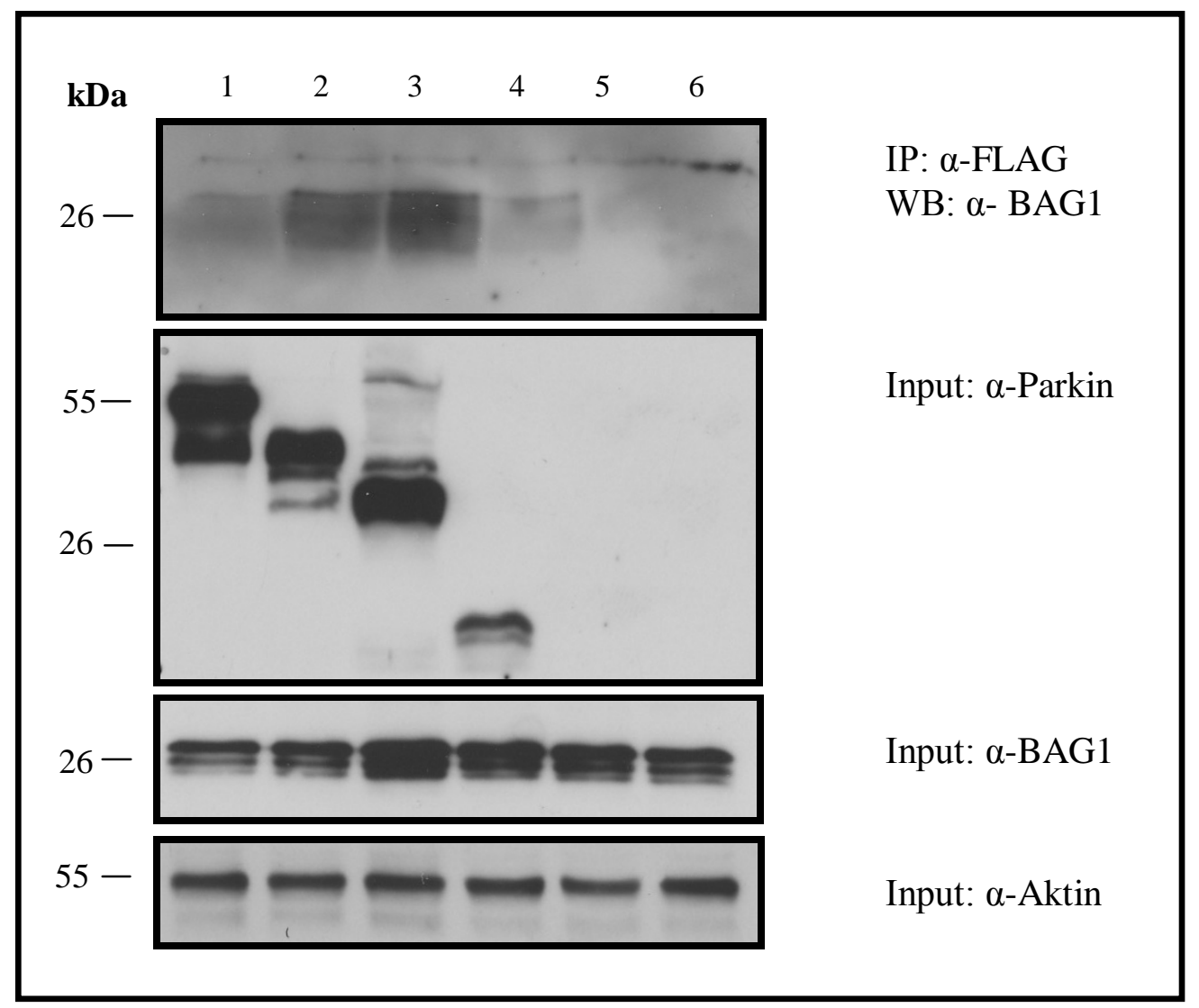

Abb. 3.9: Immunoblot nach Überexpression der Parkin-Deletionsmutanten mit BAG1 in HEK293Zellen. Die überexprimierten Parkin-Deletionsmutanten wurden über FLAG-Beads präzipiert. Anschließend wurde im Western Blot BAG1 detektiert (oben). Zur Kontrolle der Expression wurden das Voll-Lysat (Input) mit Parkin-, BAG1- und Aktin-Antikörpern analysiert (unten). 1: FLAG-wt-Parkin+BAG1; 2: FLAG- $\Delta U B L-$ Mutante+BAG1; 3: FLAG- $\Delta$ Linker-Mutante+BAG1; 4: FLAG- $\Delta$ Ring1-Mutante+BAG1; 5: FLAG- $\Delta$ IBRMutante+BAG1; 6: BAG1+pcDNA-LV. 


\subsection{Funktionelle Untersuchungen der E3-Ligase-Funktion von Parkin}

Parkin ist mit seiner E3-Ligase-Funktion Teil des UPS. Über die Ubiquitinylierung von Substratproteinen führt Parkin diese dem Abbau durch das Proteasom zu. Über die Ubiquitinylierung von CDCrel-1, eines der Substratproteine, oder dessen beschleunigte Abbaurate lässt sich die E3-Ligase-Aktivität untersuchen.

\subsubsection{Degradationszeitreihen unter Verwendung von Cycloheximid als Translations-}

\section{Inhibitor}

Um den Einfluss von BAG1 auf die E3-Ligase-Funktion von Parkin zu erfassen, sollte zunächst die Abbaurate des Substratproteins CDCrel-1 untersucht werden.

Hierfür wurden CSM14.1-Zellen mit HA-CDCrel-1, Parkin, BAG1 und BAG $\Delta$ C transfiziert und 17 Std später mit dem Antibiotikum Cycloheximid behandelt, wodurch über die Inhibition der Proteinbiosynthese die Halbwertszeit von Proteinen bestimmt werden kann. Die CSM14.1-Zellen wurden für 0, 1,5, 3, 6 und 9 Std mit dem Antibiotikum inkubiert und im Anschluss mittels Western Blot analysiert.

Abbildung 3.10 zeigt die zeitliche Verminderung der HA-CDCrel-1-Proteinkonzentration in den verschiedenen Konditionen.

Bei einer Co-Expression von HA-CDCrel-1 mit Parkin lässt sich ein verminderter HACDCrel-1-Proteingehalt, vorallem bei einer Inkubationszeit von 6 und 9 Std, im Vergleich zur Negativkontrolle (HA-CDCrel-1+pcDNA-LV) darstellen. Die Co-Transfektion des Substratproteins mit BAG1, BAG $\Delta \mathrm{C}$ oder Parkin und BAG1 bzw. BAG $\Delta \mathrm{C}$ ergab dagegen Proteinlevel vergleichbar mit der Negativkontrolle.

Zur Sicherstellung vergleichbarer Proteinmengen wurde sowohl eine Konzentrationsbestimmung mittels eines BCA-Assays durchgeführt als auch im Anschluss an den Western Blot die Menge an Aktin als Kontrollprotein detektiert. Aus Gründen der Übersichtlichkeit wurde jedoch auf die Darstellung der Aktinkontrolle in Abbildung 3.10 verzichtet. 


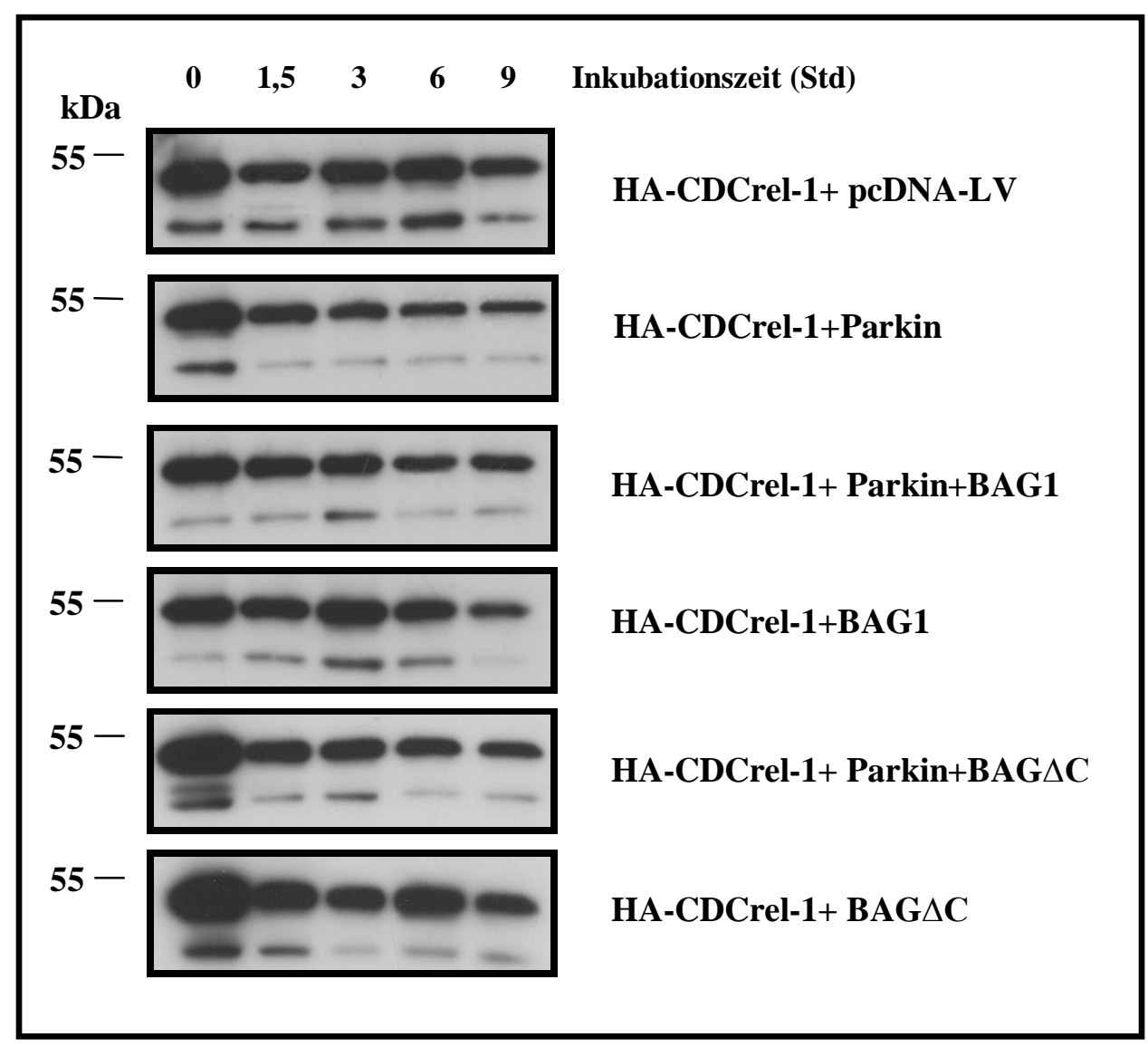

Abb. 3.10: Immunoblot der Halbwertszeit des Substratproteins HA-CDCrel-1. CSM14.1-Zellen wurden mit HA-CDCrel-1 und Parkin, BAG1 bzw. BAG $\Delta$ C überexprimiert, 17 Std nach der Transfektion mit $20 \mu \mathrm{g} / \mathrm{ml}$ Cycloheximid behandelt und für $0,1,5,3,6$ und 9 Std inkubiert. Im Western Blot wurde gegen CDCrel-1 detektiert.

\subsubsection{Die Parkin-vermittelte Ubiquitinylierung des Substratproteins CDCrel-1}

Die oben beschriebenen Beobachtungen der Cycloheximid-Experimente wurden in einem zweiten experimentellen Ansatz verifiziert. Hierbei wurde die Parkin-vermittelte Ubiquitinylierung des Substratproteins CDCrel-1 in An- bzw. Abwesenheit von BAG1 und BAG $\triangle \mathrm{C}$ im Western Blot untersucht.

CSM14.1-Zellen wurden mit HA-CDCrel-1, Parkin, BAG1 und BAG $\triangle \mathrm{C}$ überexprimiert und 12 Std nach der Transfektion mit dem Proteasom-Inhibitor MG 132 für weitere 12 Std inkubiert. Im Anschluss erfolgte die Präzipitation des Substratproteins mit Hilfe eines gegen den HA-tag gerichteten Antikörpers. Durch die Hemmung des proteasomalen Abbaus akkumulieren ubiquitinylierte Proteine in der Zelle. Diese können als hochmolekulare Banden im Western Blot als sogenannte „Ubiquitin-Leiter“ oder „Ubiquitin-smear“ nachgewiesen werden.

Bei der Untersuchung des hochmolekularen, ubiquitinylierten CDCrel-1-Anteils wurden verschiedene Ubiquitin-Antikörper verwendet. Da jedoch alle verwendeten Antikörper ein 
hohes Maß an unspezifischen Bindungen aufwiesen, wurde in der folgenden Abbildung ein spezifischer CDCrel-1 Antikörper verwendet. Die hochmolekularen Banden zeigten eine Übereinstimmung bei beiden Analysen, sodass davon ausgegangen werden kann, dass diese Banden den ubiquitinylierten CDCrel-1 entsprechen.

Bei der Präzipitation kam es zu einer Überlagerung der HA-CDCrel-1 Bande mit der schweren Kette des Antikörpers (s. Abb. 3.11 oben). Bei diesem Versuch sollten jedoch nur die höhermolekularen, ubiquitinylierten Proteinanteile berücksichtigt werden.

Der hochmolekulare Anteil des Proteins HA-CDCrel-1 und damit der Anteil des ubiquitinylierten Proteins ist quantitativ am stärksten bei der Co-Transfektion von HACDCrel-1 und Parkin ausgeprägt (s. Abb. 3.11 oben). Auch diese Beobachtung bestätigt, dass CDCrel-1 ein Parkin-Substratprotein ist und durch dieses ubiquitinyliert sowie seinem Abbau zugeführt wird.

Sowohl die Co-Expression von HA-CDCrel-1 mit BAG1, Parkin und BAG1, Parkin und BAG $\triangle \mathrm{C}$, als auch die alleinige Co-Transfektion mit BAG $\triangle \mathrm{C}$ entsprechen quantitativ der Kontrollbedingung, d.h. einer Überexpression des Substratproteins mit pcDNA-LV.

Es kann daher davon ausgegangen werden, dass BAG1 einen inhibierenden Einfluss auf die E3-Ligase-Funktion von Parkin hat, da hier der Anteil des ubiquitinylierten Substratproteins vermindert ist. Die Deletionsmutante des BAG1, BAG $\Delta$ C, übt den gleichen hemmenden Effekt auf Parkin aus.

Die in Abbildung 3.11 dargestellte verminderte Parkin-vermittelte Ubiquitinylierung des Substratproteins CDCrel-1 bei Anwesenheit von BAG1 und BAG $\Delta \mathrm{C}$ sind somit kongruent mit den in Kapitel 3.3.1 gezeigten Ergebnissen. 


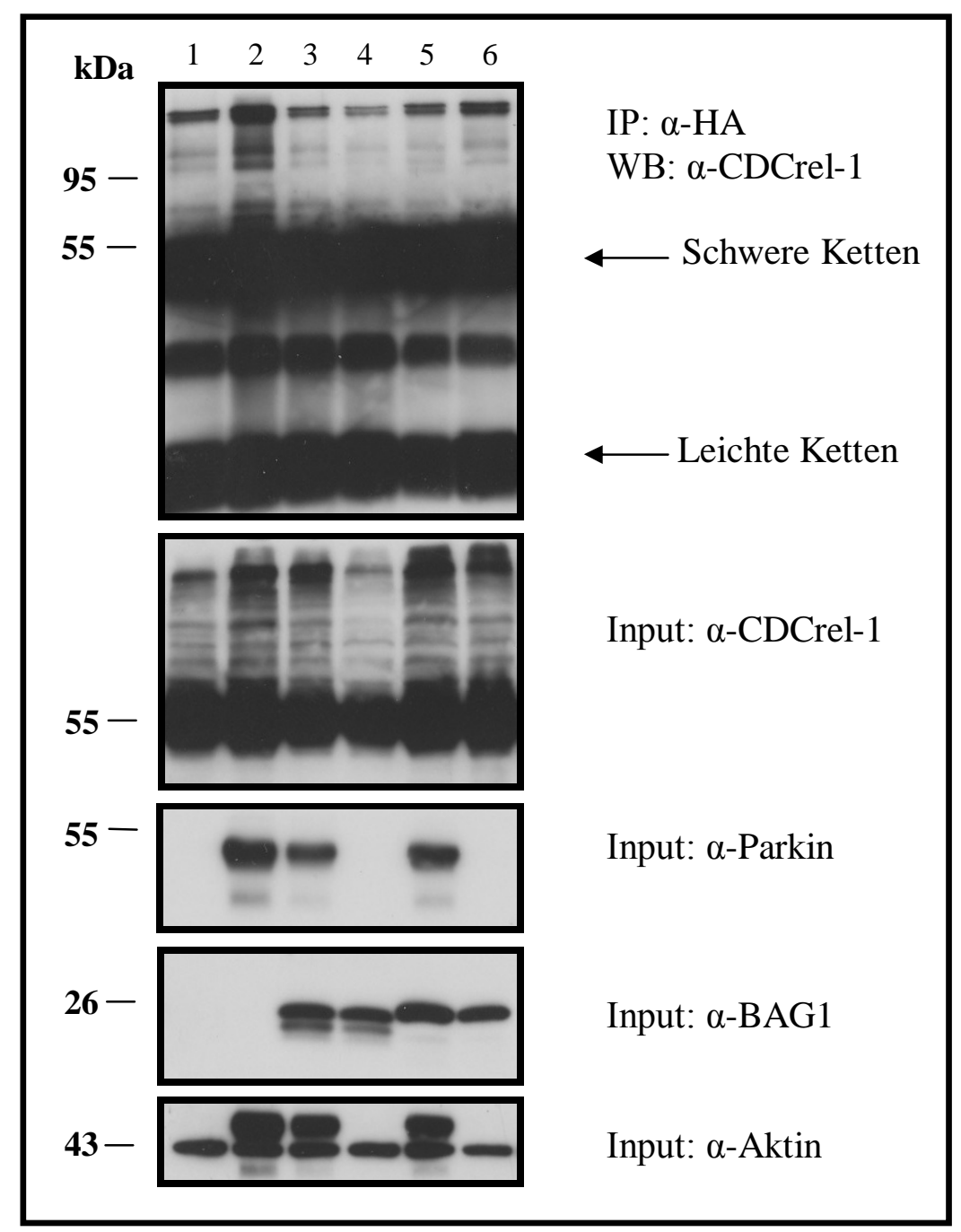

Abb. 3.11: Immunoblot der Ubiquitinylierung des Substratproteins HA-CDCrel-1. CSM14.1-Zellen wurden transient mit HA-CDCrel-1, Parkin, BAG1 sowie BAG $\Delta$ C transfiziert. HA-CDCrel-1 wurde über HABeads präzipiert und anschließend im Western Blot über $\alpha$-CDCrel-1 detektiert (oben). Zur Kontrolle wurde das Voll-Lysat (Input) mit CDCrel-1, Parkin-, BAG1- und Aktin-Antikörper analysiert (unten). 1: HA-CDCrel1+pcDNA-LV; 2: HA-CDCrel-1+Parkin; 3: HA-CDCrel-1+Parkin+BAG1; 4: HA-CDCrel-1+BAG1; 5: HACDCrel-1+Parkin+BAG $\Delta \mathrm{C} ; 6$ : HA-CDCrel-1+BAG $\Delta$ C.

Mit diesen beiden Experimenten konnte gezeigt werden, dass BAG1 und auch die Deletionsmutante $\mathrm{BAG} \Delta \mathrm{C}$ einen inhibierenden Einfluss auf die E3-Ligase-Funktion von Parkin zu haben scheint. Sowohl die Abbaurate, als auch die Parkin-vermittelte Ubiquitinylierung des Substratproteins CDCrel-1 waren bei einer Co-Expression mit BAG1 oder BAG $\Delta \mathrm{C}$ vermindert. 


\subsection{Der Einfluss von BAG1 auf die Lokalisation und Löslichkeit von Parkin}

\subsubsection{Untersuchung zur subzellulären Lokalisation von Parkin}

Als nächstes sollte die subzelluläre Verteilung von Parkin und die Einflussnahme von BAG1 bzw. BAG $\Delta$ C mittels Western Blot untersucht werden. Durch eine fraktionierte Lyse von SHSY5Y-Zellen mit vier unterschiedlichen Puffern erfolgte eine Aufteilung der Proteine in Zytoplasma, Membran und Zellorganellen, Nukleus sowie Zytoskelett. Die erfolgreiche Fraktionierung wurde durch die Detektion spezifischer Proteine der einzelnen Kompartimente belegt (s. Abb. $3.12 \mathrm{~A}$ und B unten).

Parkin konnte in den Fraktionen Zytoplasma, Membran und Organellen, sowie Zytoskelett sowohl in An-, als auch in Abwesenheit von BAG1 bzw. BAG $\Delta \mathrm{C}$ detektiert werden. Im nukleären Kompartiment konnte Parkin in keiner der Konditionen dargestellt werden (s. Abb. 3.12 A). Auffällig ist jedoch, dass bei der Co-Expression mit BAG1, Parkin deutlich reduziert in allen oben genannten Fraktionen nachweisbar war. Die gleichzeitige Überexpression mit $\mathrm{BAG} \Delta \mathrm{C}$ ergab in der zytoplasmatischen und membranösen Fraktion ein ähnliches Verteilungsmuster zur alleinigen Parkin-Expression. Im zytoskelettalen Kompartiment konnte Parkin jedoch auch hier deutlich vermindert nachgewiesen werden (s. Abb. 3.12 A).

Die subzelluläre Lokalisation von Parkin sollte in einem zweiten Ansatz unter Inhibition des Proteasoms untersucht werden. Hierfür wurden die SH-SY5Y-Zellen zusätzlich mit MG 132 für 12 Std inkubiert.

Bei diesem Versuch konnte Parkin in allen vier Kompartimenten, also auch der nukleären Fraktion nachgewiesen werden. Die oben beschriebene Beobachtung eines verminderten Parkin-Proteinlevels bei der Co-Expression mit BAG1 konnte auch bei der Inhibition des Proteasoms mit MG 132 beobachtet werden (s. Abb. 3.12 B). Am stärksten wurde dieser Unterschied in der Fraktion des Zytoskeletts sichtbar. Hier wurde vor allem der hochmolekulare Anteil von Parkin vermindert detektiert.

Bei der Co-Expression mit BAG $\Delta \mathrm{C}$ zeigte sich in den Fraktionen Zytoplasma, Membran und Organellen, sowie Nukleus eine annähernd gleich starke Parkin-Verteilung vergleichbar mit der alleinigen Expression von Parkin. Lediglich im zytoskelettalen Kompartiment konnten die hochmolekularen Anteile von Parkin vermindert nachgewiesen werden (s. Abb. 3.12 B). Dies entspricht der Verteilung ohne den Proteasom-Inhibitor.

Zusammenfassend konnte Parkin bei einer Co-Expression mit BAG1 in allen zellulären Kompartimenten vermindert nachgewiesen werden. Vorallem in der zytoskelettalen Fraktion wurde ein geringerer Anteil des hochmolekularen, ubiquitinylierten Parkins detektiert. Im 
nukleären Kompartiment kam Parkin nur nach vorheriger Inhibition des Proteasoms zur Darstellung.

Als Ursache für die geringere Nachweisbarkeit wurden Änderungen in der Halbwertszeit und Löslichkeit von Parkin vermutet. Dieses sollte in den nächsten Experimenten näher untersucht werden.

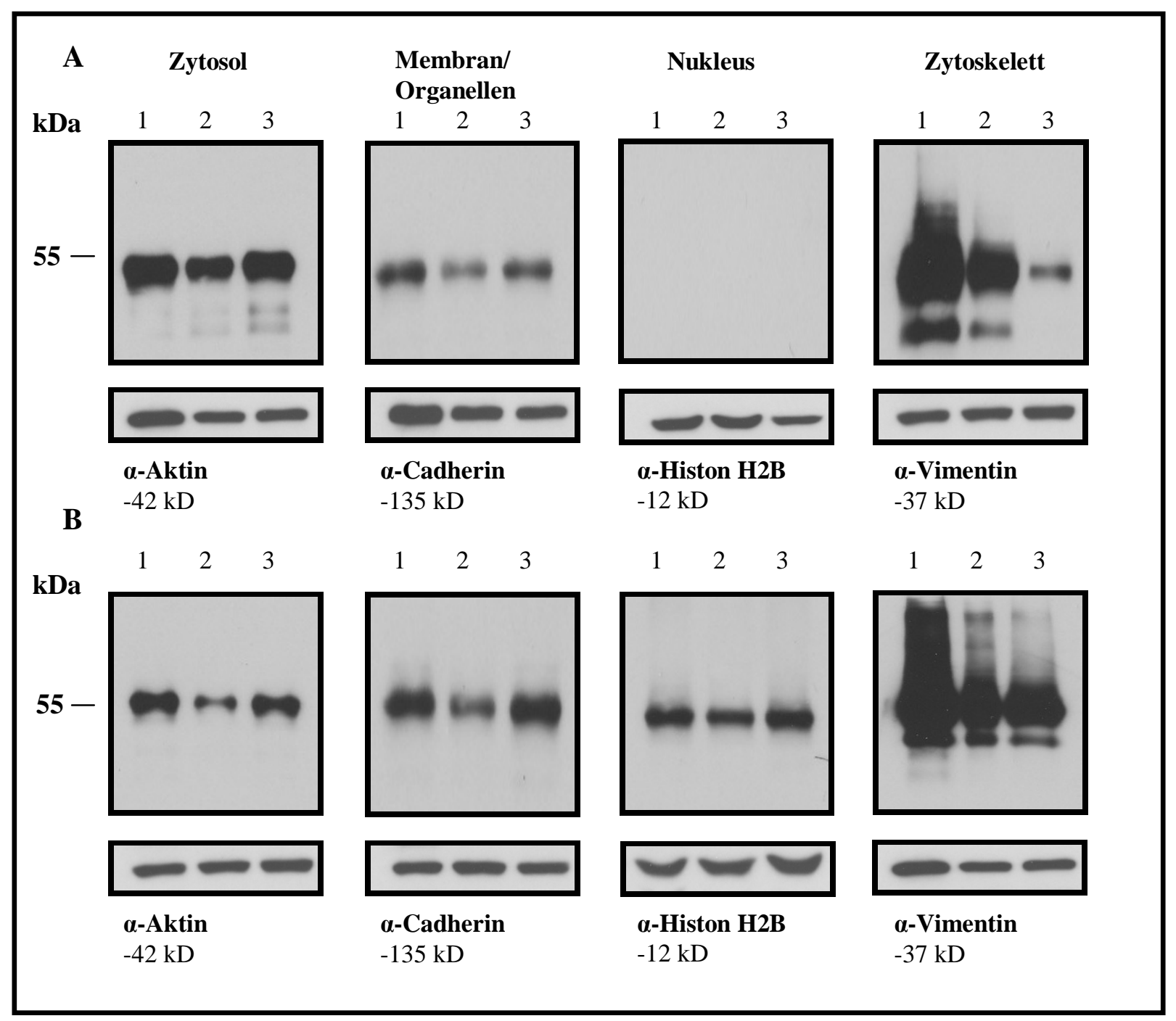

Abb. 3.12: Immunoblot der subzelluläre Fraktionierung von Parkin in SH-SY5Y-Zellen. SH-SY5Y-Zellen wurden mit Parkin, BAG1 und BAG $\Delta \mathrm{C}$ überexprimiert und eine subzelluläre Fraktionierung durchgeführt. Im Anschluss wurde Parkin mittels Western Blot analysiert (A und B oben). Zur Kontrolle der korrekten Lysierung wurden Aktin (Zytosol), Cadherin (Membran/Organellen), Histon H2B (Nukleus) und Vimentin (Zytoskelett) verwendet. SH-SY5Y-Zellen zusätzlich mit $20 \mu \mathrm{M}$ MG 132 für 12 Std inkubiert (B). 1: Parkin+pcDNA-LV; 2: Parkin+BAG1; 3: Parkin+BAG $\Delta$ C. 


\subsubsection{Untersuchungen zur Löslichkeit und Ubiquitinylierung von Parkin}

Bei den in Kap. 3.1.2 beschriebenen Immunozytochemie-Versuchen konnten einzelne ParkinAggregate nachgewiesen werden und auch bei der subzellulären Lysierung in Kap. 3.4.1 wurden Vermutungen über eine verminderte Löslichkeit von Parkin bei Co-Expression von BAG1 gestellt. Diese Hypothese sollte in weiteren Versuchen objektiviert werden.

Hierfür wurde zunächst das Aggregationsverhalten von Parkin in ImmunozytochemieVersuchen morphologisch untersucht und im Anschluss manuell ausgezählt.

Morphologisch konnten in überexprimierten CSM14.1-Zellen sowohl viele kleinere peripher gelegene Parkin-Akkumulationen (s. Abb. 3.3), als auch singuläre perinukläre Aggregate dargestellt werden (s. Abb. 3.13 A). Diese Parkin-Akkumulation zeigte sich sowohl bei der alleinigen Expression von Parkin, als auch bei der Co-Transfektion mit BAG1 und BAG $\Delta \mathrm{C}$.

Bei der Anfärbung von Tubulin zeigte sich zudem, dass das Zytoskelett eine Art „Korb“ um diese Aggregate bildet und diese so vom Rest des Zytoplasmas abschottet (s. Abb. 3.13 B).

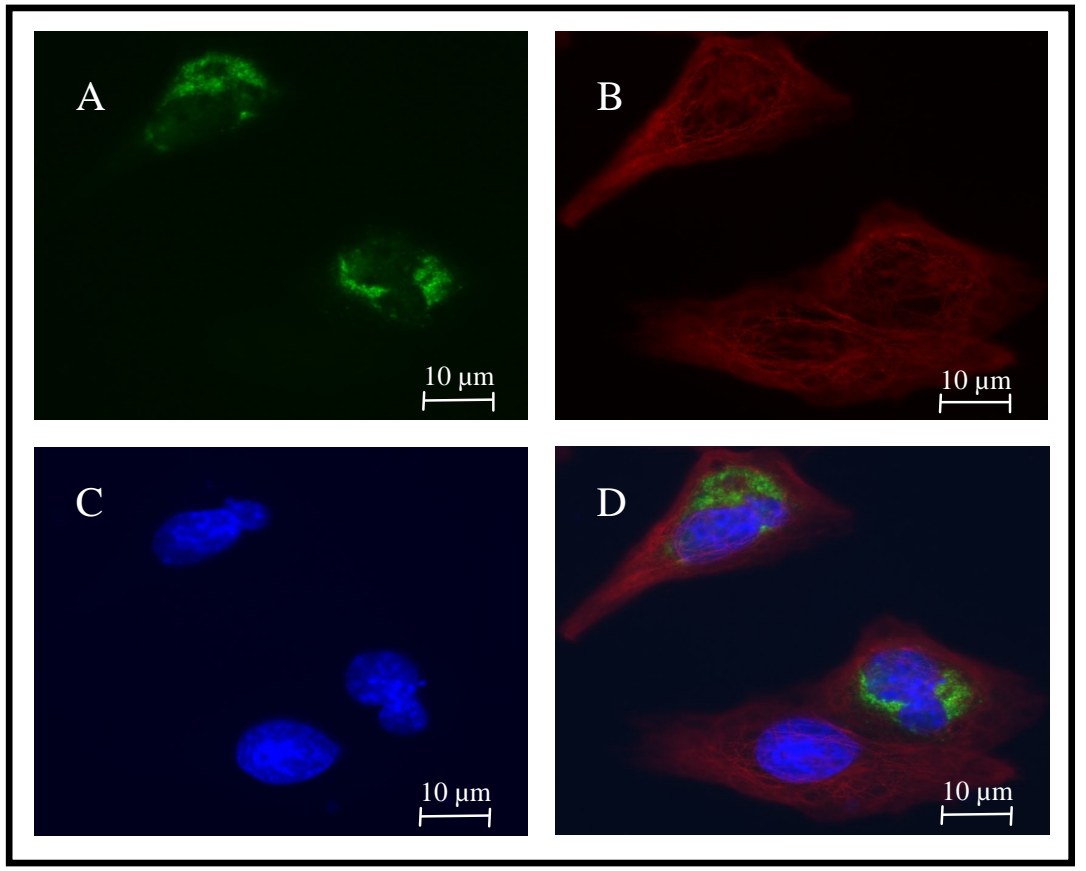

Abb. 3.13: Fluoresenzmikroskopische Aufnahme (63x Objektiv) nach Überexpression von GFP-Parkin mit BAG1 in CSM14.1-Zellen. Dargestellt sind perinukleäre Parkin-Aggregationen mit einem umgebenden Tubulin-,,Korb“. Tubulin wurde mit einem Cy3-gekoppeltem Antikörper gefärbt. A: GFP-Parkin; B: Tubulin; C: DAPI; D: Überlagerung.

Zur Analyse, ob die Anwesenheit von BAG1 bzw. BAG $\Delta$ C Einfluss auf das Akkumulationsverhalten von Parkin in der Immunozytochemie hat, erfolgte eine Auszählung der aggregathaltigen Zellen in den jeweiligen Konditionen unter dem Fluoreszenzmikroskop bei 40-facher Vergrößerung. Hierfür wurden auf je drei Cover-Slips alle CSM14.1-Zellen mit mindesten einem sichtbaren Aggregat gezählt und der Quotient zu allen transfizierten Zellen 
errechnet. Dabei wurden nur doppelt transfizierte Zellen berücksichtigt. Eine zweite Auszählung erfolgte mit MG 132 behandelten CSM14.1-Zellen.

Bei der Co-Transfektion von GFP-Parkin mit BAG1 konnte mit Hilfe eines Student-T-Testes $(\mathrm{p}<0,01)$ ein signifikant erhöhter Anteil von CSM14.1-Zellen mit Parkin-Aggregaten im Vergleich zur alleinigen Parkin-Transfektion und Co-Transfektion mit BAG $\Delta \mathrm{C}$ nachgewiesen werden. Bei der Anwesenheit von BAG1 hatten im Mittel 47,1\% +/- 1,5\% der doppelt transfizierten Zellen ein oder mehr Parkin-Aggregate. Bei Überexpression von Parkin mit pcDNA-LV lag der Anteil durchschnittlich nur bei etwa 19,9\% ${ }^{+} /-$3,1\%. Ein annähernd ähnlicher Prozentsatz von aggregathaltigen Zellen ergab die Co-Transfektion von Parkin mit Bag $\Delta$ C. Hier ließen sich bei $21,9 \%{ }^{+} /-3 \%$ der Zellen Parkin-Aggregate nachweisen (s. Abb.

\section{$3.14 \mathrm{~A})$.}

Ein vergleichbares Bild ergab die Auszählung der mit dem Proteasom-Inhibitor MG 132 behandelten CSM14.1-Zellen. Auch hier konnte ein signifikant erhöhter Anteil Parkinaggregathaltiger Zellen bei einer Überexpression von Parkin mit BAG1 im Student-T-Test $(\mathrm{p}<0,05)$ nachgewiesen werden. Hier wiesen durchschnittlich $61,3 \%+-2,4 \%$ bzw. $64,6 \%{ }^{+} /-$ 2,6 der Zellen bei Co-Transfektion von Parkin mit pcDNA-LV bzw. BAG $\Delta \mathrm{C}$ zytoplasmatische Parkin-Aggregate auf. Dagegen konnten bei 83,4 \% ${ }^{+} /-2,8 \%$ der mit Parkin und BAG1 co-transfizierten Zellen Aggregate beobachtet werden (s. Abb. 3.14 B).

Diese Beobachtung bekräftigt die Vermutung, dass BAG1 zu einer vermehrten Aggregation von Parkin führt. Einen Einfluss von BAG $\Delta \mathrm{C}$ im Vergleich zur Negativkontrolle lässt sich jedoch nicht nachweisen.

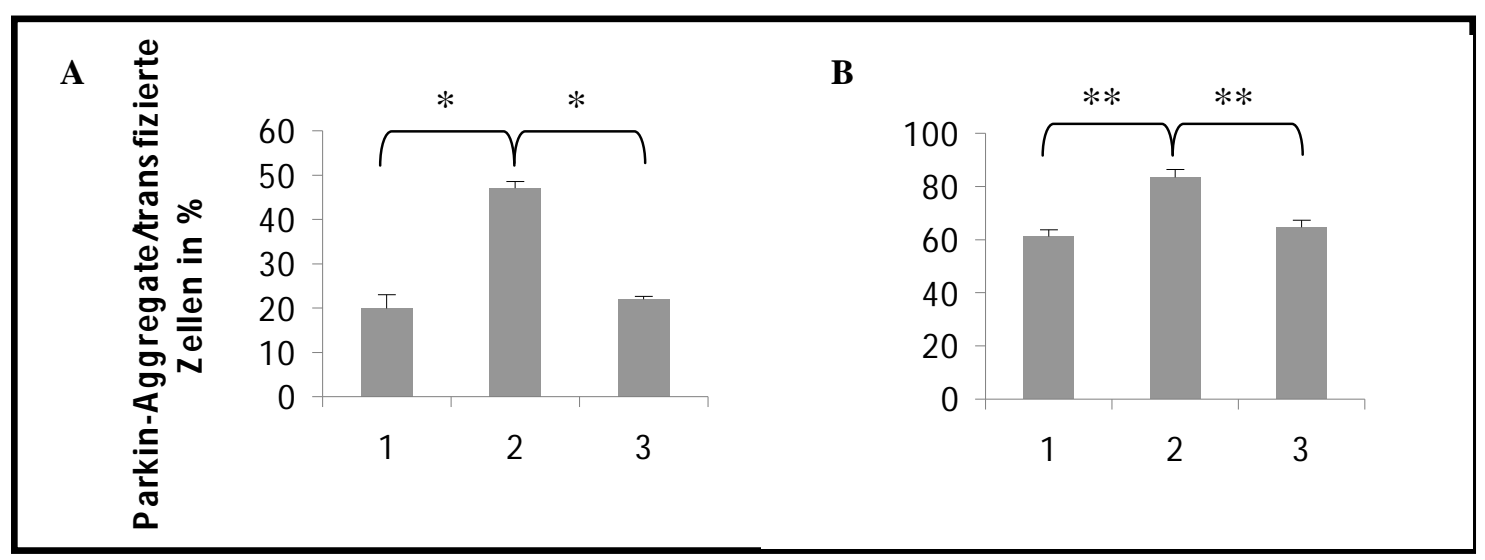

Abb. 3.14: Auszählung von Parkin-aggregathaltiger CSM14.1-Zellen in Immunozytochemie-Versuchen. Dargestellt sind die Mittelwerte zuzüglich Standardabweichung von überexprimierten CSM14.1-Zellen mit einem oder mehr Parkin-Aggregaten im Vergleich zu allen transfizierten Zellen (A). CSM14.1-Zellen wurden zusätzlich mit MG 132 für 12 Std inkubiert (B). * p<0,01; **p<0,05; 1: GFP-Parkin+pcDNA-LV, 2: GFPParkin+BAG 1, 3: GFP-Parkin+BAG $\Delta$ C. 
In weiteren Experimenten sollte darüber hinaus untersucht werden, ob Parkin BAG1-abhängig vermehrt ubiquitinyliert und hierdurch verstärkt in unlösliche Aggregate akkumuliert.

Zunächst wurden HEK293-Zellen mit Parkin, BAG1 bzw. BAG $\Delta$ C überexprimiert und für Western-Blot-Analysen sowohl mit RIPA-Puffer, als auch mit 8 M Urea-Puffer lysiert.

Anders als bei der Lyse mit RIPA-Puffer können bei einer Lyse mit Urea-Puffer auch hochmolekulare Proteinanteile und zelluläre Aggregate gelöst und so analysiert werden.

Wie schon in Kapitel 3.3.2 beschrieben, wurden auch für diesen Versuch verschiedene Ubiquitin-Antikörper getestet. Es zeigte sich ein hohes Maß an unspezifischen Bindungen, vor allem in dem zu detektierenden höhermolekularen Bereich, wodurch ein deutliches „smear"-Phänomen entstand und die Beurteilbarkeit erschwert wurde (s. Abb. 3.15). Um eine gezielte Aussage über die ubiquitinylierten Anteile des Parkin-Proteins zu treffen, wurde daher nachfolgend mit dem spezifischen Parkin-Antikörper detektiert.

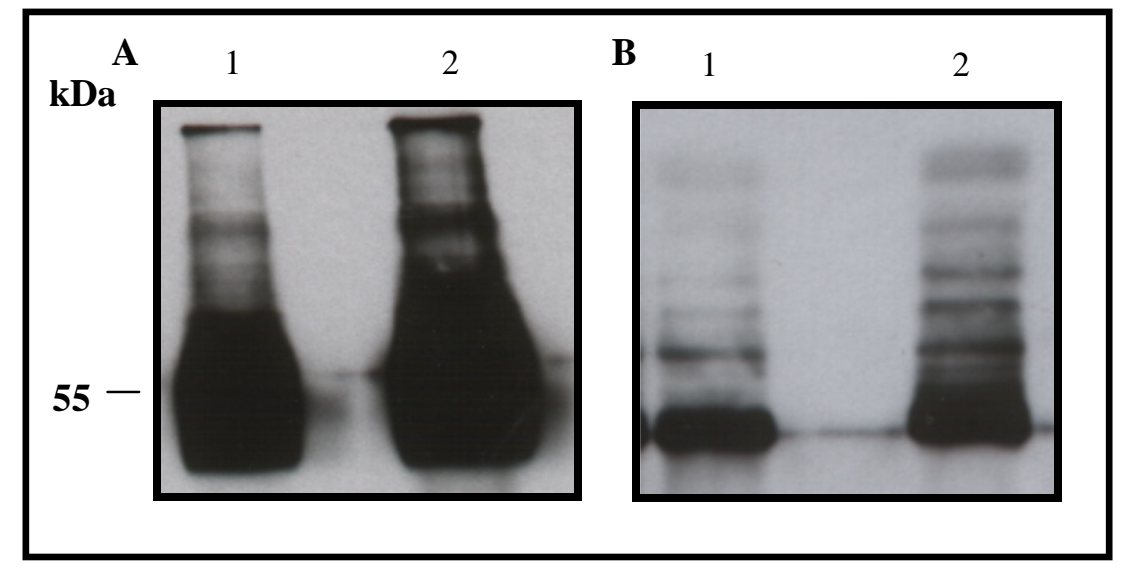

Abb. 3.15: Immunoblot zum Vergleich der höhermolekularen Parkin-Banden von Ubiquitin- und ParkinAntikörper. HEK293-Zellen wurden transient mit FLAG-Parkin und BAG1 transfiert. FLAG-Parkin wurde über Flag-tags präzipiert und im Anschluss im Western Blot über $\alpha$-Ubiquitin (A) und $\alpha$-Parkin (B) detektiert. 1: FLAG-Parkin+pcDNA-LV; 2: FLAG-Parkin+BAG1

Die Western-Blot-Analyse mit RIPA-Zelllyse zeigte eine quantitativ schwächere ParkinBande bei der Co-Transfektion von Parkin mit BAG1 im Vergleich zur alleinigen ParkinExpression bzw. Co-Expression mit BAG $\Delta \mathrm{C}$ (s. Abb. 3.16 oben). Die Beobachtung bestätigt auch die Ergebnisse der subzellulären Fraktionierung in Kap. 3.4.1. Bei der Urea-Zelllyse war dieses Verhältnis hingegen genau gegensätzlich. Hier konnte bei der gleichzeitigen Anwesenheit von BAG1 mit Parkin ein quantitativ stärkeres Signal, vorallem in dem hochmolekularen, ubiquitinylierten Bereich, beobachtet werden (s. Abb. 3.16 oben). Die CoTransfektion von Parkin mit BAG $\Delta \mathrm{C}$ verhielt sich in beiden Konditionen ähnlich der alleinigen Parkin-Überexpression (s. Abb. 3.16 oben). 
Zur Objektivierung der Aggregatauszählung wurden des Weiteren Dot-Blot-Analysen durchgeführt. Hierbei werden Proteinlysate direkt auf eine Nitrozellulosemembran aufgetragen. Größere Aggregate können somit, anders als im Western Blot, aufgetragen werden. Für den Dot Blot wurden erneut HEK293-Zellen mit Parkin, BAG1 und BAG $\Delta C$ überexprimiert. Auch hier wurde ein quantitativ stärkeres Signal bei der Co-Transfektion von Parkin und BAG1 im Vergleich zu den anderen beiden Konditionen sichtbar (s. Abb. 3.16 unten). Bei einer Inkubation der HEK293-Zellen mit dem Proteasom-Inhibitor MG 132 für 12 Std konnten die Ergebnisse noch verstärkt werden (Daten nicht gezeigt).

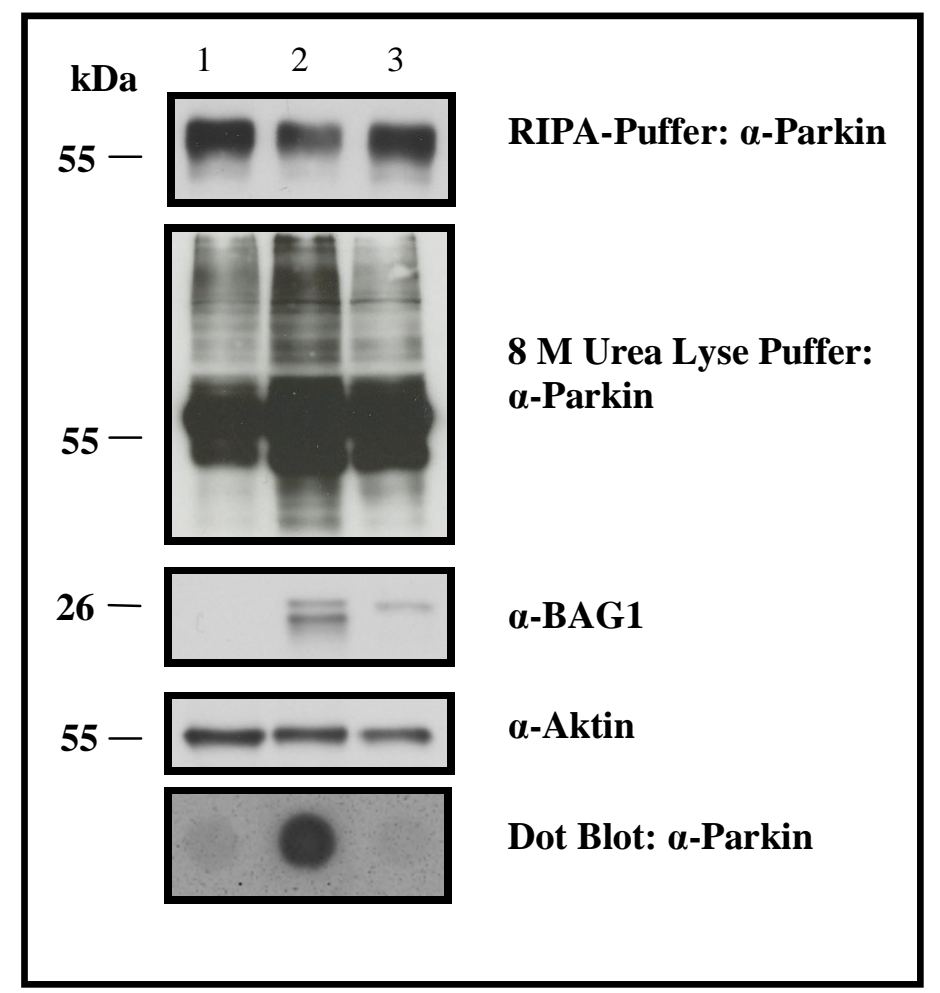

Abb. 3.16: Immunublot zur Darstellung des Aggregationsverhalten von Parkin bei verschiedenen Konditionen. HEK293-Zellen wurden mit RIPA- bzw. 8 M Urea-Puffer lysiert und mittels Western Blot (oberen vier Abbildungen) und Dot Blot (untere Abbildung) analysiert. 1: Parkin+pcDNA-LV; 2: Parkin+BAG1; 3: Parkin+BAG $\Delta$ C.

Anhand dieser Experimente konnte gezeigt werden, dass BAG1 zu einer verstärkten Ubiquitinylierung von Parkin führt. Diese Ubiquitinylierung führt zu einer verstärkten Akkumulation des Proteins und Anhäufung in zytoplasmatische Aggregate. Diese Beobachtungen lassen sich auch verstärkt bei der Inhibition des Proteasoms durch MG 132 darstellen. Die Deletionsmutante BAG $\Delta$ C verliert diesen Einfluss auf Parkin. 


\section{Diskussion}

Ziel dieser Arbeit war es, eine Interaktion zwischen Parkin und BAG1 darzustellen, die interagierende Domäne näher zu beschreiben, sowie Auswirkungen von BAG1 auf die Funktionalität der E3-Ligase und eine mögliche BAG1-vermittelte Veränderung in der Ubiquitinylierung und Löslichkeit von Parkin zu untersuchen.

Parkin spielt als Bestandteil des UPS eine entscheidende Rolle bei der Entstehung des autosomal-rezessiv vererbten MP, aber auch bei der Pathogenese des sporadischen MP gewinnt dieses Protein immer mehr an Bedeutung. BAG1 unterstützt als ein Cochaperon von Hsp70 die Re-Faltung fehlerhafter Proteine.

Über die Identifikation einer neuen Interaktion zwischen den zellulären Faltungshelfern und dem UPS sollten so Rückschlüsse über den Einfluss von BAG1 auf die Pathogenese des sporadischen MP gezogen werden.

\subsection{Identifikation von BAG1 als neuem Parkin-Interaktor}

Die Zelle hat verschiedene Möglichkeiten, mit fehlgefalteten Proteinen umzugehen. Zum einen können mutierte oder beschädigte Proteine, die sich nicht in eine korrekte Faltung überführen lassen, mit Hilfe des UPS selektiv eliminiert werden. Alternativ kommt die Entfaltung und Wiederherstellung der korrekten Proteinstruktur durch Chaperone wie Hsp70 zum Einsatz (Sherman und Goldberg 2001). Diese beiden Mechanismen sind jedoch keine unabhängigen Prozesse, sondern sind an verschiedenen Stellen verbunden. Die ATPaseUntereinheit des 26S-Proteasoms scheint neben der proteolytischen auch eine chaperonähnliche Funktion zu besitzen (Braun et al. 1999). Zudem sind die Chaperone Hsp70 und Hsp40 essentiell für die Ubiquitinylierung und schnelle Degradation von fehlerhaften Proteinen (Lee et al. 1996). Auch Cochaperone, wie die Mitglieder der BAG-Familie, wurden in etlichen Studien bereits als Bindeglieder zwischen diesen beiden Systemen beschrieben. So interagiert beispielsweise BAG5 mit Parkin und dem Cochaperon CHIP, das auch über eine E3-Ligase-Funktion verfügt (Kalia SK et al. 2004, Kalia LV et al. 2011). Auch für BAG2 konnte eine Interaktion mit CHIP nachgewiesen werden (Arndt et al. 2005). Für BAG1 sind ebenfalls Verbindungen zum UPS beschrieben. Über die UBL-Domäne bindet BAG1 direkt an das Proteasom (Alberti et al. 2002, Demand et al. 2001); auf die E3-Ligasen CHIP und Siah 1 übt BAG1 einen regulatorischen Effekt aus (Demand et al. 2001, Matsuzawa et al. 1998). Auch für das mit dem erblichen Morbus Parkinson-assoziierte Protein DJ-1 konnte 
eine Interaktion mit BAG1 beschrieben (Deeg et al. 2010) und so eine mögliche Rolle der BAG-Proteine in der Pathophysiologie des MP dokumentiert werden.

Mit der in Kapitel 3.1.1 (s. S. 40) dargestellten Interaktion zwischen der E3-Ligase Parkin und den Cochaperon BAG1 ist es gelungen, eine weitere Schnittstelle zwischen dem Chaperonund Ubiquitin-Proteasom-System zu identifizieren.

Die Bindung der beiden Proteine konnte in Co-Immunopräzipitations-Versuchen sowohl zwischen Parkin und FLAG-BAG1, als auch reziprok, d.h. über die Präzipitation von FLAGParkin und anschließender Detektion von BAG1, dargestellt werden. Unspezifische Bindungen über das FLAG-tag konnten somit weitestgehend ausgeschlossen werden.

Des Weiteren konnte mit den vorliegenden Experimenten gezeigt werden, dass auch die BAG1-Deletionsmutante BAG $\Delta \mathrm{C}$ noch die Fähigkeit besitzt, an Parkin zu binden (s. Kap. 3.1.1, S. 41). Die BAG-Domäne scheint daher nicht entscheidend für diese Interaktion zu sein, da BAG $\Delta \mathrm{C}$ in dieser Region deletiert ist.

Die bereits in Co-Immunopräzipitations-Versuchen dargestellte Interaktion konnte auch durch eine Co-Lokalisation in neuronalen CSM14.1-Zellen mittels Immunozytochemie bestätigt werden. Parkin wurde bei der Überexpression, wie bereits in der Literatur beschrieben, vor allem zytoplasmatisch dargestellt (Shimura et al. 1999, Stichel et al. 2000). BAG1 zeigte neben einer zytoplasmatischen auch eine nukleäre Lokalisation, wie bereits von Liman et al. postuliert (Liman et al. 2005). Im Zytoplasma konnte eine Co-Lokalisation von Parkin und BAG1 durch eine Überlagerung der Farbsignale bestätigt werden (s. Kap. 3.1.2, S. 42 ff). Eine Veränderung der zellulären Lokalisation der beiden Proteine bei gleichzeitiger Überexpression ließ sich nicht beobachtet.

Auch mit BAG $\Delta \mathrm{C}$ konnte die Interaktion mit Parkin durch eine zytoplasmatische CoLokalisation in CSM14.1-Zellen verifiziert werden (s. Kap. 3.1.2, S. 44). BAG $\Delta$ C verliert jedoch durch den Verlust der BAG-Domäne am C-Terminus seine Fähigkeit, sich im Nukleus anzureichern (Liman et al. 2005). 


\subsection{Beurteilung der Kartierungsexperimente zur Identifikation der interagierenden Parkin-Domäne}

Die Kartierungsexperimente dienten zur Identifizierung der mit BAG1 interagierenden Parkin-Domäne. Die dargestellten Co-Immunopräzipitations-Versuche erfolgten mit klonierten FLAG-Parkin-Deletionsmutanten und BAG1. Mit den N-terminal deletierten Mutanten, denen die UBL-, bzw. zusätzlich noch die Linker- und RING1-Domäne fehlte, konnte eine Interaktion mit BAG1 dargestellt werden. Einzig mit der kleinsten Deletionsmutante, FLAG-AIBR-Parkin, die nur noch aus der C-terminalen zweiten RINGDomäne besteht, konnte kein BAG1-Signal detektiert werden. Da jedoch bereits bei der Expression im Western Blot diese Deletionsmutante nicht darstellbar war, kann nicht automatisch darauf geschlossen werden, dass Parkin über die IBR-Domäne mit BAG1 interagiert (s. Kap. 3.2.5, S. 47 ff). Deletionsproteinen fehlt es oft an den für eine native Faltung essentiellen AS (Winkelhofer et al. 2003). Sie werden daher ebenso wie fehlgefaltete Proteine schnell über die zellulären Abbauwege degradiert. Da die FLAG- $\Delta$ IBR-Mutante stark trunkiert ist und nur noch 70 der ursprünglichen 465 Aminosäuren des Parkin-Proteins enthält, könnte daher eine fehlerhafte Faltung ursächlich für die fehlende Expression sein.

Ein weiteres Problem bei der Beurteilung dieses Experimentes stellt die Tatsache dar, dass die klonierten Parkin-Deletionsmutanten rekombinante Proteine sind, die durch eine eventuell veränderte Faltung in vitro, auch über variierte Bindungseigenschaften verfügen können (Dächsel et al. 2005).

$\mathrm{Zu}$ einer quantitativen Untersuchung der Bindungsaffinität können Co-Immunopräzipitationsversuche zudem nur bedingt herangezogen werden. Neben der Bindungsstärke könnte etwa auch eine verstärkte Aggregation der Deletionsmutanten Einfluss auf die Bandenstärke im Western Blot haben (Dächsel et al. 2005).

Eine abschließende Bewertung des Experimentes kann aufgund der oben genannten Gründe nur schwer erfolgen und eine eindeutige interagierende Parkin-Domäne konnte entgegen der Erwartung nicht identifiziert werden. Aufgrund der jeweils N-terminal deletierten Mutanten kann jedoch vermutet werden, dass die Bindungsstelle von BAG1 im Bereich des C-Terminus $\mathrm{zu}$ finden ist. 


\subsection{BAG1 inhibiert die E3-Ligase-Funktion von Parkin}

Ein regulatorischer Einfluss von BAG-Proteinen auf E3-Ligasen konnte bereits in zahlreichen Studien dargestellt werden. Für BAG5, BAG2 und auch BAG1 wurden bereits inhibierende Effekte auf die Aktivität von verschiedenen E3-Ligasen wie Parkin und CHIP bzw. Siah 1 beschrieben (Arndt et al. 2005, Chung und Dawson 2004, Kalia SK et al. 2004, Kalia LV et al. 2011, Matsuzawa et al. 1998). BAG3 scheint zudem die proteasomale Degradation von Hsp70 abhängigen Proteinen zu hemmen (Doong et al. 2003). Eine andere Studie zeigte, dass BAG1 den CHIP-vermittelten Abbau des Glukokortikoid-Rezeptors, einem Substrat von CHIP stimuliert (Demand et al. 2001). Erst kürzlich konnte auch gezeigt werden, dass das Verhältnis von BAG1 und BAG3 entscheidend für eine Inhibition der proteasomalen Degradation ist und zu einer Verschiebung hin zu anderen Abbauwegen führt (Gamerdinger et al. 2009). Folglich scheinen Cochaperone, die eine BAG-Domäne besitzen, häufige Modulatoren von E3-Ligasen zu sein.

Über Co-Immunopräzipitations- und Cycloheximid-Versuche konnte mit dem Substratprotein CDCrel-1 dargestellt werden, dass BAG1, ähnlich wie BAG5, einen inhibierenden Effekt auf die Aktivität von Parkin hat. Bei Anwesenheit von BAG1 konnte eine verminderte Parkinvermittelte Ubiquitinylierung und Abbaurate von CDCrel-1 dargestellt werden, was ebenso für BAG $\Delta$ C gilt (s. Kap. 3.3.1 und 3.3.2, S. 49 ff).

Der genaue Mechanismus, über den BAG1 die E3-Ligase-Funktion von Parkin inhibiert, muss noch geklärt werden. Aufgrund der Ergebnisse kann jedoch davon ausgegangen werden, dass eine intakte BAG-Domäne nicht erforderlich ist, da auch BAG $\Delta \mathrm{C}$ den regulatorischen Effekt auf die E3-Ligase-Funktion ausübt.

Eine mögliche Erklärung für den hemmenden Einfluss postulierten bereits Kalia et al. in ihrer Studie (Kalia SK et al. 2004). Zum einen könnte BAG1 über die Bindung sowie Blockierung der RING-Domäne am C-Terminus die Interaktion zwischen Parkin und den E2-Ligasen stören. Zum anderen könnte auch eine Konformationsänderung des Parkinproteins nach Bindung von BAG1 in einer Inhibition der E3-Ligase-Funktion resultieren (Kalia SK et al. 2004).

Mit dem Protein BAG1 konnte somit ein neuer negativer Regulator der E3-Ligase Parkin identifiziert werden.

Aufgrund der vielfältigen Interaktionen zwischen E3-Ligasen, wie Parkin oder Siah 1 (Matsuzawa et al. 1998) und des regulatorischen Einflusses auf das Chaperon Hsp70 (Liman et al. 2005, Nollen et al. 2001), kann BAG1 möglicherweise als eine Art Vermittlerprotein zwischen dem UPS und dem Chaperonsystem fungieren. 


\subsection{BAG1 führt zu einer verstärkten Ubiquitinylierung und Akkumulation von Parkin}

Die Bedeutung der Proteinaggregation hinsichtlich einer Neurotoxizität oder -protektion, sowie die Rolle bei der Entstehung und Progression von neurodegenerativen Erkrankungen wird bis heute sehr kontovers diskutiert (Haapasalo et al. 2011, Kalia SK et al. 2004, Sherman und Goldberg 2001, Winner et al. 2011).

Obwohl nur bei wenigen Patienten mit Parkinmutation-assoziierten MP (Davie 2008) Lewy Körper gefunden wurden, konnten zahlreiche Studien eine Aggregation von Parkin in Parkinson-Modellen in vitro zeigen. Eine Ubiquitinylierung von Proteinen scheint daher essentiell für ihre Aggregation zu sein (Ciechanover und Brundin 2003, Junn et al. 2002). Bei etlichen familiären Parkin-Missense-Mutationen konnte zudem eine erhöhte Tendenz zur Aggregatbildung demonstriert werden (Hampe et al. 2006, Henn 2007). Auch eine verstärkte Autoubiquitinylierung dieser Mutanten wurde beobachtet (Sriram et al. 2005). Einige Arbeitsgruppen zeigten zudem, dass Parkin und auch seine Substrate bei proteasomaler Inhibition zu sogenannten Aggresomen akkumulieren (Ardley et al. 2004, Chin et al. 2010, Junn et al. 2002, Um et al. 2010). Aggresomen sind singuläre zytoplasmatische Einschlusskörperchen, die durch eine Akkumulation von Proteinen entlang der Mikrotubuli zum Mikrotubuli-organsierenden Zentrum entstehen (Haapasalo et al. 2011). In ihrer Morphologie ähneln sie den bei Parkinson Patienten gefundenen Lewy Körpern (Junn et al. 2002). Charakteristisch für die Aggresomen sind neben polyubiquitinylierten Proteinen auch Bestandteile des UPS. Aggresomen sind zudem durch einen „Tubulin-Käfig“ vom Rest der Zelle abgeschottet (Ardley et al. 2004). Die Bildung von Aggresomen scheint eine zytoprotektive Antwort zu sein, um mutierte Proteine unschädlich zu machen und abnorme und unspezifische Proteininteraktionen zu verhindern (Haapasalo et al. 2011). Neben einer verminderten proteasomalen Aktivität, etwa durch eine Behandlung mit dem Proteasominhibitor MG 132, können auch einige Proteine die Löslichkeit von Parkin beeinträchtigen. PINK1, ein mit dem erblichem MP assoziiertes Protein, vermindert die Löslichkeit von Parkin (Um et al. 2009). Das Chaperon Hsp70 erhöht dagegen die Löslichkeit von Parkin sowie seiner Mutanten und kann so eine Aggregation vermindern (Rose et al. 2011, Winklhofer et al. 2003). Bei Überexpression von Hsp70 oder auch Hsp40 konnte ein verminderter Anteil von mutierten Proteinen sowie ein verbessertes Zellüberleben in Parkinson-Modellen beschrieben werden (McLean et al. 2004).

Auch über einen Cofaktor von Hsp70 konnte der Einfluss der Chaperone auf die ParkinLöslichkeit weiter verifiziert werden. So verstärkt BAG5 die Akkumulation von Parkin in 
zelluläre Lewy Körper-ähnliche Aggregate, vermutlich über eine Inhibition der Hsp70Aktivität (Kalia SK et al. 2004).

In der vorliegenden Arbeit konnte erstmals BAG1 als Modulator für die Löslichkeit von Parkin mit Hilfe von Western und Dot Blot Analysen sowie Immunozytochemie-Versuchen identifiziert werden. Bereits in den zur Darstellung der Proteininteraktion durchgeführten Versuchen konnten in einigen transfizierten CSM14.1-Zellen zytoplasmatische Aggregate beobachtet werden. In der Literatur wurde bereits beschrieben, dass Parkin bei Überexpression und vor allem bei einer proteasomalen Inhibition zur Bildung von Aggregaten neigt (Junn et al. 2002, Ardley et al. 2004). Diese Beobachtung konnte sowohl bei einer alleinigen Parkin-Überexpression, als auch bei Co-Expression mit BAG1 bzw. BAG $\Delta \mathrm{C}$ bestätigt werden (s. Kap. 3.4.2, S. 55 ff). Bei einer Behandlung der Zellen mit dem Proteasominhibitor MG 132 wurden in allen Konditionen verstärkt perinukleäre, Aggresomen-ähnliche Aggregate beobachtet. Die Anwesenheit von BAG1 verstärkte die Parkin-Akkumulation jedoch signifikant. Die von Ardley et al. beschriebene „Abschottung“ der Aggregate durch einen „Tubulinkäfig“ konnte ebenfalls dargestellt werden (Ardley et al. 2004) (s. Abb. 3.13, S. 55).

Neben der vermehrten Akkumulation führt BAG1 auch zu einer verstärkten Ubiquitinylierung von Parkin. Dies bekräftigt die Hypothese, dass die Aggregation an die Ubiquitinylierung des Proteins gekoppelt ist (Ciechanover und Brundin 2003, Junn et al. 2002).

Die oben genannten Ergebnisse sind vor allem interessant für die Frühphase des MP, da die proteasomale Aktivität sich mit den Alter verringert (Goto et al. 2001) und auch bei Parkinson Patienten deutlich vermindert ist (McNaught et al. 2003).

Interessanterweise war jedoch dieser Einfluss auf die Löslichkeit und Ubiquitinylierung von Parkin für BAG $\Delta \mathrm{C}$ nicht darstellbar. Es wurde daher vermutet, dass BAG1, ähnlich wie BAG5, diesen Effekt über eine Interaktion mit Hsp70 ausübt (Kalia SK et al. 2004). BAG $\Delta C$ verliert durch die C-terminale Deletionsmutation die Fähigkeit an das Chaperon zu binden (Liman et al. 2005). Auch eine Bindung von Hsp70 selbst an Parkin konnte bereits beschrieben werden (Imai et al. 2002, Winklhofer et al. 2003). Möglich wäre daher auch eine Komplexbildung von Parkin und Hsp70 zusammen mit BAG1.

Wie bereits in zahlreichen Studien beschrieben, agiert BAG1 als Cochaperon von Hsp70 und fördert die Re-Faltung fehlgefalteter Proteine (Gassler et al. 2001, Liman et al. 2005, Takayama et al. 1997). Auf der anderen Seite konnten einige Arbeitsgruppen einen inhibierenden Effekt von BAG1 auf die Hsp70-Aktivität darstellen (Bimston et al. 1998, Nollen et al. 2001). Da BAG1 nur eines der Cochaperone von Hsp70 ist, kann der Effekt auf 
die Funktionalität aus einem komplexen Miteinander der verschiedenen Faktoren und der jeweiligen zellulären Situation resultieren. Alternativ könnte BAG1 als eine Art Vermittlermolekül fungieren, das Proteine entweder den zellulären Faltungshelfern oder den Abbau über das Proteasom zuführt.

Es bleibt zudem zu klären, ob die Rekrutierung von Parkin in Aggresomen einen aktiven Prozess der Zelle darstellt, um ubiquitinylierte fehlgefaltete Proteine effektiver abbauen zu können, oder ob Parkin passiv mit anderen ubiquitinylierten Proteinen akkumuliert und so die Funktionalität vermindert wird (Jiang Q et al. 2008). Einige Beobachtungen bekräftigen, dass die Funktionalitätsverminderung zu überwiegen scheint. Die Bedeutung einer Verminderung des Parkingehalts für die Parkinson-Erkrankung konnte schon in einigen Studien verdeutlicht werden. Eine S-Nitrosylations-vermittelte erniedrigte Parkin-Konzentration wurde vor wenigen Jahren als potentielle Verbindung zwischen dem sporadischen und erblichen MP entdeckt (Chung et al. 2004). Auch kann eine Verminderung von Parkin über die Störung des zellulären Gleichgewichtes zu einer Inhibition des Proteasoms führen (Bence et al. 2001, Petrucelli et al. 2002). Die Akkumulation des Parkin-Substrates Synphilin kann bespielsweise direkt in einer Beeinträchtigung des Proteasoms münden (Kalia SK et al. 2004) und eine Verminderung der Parkin-Expression erhöht die Zelltodrate (Petrucelli et al. 2002, Yang Y et al. 2003). Eine leichte Überexpression von Parkin scheint dagegen die mit einer Dysfunktion des UPS verbundenen Neurodegeneration zu verringern (Petrucelli et al. 2002). Möglich wäre jedoch auch, dass die Aggregation und Inhibition von Parkin Hand in Hand gehen.

Zusammenfassend wurde mit BAG1 nicht nur ein möglicher negativer Modulator der E3Ligase Parkin identifiziert, sondern auch ein Protein, das über die verminderte Löslichkeit von Parkin auch eine Rolle bei der Entstehung und Progression des sporadischen MP spielen kann. 


\subsection{Ausblick}

In der vorliegenden Arbeit konnte BAG1 erstmals als Interaktor und Inhibitor der E3-Ligase Parkin identifiziert werden. Sowohl eine verstärkte Ubiquitinylierung als auch verminderte Löslichkeit von Parkin konnten bei Anwesenheit von BAG1 beschrieben werden.

In weiteren Experimenten soll nun untersucht werden, welche Auswirkungen diese Effekte auf das Überleben von dopaminergen Neuronen haben und ob BAG1 einen Einfluss auf den bei MP typischen Zelluntergang hat. Für das BAG5-Protein konnte bereits eine erhöhte Zelltodrate von dopaminergen Neuronen in vivo beschrieben werden (Kalia SK et al. 2004). Auch bleibt weiterhin zu untersuchen, welche Rolle das Chaperon Hsp70 bei der hier beobachteten BAG1-vermittelte Ubiquitinylierung und Akkumulation von Parkin spielt. Des Weiteren soll der Einfluss von BAG1 auf die Funktion und die Löslichkeit von einigen familiären Parkin-Punktmutationen dargestellt werden, um $\mathrm{zu}$ untersuchen, welche Rolle BAG1 beim erblichen MP spielt.

In Anbetracht des Einflusses von BAG1 auf die Ubiquitinylierung und Proteinaggregation könnte BAG1 in Zukunft als möglicher pharmakologischer Angriffspunkt bei der Behandlung von neurodegenerativen Erkrankungen, wie MP dienen.

Mit Geldanamycin, einem Antibiotikum, das recht spezifisch Hsp70 induziert und somit vor einer Proteinaggregation in einem Fliegen-Modell der Parkinson-Erkrankung schützt, wurde bereits ein möglicher pharmakologischer Angriffspunkt für eine neuroprotektive Therapie beim MP gefunden (McLean et al. 2004). Auch weitere Substanzen, die in das ChaperonSystem eingreifen, werden bereits in präklinischen Studien getestet (Kalia SK et al. 2010). 


\section{Zusammenfassung}

\subsection{Deutsch}

Parkin spielt als E3-Ligase eine entscheidende Rolle für die Entstehung des autosomalrezessiv vererbten Morbus Parkinson (MP). Eine Verminderung der Parkin-Aktivität kann auch zum Zelluntergang der dopaminergen Neurone beim sporadischen MP beitragen. Bcl-2associated athanogene 1 (BAG1), ein Mitglied der BAG-Familie, wirkt als Cochaperon modulierend auf Hsp70 ein und stellt ein wichtiges Bindeglied zwischen den zellulären Faltungshelfern und dem Ubiquitin-Proteasom-System dar. In der vorliegenden Arbeit konnte mit Hilfe von Co-Immunopräzipitations- und Immunozytochemie-Versuchen gezeigt werden, dass BAG1 mit Parkin interagiert. Zudem wurde dargestellt, dass BAG $\Delta \mathrm{C}$, eine Deletionsmutante von BAG1, die zum Verlust der BAG-Domäne führt, immer noch die Fähigkeit besitzt, mit Parkin zu interagieren. Eine eindeutige wechselwirkende ParkinDomäne konnte jedoch in Co-Immunopräzipitations-Versuchen nicht verifiziert werden. Mit Hilfe von Western-Blot-Analysen konnte ein inhibierender Effekt von BAG1 auf die E3Ligase-Funktion von Parkin aufgezeigt werden. BAG1 führte sowohl zu einer verminderten Parkin-vermittelten Abbaurate als auch Ubiquitinylierung des Substratproteins CDCrel-1. Auch für BAG $\Delta \mathrm{C}$ ließ sich dieser Effekt auf die Parkin-Aktivität nachweisen.

Schließlich konnte in Western- und Dot-Bot-Analysen sowie in ImmunozytochemieVersuchen gezeigt werden, dass BAG1 zu einer verstärkten Ubiquitinylierung und Akkumulation von Parkin in zelluläre Aggregate führt. BAG $\Delta \mathrm{C}$ hingegen verliert diesen Einfluss auf die Ubiquitinylierung und Löslichkeit von Parkin. Daher wurde vermutet, dass das Chaperon Hsp70, an der verminderten Löslichkeit von Parkin beteiligt ist. BAG $\Delta \mathrm{C}$ verliert durch die Deletion in der BAG-Domäne die Fähigkeit, mit Hsp70 zu interagieren. Zusammenfassend konnten wir in dieser Arbeit mit der Interaktion von Parkin und BAG1 eine neue wichtige Verbindung zwischen dem Chaperon- und Ubiquitin-Proteasomsystem darstellen. Diese Ergebnisse bestätigen Beobachtungen, die bereits mit BAG5 und BAG2 erzielt wurden (Arndt et al. 2005, Kalia SK et al. 2004). Wir vermuten daher, dass BAG1 durch die Inhibition von Parkin und die Akkumulation in zelluläre Aggregate eine Rolle bei der Entstehung und Progression des sporadischen MP spielt. 


\subsection{Englisch}

Through its function as an E3 ubiquitin ligase Parkin plays an important role for the development of early-onset Parkinson's disease (PD). Decreased Parkin activity may also contribute to the neurodegeneration of dopaminerg neurons in sporadic forms of PD. As a member of the BAG family Bcl-2-associated athanogen 1 (BAG1) modulates the activity of the chaperon Hsp70 and is an important link between the chaperon and the ubiquitin proteasom system.

In this study, we show via co-immunoprecipitation and immunocytochemistry experiments that BAG1 interacts with Parkin. Futhermore, we demonstrate that BAG $\Delta$ C, a BAG1 deletion mutant that misses the BAG domain at the C-terminus, still has the ability to interact with the E3 ligase Parkin. A definite Parkin binding domain could not be verified.

In Western Blot analyses we illustrate an inhibitory effect of BAG1 on the E3 ligase function of Parkin. BAG1 not only leads to decreased levels of the Parkin mediated degradation rate but also to a lower ubiquitinylation of the substrate protein CDCrel-1.

Even for BAG $\Delta \mathrm{C}$ this effect on E3 ligase function could be detected.

Finally, we show that BAG1 leads to an increased level of ubiquitylated Parkin and enhances the accumulation of Parkin into protein aggregates. Interestingly, BAG $\Delta \mathrm{C}$ lacks this effect. Hence, we hypothesize that the chaperon Hsp70 may be involved in Parkin accumulation due to the inability of BAG $\Delta \mathrm{C}$ to interact with Hsp70.

In this study, we could demonstrate a new protein interaction between Parkin and BAG1 representing an important link between the chaperon and the ubiquitin-proteasom system. This observation validates results that have already been established with BAG5 and BAG2 (Arndt et al. 2005, Kalia SK et al. 2004). Presumably, BAG1 may be involved in pathogenesis and progression of sporadic forms of PD through the inhibition of Parkin and its accumulation into cellular aggregates. 


\section{Literaturverzeichnis}

Abbas N, Lücking CB, Ricard S, Dürr A, Bonifati V, De Michele G, Bouley S, Vaughan JR, Gasser T, Marconi R, et al. (1999): A wide variety of mutations in the parkin gene are responsible for autosomal recessive parkinsonism in Europe. French Parkinson's Disease Genetics Study Group and the European Consortium on Genetic Susceptibility in Parkinson's Disease. Hum Mol Genet, $\underline{8}, 567-574$

Alberti S, Demand J, Esser C, Emmerich N, Schild H, Hohfeld J (2002): Ubiquitylation of BAG-1 suggests a novel regulatory mechanism during the sorting of chaperone substrates to the proteasome. J Biol Chem, 277, 45920-45927

Alberti S, Esser C, Höhfeld J (2003): BAG-1-a nucleotide exchange factor of Hsc70 with multiple cellular functions. Cell Stress Chaperones, $\underline{8}, 225-231$

Ardley HC, Scott GB, Rose SA, Tan NG, Robinson PA (2004): UCH-L1 aggresome formation in response to proteasome impairment indicates a role in inclusion formation in Parkinson's disease. J Neurochem, $\underline{\text { 90, 379-391 }}$

Arndt V, Daniel C, Nastainczyk W, Alberti S, Höhfeld J (2005): BAG-2 acts as an inhibitor of the chaperone-associated ubiquitin ligase CHIP. Mol Biol Cell, $\underline{16}$, 5891-5900

Bardelli A, Longati P, Albero D, Goruppi S, Schneider C, Ponzetto C, Comoglio PM (1996): HGF receptor associates with the anti-apoptotic protein BAG-1 and prevents cell death. EMBO J, 15, 6205-6212

Baumeister W, Walz J, Zühl F, Seemüller E (1998): The proteasome: paradigm of a selfcompartmentalizing protease. Cell, $\underline{92}, 367-380$

Bence NF, Sampat RM, Kopito RR (2001): Impairment of the ubiquitin-proteasome system by protein aggregation. Science, $\underline{292}, 1552-1555$

Betarbet R, Sherer TB, Greenamyre JT (2005): Ubiquitin-proteasome system and Parkinson's diseases. Exp Neurol, 191, 17-27

Biasini E, Fioriti L, Ceglia I, Invernizzi R, Bertoli A, Chiesa R, Forloni G (2004): Proteasome inhibition and aggregation in Parkinson's disease:a comparative study in untransfected and transfected cells. J Neurochem, $\underline{88}, 545-553$

Biedler JL, Helson L, Spengler BA (1973): Morphology and growth, tumorigenicity, and cytogenetics of human neuroblastoma cells in continuous culture. Cancer Res, 33, 2643-2652

Bimston D, Song J, Winchester D, Takayama S, Reed JC, Morimoto RI (1998): BAG-1, a negative regulator of Hsp70 chaperone activity, uncouples nucleotide hydrolysis from substrate release. EMBO J, 17, 6871-6878

Bosboom JL, Stoffers D, Wolters ECh (2004): Cognitive dysfunction and dementia in Parkinson's disease. J Neural Transm, $\underline{111}$, 1303-1315

Braun BC, Glickman M, Kraft R, Dahlmann B, Kloetzel PM, Finley D, Schmidt M (1999): The base of the proteasome regulatory particle exhibits chaperone-like activity. Nat Cell Biol, 1, 221-226 
Burns RS, Chiueh CC, Markey SP, Ebert MH, Jacobowitz DM, Kopin IJ (1983): A primate model of parkinsonism: selective destruction of dopaminergic neurons in the pars compacta of the substantia nigra by N-methyl-4-phenyl-1,2,3,6-tetrahydropyridine. Proc Natl Acad Sci USA, $\underline{80}$, $4546-4550$

Cesari R, Martin ES, Calin GA, Pentimalli F, Bichi R, McAdams H, Trapasso F, Drusco A, Shimizu $\mathrm{M}$ et al. (2003): Parkin, a gene implicated in autosomal recessive juvenile parkinsonism, is a candidate tumor suppressor gene on chromosome 6q25-q27. Proc Natl Acad Sci USA, 100, 5956-5961

Chaudhuri KR, Healy DG, Schapira AH (2006): Non-motor symptoms of Parkinson's disease: diagnosis and management. Lancet Neurol, $\underline{5}, 235-245$

Cheon SM, Park MJ, Kim WJ, Kim JW (2009): Non-motor off symptoms in Parkinson's disease. J Korean Med Sci, 24, 311-314

Chin LS, Olzmann JA, Li L (2010): Parkin-mediated ubiquitin signalling in aggresome formation and autophagy. Biochem Soc Trans, $\underline{38}, 144-149$

Choi P, Snyder H, Petrucelli L, Theisler C, Chong M, Zhang Y, Lim K, Chung KK, Kehoe K, D'Adamio L, et al. (2003): SEPT5_v2 is a parkin-binding protein. Brain Res Mol Brain Res, $\underline{117}, 179-189$

Chung KK, Dawson TM (2004): Parkin and Hsp70 sacked by BAG5. Neuron, 44, 899-901

Chung KK, Zhang Y, Lim KL, Tanaka Y, Huang H, Gao J, Ross CA, Dawson VL, Dawson TM (2001): Parkin ubiquitinates the alpha-synuclein-interacting protein, synphilin-1: implications for Lewy-body formation in Parkinson disease. Nat Med, $\underline{7}, 1144-1150$

Chung KK, Thomas B, Li X, Pletnikova O, Troncoso JC, Marsh L, Dawson VL, Dawson TM (2004): S-nitrosylation of parkin regulates ubiquitination and compromises parkin's protective function. Science, $\underline{304}$, 1328-1331

Ciechanover A, Brundin P (2003): The ubiquitin proteasome system in neurodegenerative diseases: sometimes the chicken, sometimes the egg. Neuron, $\underline{40}, 427-446$

Corti O, Hampe C, Koutnikova H, Darios F, Jacquier S, Prigent A, Robinson JC, Pradier L, Ruberg M, Mirande M, et al. (2003): The p38 subunit of the aminoacyl-tRNA synthetase complex is a Parkin substrate: linking protein biosynthesis and neurodegeneration. Hum Mol Genet, $\underline{12}$, $1427-1437$

Dächsel JC, Lücking CB, Deeg S, Schultz E, Lalowski M, Casademunt E, Corti O, Hampe C, Patenge N, Vaupel K et al. (2005): Parkin interacts with the proteasome subunit alpha4. FEBS Lett, $\underline{579}$, 3913-3919

Damier P, Hirsch EC, Agid Y, Graybiel AM (1999): The substantia nigra of the human brain. II. Patterns of loss of dopamine-containing neurons in Parkinson's disease. Brain, 122, 1437-1448

Dauer W, Przedborski S (2003): Parkinson's disease: mechanisms and models. Neuron, $\underline{39}, 889-909$

Davie CA (2008): A review of Parkinson's disease. Br Med Bull, $\underline{86}, 109-127$ 
Davis GC, Williams AC, Markey SP, Ebert MH, Caine ED, Reichert CM, Kopin IJ (1979): Chronic Parkinsonism secondary to intravenous injection of meperidine analogues. Psychiatry Res, 1 , 249-254

Deeg S, Gralle M, Sroka K, Bähr M, Wouters FS, Kermer P (2010): BAG1 restores formation of functional DJ-1 L166P dimers and DJ-1 chaperone activity. J Cell Biol, $188,505-513$

Demand J, Alberti S, Patterson C, Höhfeld J (2001): Cooperation of a ubiquitin domain protein and an E3 ubiquitin ligase during chaperone/proteasome coupling. Curr Biol, 11, 1569-1577

Doong H, Vrailas A, Kohn EC (2002): What's in the 'BAG'? - a functional domain analysis of the BAG-family proteins. Cancer Lett, $\underline{188}, 25-32$

Doong H, Rizzo K, Fang S, Kulpa V, Weissman AM, Kohn EC (2003): CAIR-1/BAG-3 abrogates heat shock protein-70 chaperone complex-mediated protein degradation: accumulation of polyubiquitinated Hsp90 client proteins. J Biol Chem, 278, 28490-28500

Durand MM, Chugani DC, Mahmoudi M, Phelps ME (1990): Characterization of neuron- like cell line immortalized from primary rat mesencephalon cultures. Soc Neurosci Abstr, 16, 40

Dusonchet J, Bensadoun JC, Schneider BL, Aebischer P (2009): Targeted overexpression of the parkin substrate Pael-R in the nigrostriatal system of adult rats to model Parkinson's disease. Neurobiol Dis, $\underline{35}, 32-41$

Elliott E, Tsvetkov P, Ginzburg I (2007): BAG-1 associates with Hsc70.Tau complex and regulates the proteasomal degradation of Tau protein. J Biol Chem, 282, 37276-37284

Elliott E, Laufer O, Ginzburg I (2009): BAG-1M is up-regulated in hippocampus of Alzheimer's disease patients and associates with tau and APP proteins. J Neurochem, 109, 1168-1178

Exner N, Treske B, Paquet D, Holmström K, Schiesling C, Gispert S, Carballo-Carbajal I, Berg D, Hoepken HH (2007): Loss-of-function of human PINK1 results in mitochondrial pathology and can be rescued by parkin. J Neurosci, 27, 12413-12418

Fallon L, Moreau F, Croft BG, Labib N, Gu WJ, Fon EA (2002): Parkin and CASK/LIN-2 associate via a PDZ-mediated interaction and are co-localized in lipid rafts and postsynaptic densities in brain. J Biol Chem, 277, 486-491

Froesch BA, Takayama S, Reed JC (1998): BAG-1L protein enhances androgen receptor function. J Biol Chem, 273, 11660-11666

Gamerdinger M, Hajieva P, Kaya AM, Wolfrum U, Hartl FU, Behl C (2009): Protein quality control during aging involves recruitment of the macroautophagy pathway by BAG3. EMBO J, 28, 889901

Gandhi S, Muqit MM, Stanyer L, Healy DG, Abou-Sleiman PM, Hargreaves I, Heales S, Ganguly M, Parsons L, Lees AJ, et al. (2006): PINK1 protein in normal human brain and Parkinson's disease. Brain, $\underline{129}, 1720-1731$

Gassler CS, Wiederkehr T, Brehmer D, Bukau B, Mayer MP (2001): Bag-1M accelerates nucleotide release for human $\mathrm{Hsc70}$ and $\mathrm{Hsp} 70$ and can act concentration-dependent as positive and negative cofactor. J Biol Chem, 276, 32538-32544 
Giasson BI and Lee VM( 2001): Parkin and the Molecular Pathways of Parkinson's Disease. Neuron, $\underline{31,885-888}$

Glickman MH, Rubin DM, Coux O, Wefes I, Pfeifer G, Cjeka Z, Baumeister W, Fried VA, Finley D (1998): A subcomplex of the proteasome regulatory particle required for ubiquitin-conjugate degradation and related to the COP9-signalosome and eIF3. Cell, $\underline{94}, 615-623$

Goto S, Takahashi R, Kumiyama AA, Radák Z, Hayashi T, Takenouchi M, Abe R (2001): Implications of protein degradation in aging. Ann N Y Acad Sci, 928, 54-64

Graham FL, Smiley J, Russell WC, Nairn R (1977): Characteristics of a Human Cell Line Transformed by DNA from Human Adenovirus Type 5. J Gen Virol, $\underline{36}$, 59-74

Greenamyre JT, Sherer TB, Betarbet R, Panov AV (2001): Complex I and Parkinson's disease. IUBMB Life, $\underline{52}, 135-141$

Haapasalo A, Viswanathan J, Kurkinen KM, Bertram L, Soininen H, Dantuma NP, Tanzi RE, Hiltunen M (2011): Involvement of ubiquilin-1 transcript variants in protein degradation and accumulation. Commun Integr Biol, $\underline{4}, 428-432$

Hald A, Lotharius J (2005): Oxidative stress and inflammation in Parkinson's disease: is there a causal link? Exp Neurol, 193, 279-290

Hampe C, Ardila-Osorio H, Fournier M, Brice A, Corti O (2006): Biochemical analysis of Parkinson's disease-causing variants of Parkin, an E3 ubiquitin-protein ligase with monoubiquitylation capacity. Hum Mol Genet, $\underline{15}$, 2059-2075

Hancock DB, Martin ER, Mayhew GM, Stajich JM, Jewett R, Stacy MA, Scott BL, Vance JM, Scott WK (2008): Pesticide exposure and risk of Parkinson's disease: a family-based case-control study. BMC Neurol, $\underline{8}, 6$

Henn IH: Die Rolle von Parkin bei der Parkinson-Erkrankung: Physiologische Funktion und Mechanismen der Inaktivierung. Pharm. Diss. München 2007

Hernán MA, Takkouche B, Caamaño-Isorna F, Gestal-Otero JJ (2002): A meta-analysis of coffee drinking, cigarette smoking, and the risk of Parkinson's disease. Ann Neurol, $\underline{52}, 276-284$

Herrera AJ, Tomás-Camardiel M, Venero JL, Cano J, Machado A (2005): Inflammatory process as a determinant factor for the degeneration of substantia nigra dopaminergic neurons. J Neural Transm, 112, 111-119

Hicke L (1999): Gettin' down with ubiquitin: turning off cell-surface receptors, transporters and channels. Trends Cell Biol, $\underline{9}, 107-112$

Hicke L (2001): Protein regulation by monoubiquitin. Nat Rev Mol Cell Biol, 2 , 195-201

Hochstrasser M (1996): Ubiquitin-dependent protein degradation. Annu Rev Genet, $\underline{30}$, 405-439

Horowitz JM, Myers J, Stachowiak MK, Torres G (1999): Identification and distribution of Parkin in rat brain. Neuroreport, 10, 3393-3397

Hristova VA, Beasley SA, Rylett RJ, Shaw GS (2009): Identification of a novel Zn2+-binding domain in the autosomal recessive juvenile Parkinson-related E3 ligase parkin. J Biol Chem, 284, $14978-14986$ 
Huynh DP, Scoles DR, Ho TH, Del Bigio MR, Pulst SM (2000): Parkin is associated with actin filaments in neuronal and nonneural cells. Ann Neurol, $\underline{48}, 737-744$

Huynh DP, Scoles DR, Nguyen D, Pulst SM (2003): The autosomal recessive juvenile Parkinson disease gene product, parkin, interacts with and ubiquitinates synaptotagmin XI. Hum Mol Genet, $\underline{12}$, 2587-2597

Huynh DP, Nguyen DT, Pulst-Korenberg JB, Brice A, Pulst SM (2007): Parkin is an E3 ubiquitinligase for normal and mutant ataxin-2 and prevents ataxin-2-induced cell death. Exp Neurol, $\underline{203}, 531-541$

Imai Y, Soda M, Takahashi R (2000): Parkin suppresses unfolded protein stress-induced cell death through its E3 ubiquitin-protein ligase activity. J Biol Chem, 275, 35661-35664

Imai Y, Soda M, Inoue H, Hattori N, Mizuno Y, Takahashi R (2001): An unfolded putative transmembrane polypeptide, which can lead to endoplasmic reticulum stress, is a substrate of Parkin. Cell, $\underline{105}, 891-902$

Imai Y, Soda M, Hatakeyama S, Akagi T, Hashikawa T, Nakayama KI, Takahashi R (2002): CHIP is associated with Parkin, a gene responsible for familial Parkinson's disease, and enhances its ubiquitin ligase activity. Mol Cell, $\underline{10}, 55-67$

Ishikawa A, Tsuji S (1996): Clinical analysis of 17 patients in 12 Japanese families with autosomalrecessive type juvenile parkinsonism. Neurology, $\underline{47}, 160-166$

Jiang H, Jiang Q, Feng J (2004): Parkin increases dopamine uptake by enhancing the cell surface expression of dopamine transporter. J Biol Chem, 279, 54380-54386

Jiang Q, Ren Y, Feng J (2008): Direct binding with histone deacetylase 6 mediates the reversible recruitment of parkin to the centrosome. J Neurosci, 28, 12993-13002

Junn E, Lee SS, Suhr UT, Mouradian MM (2002): Parkin accumulation in aggresomes due to proteasome impairment. J Biol Chem, 277, 47870-47877

Kahle PJ, Haass C (2004): How does parkin ligate ubiquitin to Parkinson's disease? EMBO Rep, $\underline{5}$, 681-685

Kalia LV, Kalia SK, Chau H, Lozano AM, Hyman BT, McLean PJ (2011): Ubiquitinylation of $\alpha-$ synuclein by carboxyl terminus Hsp70-interacting protein (CHIP) is regulated by Bcl-2associated athanogene 5 (BAG5). PLoS One, $\underline{6}, 14695$

Kalia SK, Lee S, Smith PD, Liu L, Crocker SJ, Thorarinsdottir TE, Glover JR, Fon EA, Park DS, Lozano AM (2004): BAG5 inhibits parkin and enhances dopaminergic neuron degeneration. Neuron, $\underline{449}, 31-45$

Kalia SK, Kalia LV, McLean PJ (2010): Molecular chaperones as rational drug targets for Parkinson's disease therapeutics. CNS Neurol Disord Drug Targets, $\underline{9}, 741-753$

Karow T, Lang-Roth R: Pharmakologie und Toxikologie, 18. Auflage, Eigenverlag, Köln 2010

Kermer P, Krajewska M, Zapata JM, Takayama S, Mai J, Krajewski S, Reed JC (2002): Bag1 is a regulator and marker of neuronal differentiation. Cell Death Differ, $\underline{9}, 405-413$ 
Kermer P, Digicaylioglu MH, Kaul M, Zapata JM, Krajewska M, Stenner-Liewen F, Takayama S, Krajewski S, Lipton SA, Reed JC (2003): BAG1 over-expression in brain protects against stroke. Brain Pathol, 13, 495-506

Kitada T, Asakawa S, Hattori N, Matsumine H, Yamamura Y, Minoshima S, Yokochi M, Mizuno Y, Shimizu N (1998): Mutations in the parkin gene cause autosomal recessive juvenile parkinsonism. Nature, 392, 605-608

Kitada T, Asakawa S, Minoshima S, Mizuno Y, Shimizu N (2000): Molecular cloning, gene expression, and identification of a splicing variant of the mouse parkin gene. Mamm Genome, $\underline{11}, 417-421$

Ko HS, Kim SW, Sriram SR, Dawson VL, Dawson TM (2006): Identification of far upstream element-binding protein-1 as an authentic Parkin substrate. J Biol Chem, 281, 16193-16196

Kubo SI, Kitami T, Noda S, Shimura H, Uchiyama Y, Asakawa S, Minoshima S, Shimizu N, Mizuno Y, Hattori N (2001): Parkin is associated with cellular vesicles. J Neurochem, $\underline{78}, 42-54$

Kullmann M, Schneikert J, Moll J, Heck S, Zeiner M, Gehring U, Cato AC (1998): RAP46 is a negative regulator of glucocorticoid receptor action and hormone-induced apoptosis. J Biol Chem, 273, 14620-14625

Lang AE, Lozano AM (1998a): Parkinson`s Disease-First of Two Parts, N Engl J Med, $\underline{339}$, 10441053

Lang AE, Lozano AM (1998b): Parkinson's disease. Second of two parts. N Engl J Med, $\underline{339}, 1130-$ 1143

Langston JW (1998): Epidemiology versus genetics in Parkinson's disease: progress in resolving an age-old debate. Ann Neurol, $\underline{44}, 45-52$

Lee DH, Sherman MY, Goldberg AL (1996): Involvement of the molecular chaperone Ydj1 in the ubiquitin-dependent degradation of short-lived and abnormal proteins in Saccharomyces cerevisiae. Mol Cell Biol, $\underline{16}$, 4773-4781

Lees AJ, Hardy J, Revesz T (2009): Parkinson's disease. Lancet, 373, 2055-2066

Lesage S, Brice A (2009): Parkinson's disease: from monogenic forms to genetic susceptibility factors. Hum Mol Genet, $\underline{18}, 48-59$

Li Y, Wan OW, Xie W, Chung KK (2011): p32 regulates mitochondrial morphology and dynamics through parkin. Neuroscience, [Epub ahead of print]

Lim KL, Tan JM (2007): Role of the ubiquitin proteasome system in Parkinson's disease. BMC Biochem, $\underline{8}, 13$

Lim KL, Dawson VL, Dawson TM (2003): The cast of molecular characters in Parkinson's disease: felons, conspirators, and suspects. Ann N Y Acad Sci, 991, 80-92

Liman J, Ganesan S, Dohm CP, Krajewski S, Reed JC, Bähr M, Wouters FS, Kermer P (2005): Interaction of BAG1 and Hsp70 mediates neuroprotectivity and increases chaperone activity. Mol Cell Biol, 25, 3715-3725 
Lin J, Hutchinson L, Gaston SM, Raab G, Freeman MR (2001): BAG-1 is a novel cytoplasmic binding partner of the membrane form of heparin-binding EGF-like growth factor: a unique role for proHB-EGF in cell survival regulation. J Biol Chem, 276, 30127-30132

Lin TK, Liou CW, Chen SD, Chuang YC, Tiao MM, Wang PW, Chen JB, Chuang JH (2009): Mitochondrial dysfunction and biogenesis in the pathogenesis of Parkinson's disease. Chang Gung Med J, 32, 589-599

Liu R, Takayama S, Zheng Y, Froesch B, Chen GQ, Zhang X, Reed JC, Zhang XK (1998): Interaction of BAG-1 with retinoic acid receptor and its inhibition of retinoic acid-induced apoptosis in cancer cells. J Biol Chem, 273, 16985-16992

Lücking CB, Dürr A, Bonifati V, Vaughan J, De Michele G, Gasser T, Harhangi BS, Meco G, Denèfle P, Wood NW, et al. (2000): French Parkinsons Disease Genetics Study Group; European Consortium on Genetic Susceptibility in Parkinsons Disease. Association between early-onset Parkinsons disease and mutations in the parkin gene. N Engl J Med, $\underline{342,1560-1567}$

Matsuzawa S, Takayama S, Froesch BA, Zapata JM, Reed JC (1998): p53-inducible human homologue of Drosophila seven in absentia (Siah) inhibits cell growth: suppression by BAG-1. EMBO J, 17, 2736-2747

McLean PJ, Klucken J, Shin Y, Hyman BT (2004): Geldanamycin induces Hsp70 and prevents alphasynuclein aggregation and toxicity in vitro. Biochem Biophys Res Commun, $\underline{321}$, 665-669

McNaught KS, Belizaire R, Isacson O, Jenner P, Olanow CW (2003): Altered proteasomal function in sporadic Parkinson's disease. Exp Neurol, $\underline{179}, 38-46$

Mizuno Y, Hattori N, Kubo S, Sato S, Nishioka K, Hatano T, Tomiyama H, Funayama M, Machida Y, Mochizuki H (2008): Progress in the pathogenesis and genetics of Parkinson's disease. Philos Trans R Soc Lond B Biol Sci, $\underline{363}$, 2215-2227

Moore DJ, Zhang L, Troncoso J, Lee MK, Hattori N, Mizuno Y, Dawson TM, Dawson VL (2005): Association of DJ-1 and parkin mediated by pathogenic DJ-1 mutations and oxidative stress. Hum Mol Genet, $\underline{14}, 71-84$

Nicklas WJ, Youngster SK, Kindt MV, Heikkila RE (1987): MPTP, MPP+ and mitochondrial function. Life Sci, $\underline{40}, 721-729$

Nollen EA, Kabakov AE, Brunsting JF, Kanon B, Höhfeld J, Kampinga HH (2001): Modulation of in vivo HSP70 chaperone activity by Hip and Bag-1. J Biol Chem, 276, 4677-4682

Novoselov SS, Novoselova TV, Verbova MV, Margulis BA, Guzhova IV (2005): The balance between Hsp70 and its cochaperones Hdj1 and Bag1 determines its substrate-binding activity. Tsitologiia, $\underline{47}, 220-229$

Nuytemans K, Theuns J, Cruts M, Van Broeckhoven C (2010): Genetic etiology of Parkinson disease associated with mutations in the SNCA, PARK2, PINK1, PARK7, and LRRK2 genes: a mutation update. Hum Mutat, $\underline{31}$, 763-780

Olanow CW, McNaught KS (2006): Ubiquitin-proteasome system and Parkinson's disease. Mov Disord, 21, 1806-1823

Parkinson J (2002): An essay on the shaking palsy. J Neuropsychiatry Clin Neurosci, 14, 223-236 
Periquet M, Latouche M, Lohmann E, Rawal N, De Michele G, Ricard S, Teive H, Fraix V, Vidailhet M, Nicholl D, et al. (2003): French Parkinsons Disease Genetics Study Group; European Consortium on Genetic Susceptibility in Parkinsons Disease.Parkin mutations are frequent in patients with isolated early-onset parkinsonism. Brain, $\underline{126}, 1271-1278$

Petrucelli L, O'Farrell C, Lockhart PJ, Baptista M, Kehoe K, Vink L, Choi P, Wolozin B, Farrer M, Hardy J, Cookson MR (2002): Parkin protects against the toxicity associated with mutant alphasynuclein: proteasome dysfunction selectively affects catecholaminergic neurons. Neuron, $\underline{36}$, 1007-1019

Ren Y, Zhao J, Feng J (2003): Parkin Binds to $\alpha / \beta$ Tubulin and Increases their Ubiquitination and Degradation. J Neurosci, 23, 3316-3324

Robzyk K, Recht J, Osley MA (2000): Rad6-dependent ubiquitination of histone H2B in yeast. Science, $\underline{287}, 501-504$

Rose JM, Novoselov SS, Robinson PA, Cheetham ME (2011): Molecular chaperone-mediated rescue of mitophagy by a Parkin RING1 domain mutant. Hum Mol Genet, 20, 16-27

Safadi SS, Shaw GS (2010): Differential interaction of the E3 ligase parkin with the proteasomal subunit S5a and the endocytic protein Eps15. J Biol Chem, 285, 1424-1434

Sakata E, Yamaguchi Y, Kurimoto E, Kikuchi J, Yokoyama S, Yamada S, Kawahara H, Yokosawa H, Hattori N, Mizuno Y et al. (2003): Parkin binds the Rpn10 subunit of 26S proteasomes through its ubiquitin-like domain. EMBO Rep, 4, 301-306

Schlossmacher MG, Frosch MP, Gai WP, Medina M, Sharma N, Forno L, Ochiishi T, Shimura H, Sharon R, Hattori N, et al. (2002): Parkin localizes to the Lewy bodies of Parkinson disease and dementia with Lewy bodies. Am J Pathol, 160, 1655-1667

Sherman MY, Goldberg AL (2001): Cellular defenses against unfolded proteins: a cell biologist thinks about neurodegenerative diseases. Neuron, $\underline{29}, 15-32$

Shimura H, Hattori N, Kubo S, Yoshikawa M, Kitada T, Matsumine H, Asakawa S, Minoshima S, Yamamura Y, Shimizu N, Mizuno Y (1999): Immunohistochemical and subcellular localization of Parkin protein: absence of protein in autosomal recessive juvenile parkinsonism patients. Ann Neurol, 45, 668-672

Shimura H, Hattori N, Kubo S, Mizuno Y, Asakawa S, Minoshima S, Shimizu N, Iwai K, Chiba T, Tanaka K, Suzuki T (2000): Familial Parkinson disease gene product, parkin, is a ubiquitinprotein ligase. Nat Genet, $\underline{25}, 302-305$

Shimura H, Schlossmacher MG, Hattori N, Frosch MP, Trockenbacher A, Schneider R, Mizuno Y, Kosik KS, Selkoe DJ (2001): Ubiquitination of a new form of alpha-synuclein by parkin from human brain: implications for Parkinson's disease. Science, 293, 263-269

Sian J, Dexter DT, Lees AJ, Daniel S, Agid Y, Javoy-Agid F, Jenner P, Marsden CD (1994): Alterations in glutathione levels in Parkinson's disease and other neurodegenerative disorders affecting basal ganglia. Ann Neurol, $\underline{36}, 348-355$

Simón-Sánchez J, Schulte C, Bras JM, Sharma M, Gibbs JR, Berg D, Paisan-Ruiz C, Lichtner P, Scholz SW, Hernandez DG, et al. (2009): Genome-wide association study reveals genetic risk underlying Parkinson's disease. Nat Genet, $\underline{41}, 1308-1312$ 
Smith WW, Pei Z, Jiang H, Moore DJ, Liang Y, West AB, Dawson VL, Dawson TM, Ross CA (2005): Leucine-rich repeat kinase 2 (LRRK2) interacts with parkin, and mutant LRRK2 induces neuronal degeneration. Proc Natl Acad Sci U S A, 102, 18676-18681

Song J, Takeda M, Morimoto RI (2001): Bag1-Hsp70 mediates a physiological stress signalling pathway that regulates Raf-1/ERK and cell growth. Nat Cell Biol, $\underline{3}, 276-282$

Sriram SR, Li X, Ko HS, Chung KK, Wong E, Lim KL, Dawson VL, Dawson TM (2005): Familialassociated mutations differentially disrupt the solubility, localization, binding and ubiquitination properties of parkin. Hum Mol Genet, $\underline{14}$, 2571-2586

Sroka, K: Huntingtin toxicity is ameliorated by BAG1 through modulation of its aggregation, degradation and subcellular distribution. Biol. Diss. Göttingen 2008

Spillantini MG, Crowther RA, Jakes R, Hasegawa M, Goedert M (1998): alpha-Synuclein in filamentous inclusions of Lewy bodies from Parkinson's disease and dementia with lewy bodies. Proc Natl Acad Sci U S A, 95, 6469-6473

Staropoli JF, McDermott C, Martinat C, Schulman B, Demireva E, Abeliovich A (2003): Parkin is a component of an SCF-like ubiquitin ligase complex and protects postmitotic neurons from kainate excitotoxicity. Neuron, $\underline{37}, 735-749$

Stichel CC, Augustin M, Kühn K, Zhu XR, Engels P, Ullmer C, Lübbert H (2000): Parkin expression in the adult mouse brain. Eur J Neurosci, 12, 4181-4194

Takayama S, Sato T, Krajewski S, Kochel K, Irie S, Millan JA, and Reed JC (1995): Cloning and functional analysis of BAG-1: a novel Bcl-2-binding protein with anti-cell death activity. Cell, $\underline{80}, 279-284$

Takayama S, Bimston DN, Matsuzawa S, Freeman BC, Aime-Sempe C, Xie Z, Morimoto RI, Reed JC (1997): BAG-1 modulates the chaperone activity of Hsp70/Hsc70. EMBO J, 16, 4887-4896

Takayama S, Krajewski S, Krajewska M, Kitada S, Zapata JM, Kochel K, Knee D, Scudiero D, Tudor G, Miller GJ, et al. (1998): Expression and location of Hsp70/Hsc-binding anti-apoptotic protein BAG-1 and its variants in normal tissues and tumor cell lines. Cancer Res, $\underline{58}, 3116-3131$

Takayama S, Xie Z, Reed JC (1999): An evolutionarily conserved family of Hsp70/Hsc70 molecular chaperone regulators. J Biol Chem, 274, 781-786

Thomas B, Beal MF (2007): Parkinson`s disease. Hum Mol Genet, 16, 183-94

Um JW, Min DS, Rhim H, Kim J, Paik SR, Chung KC (2006): Parkin ubiquitinates and promotes the degradation of RanBP2. J Biol Chem, 281, 3595-3603

Um JW, Stichel-Gunkel C, Lübbert H, Lee G, Chung KC (2009): Molecular interaction between parkin and PINK1 in mammalian neuronal cells. Mol Cell Neurosci, $\underline{40}$, 421-432

Um JW, Park HJ, Song J, Jeon I, Lee G, Lee PH, Chung KC (2010): Formation of parkin aggregates and enhanced PINK1 accumulation during the pathogenesis of Parkinson's disease. Biochem Biophys Res Commun, 393, 824-828

Valente EM, Abou-Sleiman PM, Caputo V, Muqit MM, Harvey K, Gispert S, Ali Z, Del Turco D, Bentivoglio AR, Healy DG, et al. (2004): Hereditary early-onset Parkinson's disease caused by mutations in PINK1. Science, 304, 1158-1160 
Van Humbeeck C, Cornelissen T, Vandenberghe W (2011): Ambra1: A Parkin-binding protein involved in mitophagy. Autophagy, [Epub ahead of print]

Volkmann J (2004): Deep brain stimulation for the treatment of Parkinson's disease. J Clin Neurophysiol, 21, 6-17

von Coelln R, Dawson VL, Dawson TM (2004): Parkin-associated Parkinson's disease. Cell Tissue Res, $\underline{318}, 175-184$

Wang M, Pickart CM (2005): Different HECT domain ubiquitin ligases employ distinct mechanisms of polyubiquitin chain synthesis. EMBO J, 24, 4324-4333

Weintraub D, Comella CL, Horn S (2008): Parkinson's disease-Part 1: Pathophysiology, symptoms, burden, diagnosis, and assessment. Am J Manag Care, 14, 40-48

West A, Periquet M, Lincoln S, Lücking CB, Nicholl D, Bonifati V, Rawal N, Gasser T, Lohmann E, Deleuze JF, et al. (2002): Complex relationship between Parkin mutations and Parkinson disease. Am J Med Genet, 114, 584-591

Winklhofer KF, Henn IH, Kay-Jackson PC, Heller U, Tatzelt J (2003): Inactivation of parkin by oxidative stress and $\mathrm{C}$-terminal truncations: a protective role of molecular chaperones. J Biol Chem, 278, 47199-47208

Winner B, Jappelli R, Maji SK, Desplats PA, Boyer L, Aigner S, Hetzer C, Loher T, Vilar M, Campioni $S$, et al. (2011): In vivo demonstration that $\{$ alpha $\}$-synuclein oligomers are toxic. Proc Natl Acad Sci USA, 108, 4194-4199

Xiong H, Wang D, Chen L, Choo YS, Ma H, Tang C, Xia K, Jiang W, Ronai Z, Zhuang X, Zhang Z (2009): Parkin, PINK1, and DJ-1 form a ubiquitin E3 ligase complex promoting unfolded protein degradation. J Clin Invest, $\underline{119}, 650-660$

Xiromerisiou G, Dardiotis E, Tsimourtou V, Kountra PM, Paterakis KN, Kapsalaki EZ, Fountas KN, Hadjigeorgiou GM (2010): Genetic basis of Parkinson disease. Neurosurg Focus, 28, 1-7

Yang X, Chernenko G, Hao Y, Ding Z, Pater MM, Pater A and Tang SC (1998): Human BAG1/RAP46 protein is generated as four isoforms by alternative translation initiation and overexpressed in cancer cells. Oncogene, 17, 981-989

Yang Y, Nishimura I, Imai Y, Takahashi, Lu B (2003): Parkin suppresses dopaminergic neuronselective neurotoxicity induced by Pael-R in Drosophila. Neuron, $\underline{37}, 911-924$

Zeiner M, Niyaz Y, Gehring U (1999): The hsp70-associating protein Hap46 binds to DNA and stimulates transcription. Proc Natl Acad Sci U S A, 무, 10194-10199

Zhang Y, Gao J, Chung KK, Huang H, Dawson VL, Dawson TM (2000): Parkin functions as an E2dependent ubiquitin- protein ligase and promotes the degradation of the synaptic vesicleassociated protein, CDCrel-1. Proc Natl Acad Sci U S A, 97, 13354-13359

Zhong L, Tan Y, Zhou A, Yu Q, Zhou J (2005): RING finger ubiquitin-protein isopeptide ligase Nrdp1/FLRF regulates parkin stability and activity. J Biol Chem, 280, 9425-9430 
7 Veröffentlichung zum Thema der Dissertation

Teile der vorliegenden Dissertation wurden in folgendem Beitrag vorab veröffentlicht:

Poster:

Schuenemann J, Deeg S, Kermer P: Modulation of Parkin enzyme activity by BAG1. 84 . Kongress der deutschen Gesellschaft für Neurologie. 28. September bis 1.Oktober 2011 in Wiesbaden

Sieger des Posterpreises in der Kategorie Neurogenetik 


\section{Danksagung}

An erster Stelle möchte ich mich bei Prof. Dr. Mathias Bähr bedanken für die Möglichkeit, in seiner Arbeitsgruppe $\mathrm{zu}$ arbeiten und mich so an der Erforschung neurodegenerativer Erkrankungen zu beteiligen.

Meinem Doktorvater Prof. Dr. med. Pawel Kermer möchte ich herzlich danken für die freundliche Aufnahme in seine Arbeitsgruppe, die Bereitstellung des interessanten Themas sowie die immerwährende Unterstützung.

Mein besonderer Dank gilt meinem Betreuer Dr. med. Sebastian Deeg für die exzellente Einführung in die Techniken der praktischen Laborarbeit, seine Hilfsbereitschaft und Unterstützung bei allen Schwierigkeiten während meiner gesamten Dissertation.

Allen Mitgliedern der Arbeitsgruppe Bähr danke ich für die fachliche und hilfsbereite Unterstützung während meiner Arbeit. Besonders hervorheben möchte ich dabei die medizinisch-technischen Assistentinnen Sandra Gerke und Beate Veith. Danke für eure geduldige und exzellente Unterstützung.

Auch Barbara Müller, Katrin Eckermann, Christine Poser, Anja Büchner und Prof. Dr. Uwe Michel möchte ich herzlich danken.

Prof. Dr. Ted Dawson von der Johns Hopkins University in Baltimore danke ich herzlich für die Bereitstellung der CDCrel-1-Plasmide. 